\title{
Mitochondrial disturbances, tryptophan metabolites and neurodegeneration: medicinal chemistry aspects
}

Levente Szalárdy ${ }^{1}$, Péter Klivényi ${ }^{1}$, Dénes Zádori ${ }^{1}$, Ferenc Fülöp ${ }^{2}$, József Toldi ${ }^{3,4}$, László Vécsei ${ }^{*}, 1,4$

${ }^{1}$ Department of Neurology, University of Szeged, H-6725 Szeged, Semmelweis u. 6, Hungary

${ }^{2}$ Institute of Pharmaceutical Chemistry and Research Group of Stereochemistry, Hungarian Academy of Sciences, University of Szeged, H-6720, Eötvös u. 6, Hungary

${ }^{3}$ Department of Physiology, Anatomy and Neuroscience, University of Szeged, H-6726 Szeged, Közép fasor 52, Hungary

${ }^{4}$ Neuroloscience Research Group of the Hungarian Academy of Sciences and University of Szeged, $\mathrm{H}$ 6725 Szeged, Semmelweis u. 6, Hungary

Running Title: Mitochondrial dysfunction and kynurenines in neurodegeneration

*Corresponding author: László Vécsei, MD, PhD, DSc

$\triangle$ Department of Neurology, University of Szeged, H-6725 Szeged, Semmelweis u. 6, Hungary

甶Phone: Phone: +36(62)545-351, 545-348 Fax: +36(62)545-597

E-mail: vecsei.laszlo@med.u-szeged.hu

\section{Authors mailing addresses:}

\section{Levente Szalárdy}

$\triangle$ Department of Neurology, University of Szeged, H-6725 Szeged, Semmelweis u. 6, Hungary. E-mail: levente.szalardy@yahoo.com

\section{Péter Klivényi}

$\triangle$ Department of Neurology, University of Szeged, H-6725 Szeged, Semmelweis u. 6, Hungary. E-mail: klivenyi.peter@med.u-szeged.hu

\section{Dénes Zádori}

$\triangle$ Department of Neurology, University of Szeged, H-6725 Szeged, Semmelweis u. 6, Hungary. E-mail: zadorid@gmail.com

\section{Ferenc Fülöp}

$\triangle$ Institute of Pharmaceutical Chemistry and Research Group of Stereochemistry, Hungarian Academy of Sciences, University of Szeged, H-6720, Eötvös u. 6, Hungary.

E-mail: fulop@pharm.u-szeged.hu

\section{József Toldi}

$\triangle$ Department of Physiology, Anatomy and Neuroscience, University of Szeged, H-6726 Szeged, Közép fasor 52, Hungary

E-mail: toldi@bio.u-szeged.hu 


\begin{abstract}
Neurodegenerative disorders, e.g. Parkinson's, Huntington's and Alzheimer's diseases are distinct clinical and pathological entities sharing a number of leading features in their underlying processes. These common features involve the disturbances in the normal functioning of the mitochondria and the alterations in the delicate balance of tryptophan metabolism. The development of agents capable of halting the progression of these diseases is in the limelight of neuroscience research. This review highlights the role of mitochondria in the development of neurodegenerative processes with special focus on the involvement of neuroactive kynurenines both as pathological agents and potential targets and tools for future therapeutic approaches by providing a comprehensive summary of the main streams of rational drug design and giving an insight into present clinical achievements.
\end{abstract}

Key words: clinical trials, drug discovery, excitotoxicity, kynurenic acid, kynurenine system, mitochondria, neurodegeneration, neuroprotection, quinolic acid, tryptophan metabolism.

\title{
INTRODUCTION
}

Neurodegeneration is characterized by progressive injury and loss of neurons in certain brain regions. The loss of function of these regions results in the development of distinct syndromes, e.g. Parkinson's, Huntington's and Alzheimer's diseases. These disorders are different clinical, biochemical and histopathological entities; however, they share some main common characteristics such as mitochondrial dysfunction, excitotoxicity, impaired antioxidant capacity and disturbances in tryptophan metabolism. The presence of either inherited or sporadic mutations as well as chronic exposure to certain environmental factors can all contribute to the complex etiology of neurodegenerative disorders. The beginning of the pathological processes precedes the onset of clinical symptoms by years or even decades, thus, the possible approaches to protect neurons from progressive degeneration and cell death are in the focus of research in neuroscience with promising results in the preclinical but rather disappointing ones in the clinical phases.

This review highlights the indisputable role of mitochondria in the development of neurodegenerative processes with special focus on the involvement of neuroactive kynurenines both as pathological agents and potential targets and tools for future therapeutic approaches.

\section{MITOCHONDRIA}

\section{Mitochondrial structure and physiology}

Mitochondria are membrane-bound elongated organelles in the cytoplasm supposed to evolutionary originate from the endosymbiosis of an ancient aerobic prokaryote from the Proteobacteria phylum into an early eukaryotic cell [1]. A mitochondrion comprises four distinct compartments. The porous outer membrane, which is freely permeable to ions and small molecules, contains important receptors and enzymes. The invaginated and convoluted inner membrane with cristae contains the enzymatic apparatus of the respiratory chain and 
oxidative phosphorylation, some essential co-factors and carrier molecules. The inner membrane is enriched in cardiolipin and practically impermeable to small molecules and ions including protons. The intermembrane space is localized between the two membranes. The matrix is an aqueous medium encompassed by the inner membrane. It provides environment for several essential metabolic pathways such as the urea cycle, $\beta$-oxidation, pyruvate dehydrogenase complex, citric acid cycle (Krebs-Szent-Györgyi cycle), and contains structural proteins, enzymes and also its own genome, the mitochondrial DNA (mtDNA).

Mitochondria are responsible for several physiological cellular processes such as energy supply, thermogenesis, calcium homeostasis, regulation of cell-cycle, development and aging. Biologically utilizable energy is produced by the coupled function of the citric acid cycle (also known as tricarboxylic acid cycle) and the enzymatic complexes (complex I-V) embedded in the inner membrane (reviewed in [2]). Briefly, glucose and fatty acids are catabolized outside the mitochondria to form pyruvate and acyl-CoA, respectively. These compounds are then imported to the mitochondria and transformed to acetyl-CoA that subsequently undergoes oxidation within the citric acid cycle to favor the formation of reduced coenzyme NADH and succinate through multiple enzymatic steps. These compounds provide electrons for complex I, II respectively, within the respiratory complex chain. Complexes are functionally arranged in an electrochemical hierarchy according to their gradually increasing electronegativity and redox potential. The "downstream" flow of electrons provides energy for the pumping out of protons to the intermembrane space through complexes I, III and IV, the latter being responsible for the reduction of molecular respiratory oxygen to form $\mathrm{H}_{2} \mathrm{O}$ in a process often referred as terminal oxidation. The export of protons from the matrix leads to the development of a proton gradient between the two compartments called mitochondrial membrane potential (negative inside) and an electrochemical gradient (alkaline inside). Since the inner membrane is impermeable to protons the electrochemical drive to equalize proton concentration can exclusively be achieved by the reentering of protons through $\mathrm{F}_{1} \mathrm{~F}_{0}$-ATP synthase (complex $\mathrm{V}$ ), the activation of which catalyzes the transformation of ADP into ATP in a process called oxidative phosphorylation [3]. ATP is a high-energy macromolecule that serves as the main energy source for eukaryotic cells. According to this chemiosmotic hypothesis mitochondria transform electrochemical energy into a biologically available form (Figure 1).

Figure 1. Schematic presentation of the function and organization of the mitochondrial respiratory chain 


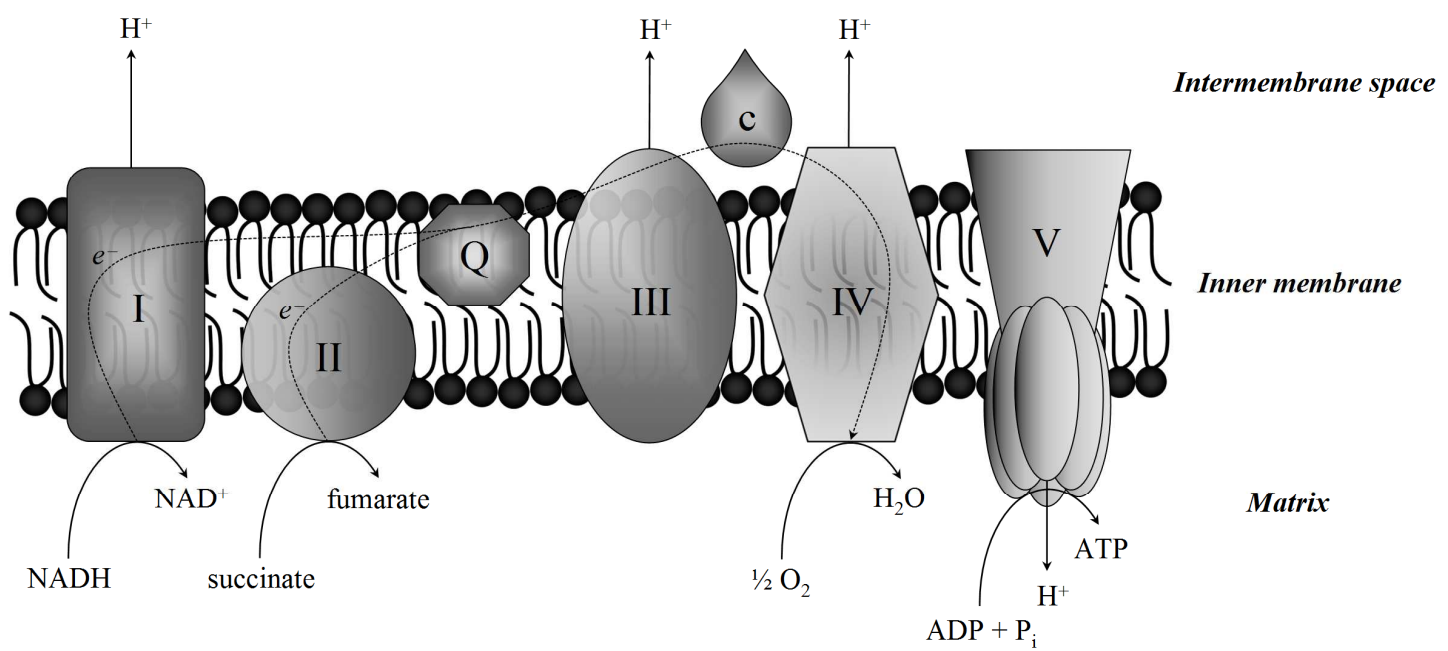

Complex I = NADH dehydrogenase; complex II = succinate dehydrogenase; $\mathrm{Q}=$ coenzyme Q10 (ubiquinone); complex III = ubiquinol-cytochrome $c$ oxidoreductase; $\mathrm{c}=$ cytochrome $c$; complex IV = cytochrome $c$ oxidase; complex V = ATP synthase.

Mitochondria possess their own genome in the matrix called mtDNA, which is a double-stranded circular DNA that is supposed to be in close relation to that of Rickettsiae. It contains 37 genes encoding 13 proteins, all of which are part of the respiratory complexes, 2 ribosomal RNAs and 22 transfer RNAs [4]. Any other mitochondrial function is carried out by proteins encoded by nuclear DNA (nDNA) and imported into the mitochondria. The mitochondrial genome is almost exclusively maternally inherited due to the ubiquitination and subsequent degradation of paternal mitochondria in the zygote [5]. It regularly replicates in postmitotic cells about once in a month in humans. Mitochondrial fission is a process in which mitochondria grow and divide in response to an increased energy demand. In addition, mitochondria are prone to constant fusion with each other resulting in the mixture (and possibly recombination) of normal and potentially mutated genomes ("heteroplasmy"). Approximately 2-15 copies of mtDNA are present in a mitochondrion ("polyplasmia") [6]. During cell division mitochondria are distributed randomly into the daughter cells. These processes, on the one hand, can protect mitochondria and their host cells from the potentially deleterious effects of mtDNA mutations. On the other hand, they somewhat counterbalance the limited possibility of genomic recombination resulting from the uniparental inheritance.

Mitochondrial matrix can serve as a temporary buffering pool for intracellular $\mathrm{Ca}^{2+}$ storing it in the form of calcium phosphate, when the level of free $\mathrm{Ca}^{2+}$ in the cytosol increases beyond a certain set-point. After cytosolic $\mathrm{Ca}^{2+}$ level decreases below the set-point, $\mathrm{Ca}^{2+}$ is subsequently released from the mitochondria (reviewed in [7]).

There is a considerable amount of evidence indicating the regulating role of mitochondria in apoptosis and necrosis, the former being involved in the physiological processes of cell-differentiation and development (reviewed in [8]). 


\section{Mitochondrial pathophysiology, implications in excitotoxicity and neurodegeneration}

During the process of terminal oxidation, the efficacy of the reduction of respiratory oxygen to $\mathrm{H}_{2} \mathrm{O}$ is approximately $98-99 \%$, while $1-2 \%$ of it is reduced incompletely to form superoxide anion $\left(\mathrm{O}_{2}^{-\bullet}\right)$, a moderately damaging but highly reactive free radical. Free radicals are molecules that possess unpaired electrons in their outer orbit making them extremely reactive towards organic macromolecules such as DNA, RNA, lipids and proteins via donating their unpaired electrons to the acceptor compounds in a process called oxidative damage. $\mathrm{O}_{2}^{-}$can be transformed into hydrogen peroxide $\left(\mathrm{H}_{2} \mathrm{O}_{2}\right)$ both spontaneously and through a reaction catalyzed by manganese superoxide dismutase (MnSOD). $\mathrm{H}_{2} \mathrm{O}_{2}$ normally undergoes degradation by glutathione peroxidase and catalase enzymes. If $\mathrm{H}_{2} \mathrm{O}_{2}$ production exceeds the degradation capacity, it can react with transition metals $\left(\mathrm{Cu}^{2+}\right.$ and $\left.\mathrm{Fe}^{2+}\right)$ in the Fenton reaction to form a highly toxic hydroxyl radical $\left(\mathrm{OH}^{-\bullet}\right) \cdot \mathrm{O}_{2}^{-\bullet}$ is able to react with nitric oxide radical $\left(\mathrm{NO}^{\circ}\right)$ to generate another highly toxic radical peroxinitrite anion $\left(\mathrm{ONOO}^{-}\right)$in a reaction that is three times as fast as the dismutation catalyzed by MnSOD. These toxic radicals are often referred to as reactive oxygen species (ROS). The major source of ROS production in the cell is the mitochondrial electron transport chain; however, other relevant sources can also be mentioned such as NADPH oxidase, myeloperoxidase, xanthine oxidase, monoamine oxidase, cytochrome p450 and NOS (nitric oxide synthase).

Proteins that underwent nitrative/nitrosative or oxidative damage are particularly susceptible to rapid proteolytic cleavage and degradation. Damages to mitochondrial proteins can severely impair essential functions such as cell cycle regulation and ATP production (reviewed in [9]). The damage to mitochondrial respiratory complex proteins by ROS results in the dysfunction of electron transport that leads to two main consequences. First, it results in the impairment of energy supply due to the decrease in ATP production. Second, it interferes with the efficacy of terminal oxidation, which in turn leads to enhanced ROS production and the generation of a vicious circle.

The damage to lipids caused by free radicals can interfere with normal membrane fluidity and may evoke the release of toxic by-products.

The mitochondrial genome is particularly sensitive to oxidative/nitrative/nitrosative injury due to several reasons [10]. It is in close vicinity to the main source of ROS production, it is not covered by protective histones, and it contains only few non-coding sequences. Because of these specific features, the mutation rate for mtDNA is approximately 10-fold higher than that for nDNA [11]. Defensive actions of mitochondria to counteract the production of ROS include a repair machinery entirely encoded by nDNA, an enzymatic apparatus to clear reactive species (e.g. SOD, catalase, peroxidase, peroxiredoxin) and low molecular weight antioxidants (reviewed in [12]). In addition, severely damaged mitochondria can be sensed, tagged and degraded in a process regulated by PINK1 and parkin genes $[13,14]$. It should be highlighted though that some mechanisms involved in mtDNA repair, e.g. the activation of poly(ADP-ribose) polymerase-1 (PARP-1) can also contribute to cell dysfunction and death by consuming $\mathrm{NAD}^{+}$and ATP per se [15]. The ability to cope with ROS-induced toxicity is thought to decline with aging [16], resulting in an increased rate of mtDNA point mutations and deletions in the somatic cells of the elderly [17]. 
The implications for the role of mitochondrial disturbances in neurodegenerative disorders come from a series of observations. First, the brain contains high amounts of polyunsaturated lipids that are extremely susceptible to ROS-induced lipid peroxidation; meanwhile, the neuronal antioxidant capacity is relatively low (reviewed in $[18,19]$ ). Second, the brain has an extreme energy demand accounting for $20 \%$ of total oxygen consumption, whereas it represents only $2 \%$ of the body mass [20]. In terms of this extremely high energy need, neurons show an absolute dependence on the constant availability of oxygen and glucose accompanied by a low capacity of glycogen storage, and a poor ability to increase glycolysis upon oxygen deprivation [21].

Glutamate is the major excitatory neurotransmitter in the human brain. The implications for a crucial role of elevated extracellular glutamate, and subsequent overactivation of ionotropic $N$-methyl-D-aspartate-sensitive glutamate receptors (NMDARs) in the etiopathology of neurodegenerative diseases are wide and thoroughly reviewed by others [22]. In the case of energy impairment, e.g. due to mitochondrial dysfunction, neurons exhibit partial membrane depolarization that can remove $\mathrm{Mg}^{2+}$ ions blocking the ionophore part of the NMDARs, allowing glutamate to evoke its downstream effects even in physiological concentrations [23]. The activation of NMDARs results in the influx of cations, predominantly $\mathrm{Ca}^{2+}$ into the cytosol. Among pathological conditions, intracellular $\mathrm{Ca}^{2+}$ level can be so high and permanent that it exceeds the buffering capacity provided by the mitochondrial $\mathrm{Ca}^{2+}$ sequestration, which in turn leads to the opening of high-conductance mitochondrial permeability transition pores (mtPTPs) [24]. It results in subsequent mitochondrial swelling, loss of mitochondrial membrane potential, impaired ATP and elevated ROS production (reviewed in [25]), and the release of apoptosis-inducing factor (AIF), procaspase-9 and cytochrome $c$ from the intermembrane space into the cytoplasm, where cytochrome $c$ takes part in the formation of apoptosomes composed by cytochrome $c$, caspase-9 and apoptotic protease activating factor 1 (Apaf-1) in a process ultimately leading to apoptosis [26]. In addition, elevated intramitochondrial $\mathrm{Ca}^{2+}$ levels can increase the activity of mitochondrial nitric oxide synthase (mtNOS) to produce highly toxic $\mathrm{NO}^{\bullet}$ [27], which is known to impair the mitochondrial electron transport by competing with $\mathrm{O}_{2}$ for the $\mathrm{O}_{2}$-bindig site in complex IV [28]. Furthermore, it is capable of causing damage and cell death in multiple ways including the potential activation of the mtPTPs [29]. In this respect, NMDARmediated $\mathrm{Ca}^{2+}$ overload can lead to mitochondrial dysfunction, enhanced ROS production, energy crisis and eventually cell death, which can be either apoptotic or necrotic depending on the severity of the initial insult [30] and the subsequent mitochondrial dysfunction [31]. However, it has been proposed that not the $\mathrm{Ca}^{2+}$ overload itself, but the mechanism through which $\mathrm{Ca}^{2+}$ ions get into the cell could be the key-holder to NMDAR-mediated excitotoxicity [32]. Sattler et al. have demonstrated that NMDARs are spatially linked to neuronal nitric oxide synthase (nNOS) by a scaffolding protein PSD-95 (postsynaptic density protein of molecular weight $95 \mathrm{kDa}$ ) allowing $\mathrm{Ca}^{2+}$ ions to evoke the synthesis of $\mathrm{NO}^{\bullet}$ in a toxic amount while entering into the cell upon NMDAR activation [33]. The possibly dominant role of nNOS in NMDAR-mediated excitotoxicity has also been supported by the results of earlier studies [34,35]. PSD-95 binds to the NR2B subunit of the NMDARs, which is fully consistent with the findings that glutamate excitotoxicity is principally mediated by NR2B subunitcontaining NMDARs [36], which predominate in the extrasynaptic sites [37], where the 
activation of these receptors has been proven to be neurotoxic (while synaptic NMDAR activation seems to be protective) [38,39].

The role of mitochondrial dysfunction and excitotoxicity in the process of neurodegeneration is clearly demonstrated (Figure 3). The development of agents being capable of intervening in the processes of mitochondrial dysfunction, particularly NMDARmediated excitotoxicity, is one of the key features in the attempts to treat or at least positively influence the course of neurodegenerative diseases.

\section{THE KYNURENINE SYSTEM}

Certain routes of the metabolism of the essential amino acid tryptophan (TRP) are widely known and have been extensively studied (e.g. serotonin pathway, melatonin pathway), whereas the main pathway of TRP metabolism has only been in the center of interest for the past 40 years. In fact, the kynurenine pathway is responsible for the catabolism of more than $95 \%$ of TRP in the brain through a multistep enzymatic process, which involves the production of niacin or nicotinic acid, providing the main component of $\mathrm{NAD}^{+}$and $\mathrm{NADP}^{+}[40,41]$. The central intermediate L-kynurenine (L-KYN) is produced via the ratelimiting step of TRP catabolism (for details, see Figure 2) and can be further metabolized through three distinct pathways resulting in the formation of anthranilic acid (ANA), 3hydroxy-L-kynurenine (3-OH-L-KYN) and kynurenic acid (KYNA). The total L-KYN content in the mammalian brain is about $200 \mathrm{ng} / \mathrm{g}$ [42], 60\% of which is produced in the periphery and taken up through the blood-brain barrier (BBB) $[43,44]$ by a large neutral amino acid carrier [45]. The group of "neuroactive kynurenines" (reviewed in [46]) consists of the three neurophysiologically relevant metabolites: KYNA, 3-OH-L-KYN and quinolinic acid (QUIN), the latter is formed by the further enzymatic metabolization of 3-OH-L-KYN and ANA [47].

KYNA is formed via the irreversible transamination of L-KYN by kynurenine aminotransferase (KAT) enzymes, which have four known distinct subtypes in the mammalian brain (reviewed in [48]). KAT I seems to play a limited role in the human brain regarding KYNA production among physiological conditions [49]; however, it is suggested that the neuronal expression of KAT I is involved in the regulation of development and apoptosis [50]. KAT II is proven to be the main enzyme of KYNA production noth in the human and in the rat brain, whereas it has been demonstrated to have the lowest activity in mice, where the main KYNA producer is KAT IV, which was found to be identical with mitochondrial aspartate aminotransferase (mtAAT) [51]. KAT III shares a number of common features with KAT I, but it has not been demonstrated to have any activity in the human brain [52]. Functionally, KYNA is a broad-spectrum antagonist of excitatory amino acid receptors with high affinity towards the strychnine-insensitive glycine coagonist site of NMDARs [53]. Besides, KYNA exerts a weak antagonistic effect on kainate- and $\alpha$-amino-3hydroxy-5-methyl-4-isoxazolepropionic acid (AMPA)-sensitive ionotropic glutamate receptors [54]. However, recent reports on the effect of KYNA on AMPA receptor-mediated responses revealed a dose-dependent dual action, which favors facilitation in low (nanomolarmicromolar [55], nanomolar [56]) concentrations, whilst neuroinhibition in high (millimolar [55], micromolar [56]) concentrations. KYNA also possesses a non-competitive inhibitory 
effect on $\alpha 7$ nicotinic acetylcholine receptors [57] through which KYNA is involved in the negative regulation of presynaptic glutamate release [58]. Moreover, KYNA increases the expression of non- $\alpha 7$ nicotinic acetylcholine receptors [57]. As a modulator of glutamate activity KYNA is proposed to be one of the endogenous neuroprotective agents (widely reviewed by Zadori et al. [59]). The dose-dependent neuroprotective efficacy of KYNA has been postulated and confirmed in a number of animal paradigms including kainate- [60,61], ibotenate- [61], QUIN- [61,62] and NMDA-induced neurotoxicity [61,63,64]. Furthermore, KYNA appears to possess a potent anticonvulsant effect even in physiological concentrations [65]. The effect of KYNA to block the activity of NMDARs is in accordance with the typical findings of behavioral studies subsequent to its intracerebroventricular administration in rats [66,67]. Additionally to its widely demonstrated anti-excitatory efficacy, KYNA has most recently been described as a potent free radical scavenger and antioxidant in vitro and in vivo [68].

QUIN is a specific, but rather weak and low-affinity competitive agonist of NMDARs that contain NR2A and NR2B subunits [69]. In contrast to KYNA, QUIN has proved to be neurotoxic in a number of animal paradigms and seem to exert its deteriorating effects on multiple ways including NMDAR activation [70], presynaptic glutamate release enhancement [71,72], astrocytic glutamate uptake inhibition [72], endogenous antioxidant depletion [73], ROS production [74] and lipid peroxidation [75]. The probable dominant role of NMDAR activation in QUIN-induced toxicity is supported by the findings that the activation of NOS enhances, its selective inhibition decreases [76], whereas the NMDAR blocker MK-801 completely abolishes lipid peroxidation induced by QUIN [77].

The detrimental effects of 3-OH-L-KYN have proven to be independent from NMDAR functioning but are rather due to its intracellular uptake and subsequent ROS production [78], and are at least partly mediated by its neurotoxic metabolite 3-OH-ANA, which is prone to undergo auto-oxidation in a process resulting in superoxide production [79]. The intrastriatal co-administration of 3-OH-L-KYN and QUIN in subtoxic doses revealed a synergistic effect of these compounds leading to a substantial loss of neurons, which provides evidence that the presence of 3-OH-L-KYN can increase the risk of neurodegeneration during excitotoxic insults if QUIN is involved in the process [80].

It is noteworthy to mention that the different types of glia cells preferentially express or quite conversely lack the expression of certain enzymes in the metabolic pathways. Astrocytes, the major producers of KYNA in the CNS, are known to lack kynurenine 3monooxygenase (KMO, kynurenine 3-hydroxylase) in favor of the synthesis of KYNA, whereas microglial cells and macrophages exhibit low KAT enzyme expression, which offsets the balance of TRP metabolism towards the direction of QUIN. A paradox role of astrocytes is revealed when surrounded by microglial cells or macrophages that can produce toxic amounts of QUIN from L-KYN excessively generated by astrocytes [81]. These preferences may contribute to the higher resistance of astrocytes against excitotoxic and ROS-generating stimuli, and also to their involvement in neuroprotection. In addition to the recent findings that TRP metabolism and KYN pathway possess a key regulatory role in the processes of immune response and tolerance (reviewed in [82]), these data provide a deeper insight into the role of inflammation accompanied by microglial and macrophage infiltration in the pathogenesis of neurodegenerative disorders. 


\section{Figure 2. The metabolism of tryptophan}

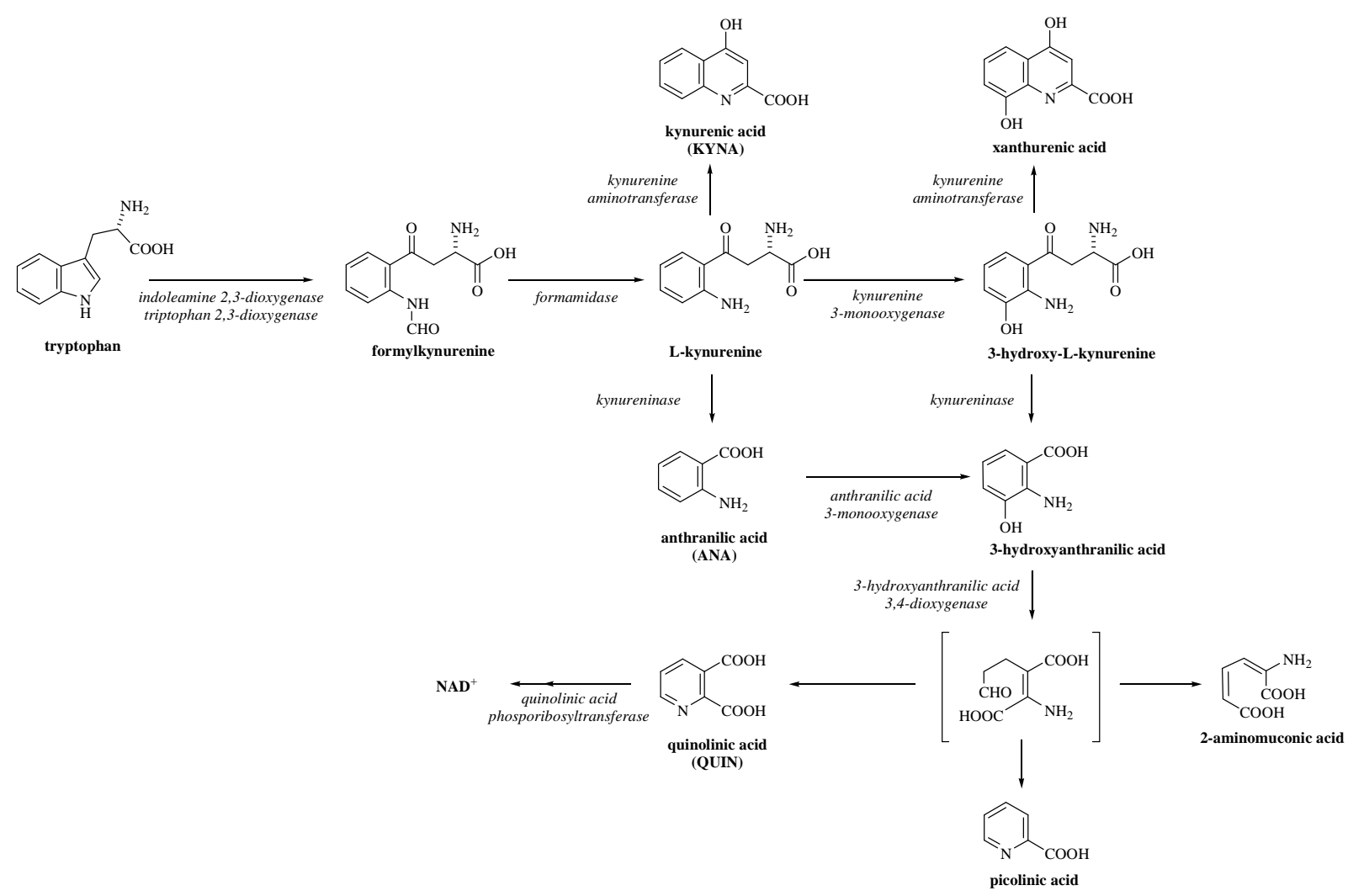

Due to the fact that KYNA itself poorly penetrates the BBB [45], and has a limited selectivity and affinity towards the glycine-binding site of the NMDARs [83], a number of pharmaceutical approaches have been established to exploit its therapeutic potential. These approaches include three mainstream strategies. The first is the synthesis of KYNA analogues and prodrugs (reviewed in [84]). The most frequent molecular modifications result in halogenated KYNA analogues (e.g. 7-Cl-KYNA [85]) and its BBB-penetrant prodrug 4-ClKYN [86,87]), thiokynurenates [88], sugar conjugates of KYNA or its analogues (e.g. Dgalactose-7-Cl-KYNA, D-glucose-7-Cl-KYNA [89] and glucosamine-KYNA [90,91]) and most recently kynurenic acid amides [92-96] that are proposed to be selective inhibitors of NR2B subunit-containing NMDARs [97]. Halogenated and thio-substituted derivatives possess increased selectivity and affinity towards the glycine-binding site of NMDARs [98], whereas the conjugation with sugars increases the penetration through the BBB via "hitchinking" on sugar transporter molecules [89]. The second strategy represents the systemic administration of L-KYN, which is known to penetrate the BBB better. L-KYN either alone or in combination with probenecid (an inhibitor of transmembrane organic acid transport) has been proven to be neuroprotective [99-102] and anticonvulsive [103,104] serving as a non-selective precursor for astrocytic KYNA synthesis. The co-administration of probenecid is a widely applied technique to overcome the rapid clearance of L-KYN, kynurenic acid and its derivatives [105]. The third main approach is the specific modulation of enzyme activities involved in TRP metabolism towards the enhancement of protective KYNA synthesis and attenuation of the detrimental metabolites QUIN and 3-OH-L-KYN. 
The three main targets of enzyme inhibitors are KMO, kynureninase and 3-hydroxyanthranic acid 3,4-dioxygenase (3-HAO). Nicotinylalanine was one of the first potent KMO inhibitors with a relatively small specificity $[100,106,107]$. The most widely used KMO inhibitors with enhanced specificity include ( $m$-nitrobenzoyl)alanine [108], 4,5-dichlorobenzoylalanine (PNU 156561, formerly referred as FCE 288833A) [109], (1S,2S)-2-(3,4-dichlorobenzoyl)cyclopropane-1-carboxylic acid (UPF 648) [110], 3,4-dimethoxy-[-N-4-(nitrophenyl)thiazol2-yl]-benzenesulfonamide (Ro 61-8048) [111] and most recently its prodrug 2-(3,4dimethoxybenzenesulfonylamino)-4-(3-nitrophenyl)-5-(piperidin-1-yl)methylthiazole (JM6) [112], which is presumed to overcome the rapid diminish of Ro 61-8048 from the circulation. The inhibition of kynureninase is achieved by structural analogues of its substrate L-KYN including (4R)- and (4S)-dihydro-L-KYNs [113], S-aryl-L-cystein $S$,S-dioxides [114], byciclic L-KYN analogues [115], phosphinic acid L-KYN analogues [116], (omethoxybenzoyl)alanine [117] and desaminokynurenine derivatives [118]. Notably the KMO inhibitors nicotinylalanine and ( $m$-nitrobenzoyl)alanine also affect the activity of kynureninase [119]. The third related enzyme 3-HAO can be inhibited by the structural analogues of 3-hydroxy-anthranilic acid (3-OH-ANA). The most widely studied derivatives are the 4-halogenated [120] and 4,6-dihalogenated 3-OH-ANAs, among which 4,6-dibromo3-OH-ANA (NCR-631) has deserved a great attention for its potent neuroprotective, antiinflammatory [121] and anticonvulsant [122] properties, especially since the applied dose has been shown to cause no alteration in brain QUIN and KYNA levels by the same research group [123]. Interestingly, (o-methoxybenzoyl)alanine, a selective kynureninase inhibitor can exert inhibition on 3-HAO as well, in a process depending on the presence of mitochondria [124]. The KYNA analogue prodrug 4-Cl-KYN is also able to exert potent inhibition on 3HAO through its metabolite 4-Cl-3-OH-ANA [125]. Though the inhibition of these enzymes can influence the syntheses of both KYNA and QUIN, it has been implicated that the reduction of QUIN levels could be more important than the elevation of KYNA regarding their protective features [126].

Although they seem to be rather secondary to the underlying processes, the alterations in the delicate balance of TRP metabolism between the pathways towards KYNA and QUIN production can possess a crucial role in the development of certain neurodegenerative diseases. Selective manipulations of the kynurenine system might harbor valuable therapeutic potential.

\section{PARKINSON'S DISEASE}

Parkinson's disease (PD) is a chronic progressive neurodegenerative disorder characterized by the loss of dopaminergic neurons in the substantia nigra pars compacta $(\mathrm{SNpc})$, the decrease of dopamine and its metabolites in the striatum and the presence of Lewy bodies [127]. Clinical symptoms include bradykinesia, rigidity, resting tremor and postural instability [128,129]. The development of Parkinson's disease has been associated with the complex interplay of environmental and genetic factors. We can distinguish between idiopathic/sporadic and familial PD. A number of genes have been associated with the development of familial PD (PARK genes) (reviewed in [130]), most of them having direct implications in mitochondrial dysfunction. 


\section{Mitochondrial dysfunction in PD}

The involvement of mitochondrial dysfunction in the pathogenesis originates from the discovery of the synthetic drug side-product 1-methyl-4-phenyl-1,2,3,6-tetrahydropyridine (MPTP), the administration of which has been found to almost perfectly recapitulate parkinsonian symptoms and pathology with the exception of Lewy body formation [131]. Accumulating within the mitochondria MPP+ (1-methyl-4-phenylpyridinium), the active metabolite of MPTP impairs the activity of complex I [132] selectively in the dopaminergic neurons of SNpc [133]. The inhibition of electron transport in these neurons has become the main animal model of PD. Besides MPTP intoxication, selective mitochondrial dysfunction can be achieved by known environmental pesticides such as the natural insecticide rotenone, the quaternary ammonium herbicide paraquat, and the manganese-containing dithiocarbamate fungicide maneb, which are capable of inhibiting complex I, I and III, respectively (widely reviewed in [134]). Human studies regarding the activity of electron transport complexes in platelets, muscle cells, SNpc and cortical neurons have provided contradictory findings. Although systemic complex I deficiency still seems to be a predominant feature in the development of PD [135], recent findings have questioned its primary role in the pathomechanism of PD-related toxins [136].

Epidemiological studies (reviewed in [137]) along with recent genome-wide single nucleotide polymorphism (SNP) analyses [138] have indicated that the development of idiopathic PD is rather due to environmental factors than mere genetic heritability; however, the presence of certain mtDNA and nDNA mutations has been associated with this form of the disease including the polymorphisms in mtDNA polymerase gamma 1 (POLG1) $[139,140]$ and complex I subunit ND5 [141]. On the other hand mtDNA haplotypes J and K [142] and the haplotype cluster UKJT [143] have been reported to be protective for their carrier population.

The majority of gene mutations found to be causative in familial PD can be associated with mitochondrial dysfunction. The gain-of-function mutation of PARK1 leads to extensive mitochondrial accumulation of its product $\alpha$-synuclein [144], the main constituent of Lewy body inclusions, leading to the inhibition of complex I in vitro [144], in vivo [145] and in post mortem human studies [144]. The interaction of $\alpha$-synuclein with complex IV has also been demonstrated [146]. Its transgenic overexpression in mice results in increased vulnerability against mitochondrial neurotoxins paraquat and MPTP [147], whereas $\alpha$-synuclein knock-out mice are resistant to MPTP and intriguingly to 3-nitropropionic acid (3NP) and malonate as well, which are mitochondrial toxins widely used in modeling Huntington's disease [148]. However, there seems to be a bidirectional relationship between mitochondrial dysfunction and $\alpha$-synuclein since the impairment of mitochondrial function itself can lead to the formation of $\alpha$-synuclein inclusion bodies [149]. The product of PARK2 gene parkin is involved in the polyubiquitin tagging of potentially dangerous and aggregation prone protein substrates for proteosomal degradation via its ubiquitin E3 ligase activity [150]. Its potential mitochondrial function includes the maintenance of physiological antioxidant status by the regulation of gluthatione metabolism [151] and SOD activity [152]. Parkin is suggested to be involved in mitochondrial replication and transcription as well, through a direct association with mitochondrial transcription factor A (TFAM) [153]. Its overexpression has demonstrated 
the important role of parkin in mitochondria-dependent cell death via the inhibition of cytochrome $c$ and caspase 3-mediated apoptosis [154], and has proven to be effective in rescuing mitochondrial dysfunction caused by PINK1 loss-of-function [155]. Animal knockout models of parkin exhibit severe mitochondrial degeneration accompanied by the decreased expression of several subunits of complex I and IV [156,157], but, interestingly, no increase in the susceptibility against MPTP intoxication has been reported [158]. PARK6 encodes the phosphatase and tensin homologue (PTEN)-induced putative kinase 1 (PINK1). PINK1 loss-of-function exhibits similar features with that of parkin including the phenotype of mitochondrial degeneration [159], and the decrement in the activity of mitochondrial complexes [160]. It is suggested that PINK1 and parkin share a common mechanistic pathway with PINK1 acting upstream of parkin [161] in a number of mitochondrial processes including the regulation mitochondrial dynamics $[13,14]$. Contrary to parkin, the defect of PINK1 has recently been reported to increase the extent of toxicity in MPP+/MPTP paradigms [162]. PINK1 is able to prevent the release of cytochrome $c$ and subsequent apoptosis via the phosphorylation of its substrate TRAP1 (tumor necrosis factor receptorassociated protein 1) in vitro [163]. The involvement of PINK1 in the regulation of cell death is further highlighted by the finding that mtPTPs can open up even due to physiological calcium stimuli in PINK1-deficient cells [164]. High temperature requirement factor A2 (HtrA2 or $\mathrm{Omi}$ ), the product of PARK13 gene also acts downstream of PINK1 in preventing mitochondrial dysfunction [165]. Omi has been demonstrated to serve as a mitochondrial protein quality controller and a regulator of autophagy [166]. Knock-out of PARK13 results in selective striatal neuronal loss and parkinsonian motor deficits in mice [165]. PARK7 protein $D J-1$ is suggested to be an oxidative stress sensor being capable of modulating mitochondrial transcription and glutathione metabolism during mitochondrial stress [167]. The loss of its function results in impaired ROS scavenging [168] and increased susceptibility to MPTP [169], paraquat and $\mathrm{H}_{2} \mathrm{O}_{2}$-induced mitochondrial toxicity [170]. Recently, DJ-1 has also been identified as a deregulator of astrocytic inflammatory processes [171]. DJ-1 seems to work in parallel with PINK1/parkin pathway to maintain mitochondrial function during oxidative environment [172]. Furthermore, a definite complex interplay has recently been suggested between these three PD-related proteins (called PPD complex) in the degradation of misfolded/unfolded proteins; however, this hypothesis warrants further investigations [173]. Apart from the knowledge that PARK8 protein leucine-rich repeat kinase 2 (LRRK2) has been found to co-localize with membrane bound intracellular structures including mitochondria [174], little has been known about its role in mitochondrial pathology until very recently. Human [175] and in vivo studies [176] indicate that the LRRK2 mutation G2019S, the most common mutation in both familial and sporadic PD is associated with impaired mitochondrial function and morphology [175] and an enhanced sensitivity to mitochondrial stressors [176].

A number of pre-clinically effective drug candidates against mitochondrial dysfunction in PD have already reached the clinical phases (widely reviewed by Klivenyi et al. [177]. The phase II safety-trial of inosine (SURE-PD), the BBB-penetrant precursor of the natural antioxidant uric acid, is on its way, based on the retrospective observation of two prior clinical studies (DATATOP [178], PERCEPT [179]) that high normal levels of serum uric acid provided marked suppression on the rate of clinical progression. 
Coenzyme $Q 10$ or ubiquinone is another potent antioxidant physiologically functioning as an electron acceptor that transfers electrons from complex I and II to complex III in the respiratory chain. After its efficiency has been proven in in vitro and in vivo models of parkinsonism [180-182], Q10 seems to slow disease progression in patients with early PD but not in midstage PD according to the results of the completed phase II [183] and phase III [184] clinical studies. A phase III trial (QE3) with larger doses is currently running; however, the recent negative findings with the mitochondria targeted quinone derivative MitoQ suggests little hope [185].

The neuroprotective efficacy of creatine via buffering energy deficit in mitochondrial dysfunction has been demonstrated in a number of neurodegenerative animal models (widely reviewed by Beal et al. [186]) including MPTP [187,188] and rotenone [189]; furthermore, its co-administration with coenzyme Q10 has provided an additive neuroprotection in chronic MPTP paradigm [190]. Creatine has already proved to be non-futile [191] and safe [192] in a phase II clinical trial (NINDS NET-PD) and has showed $~ 50 \%$ improvement in Unified Parkinson's Disease Rating Scale at one year. The phase III trial is currently ongoing (NETPD LS-1).

Peroxisome proliferator-activated receptor- $\gamma$ (PPAR $\gamma$ ) coactivator-1 $\alpha$ (PGC-1 $\alpha)$ possesses a key integratory role in the transcriptional control of cellular energy metabolism, mitochondrial function and biogenesis, and oxidative stress defense (reviewed in [193]). PGC-1 $\alpha$ knock-out mice exhibit increased vulnerability against both MPTP and kainic acid treatment [194], whereas its overexpression protects neurons against mitochondrial dysfunction due to mutant $\alpha$-synuclein [195] and rotenone [195]. Correspondingly, the underexpression of genes depending on the function of PGC- $1 \alpha$ system has also been demonstrated in human patients with Parkinsons's disease in a very recent genome-wide meta-analysis [195], and an SNP study has revealed possible associations of PGC-1 $\alpha$ polymorphisms with risk, age of onset and longevity in PD [196]. Pioglitazone, a widely known agonist of PPAR $\gamma$ enhances the activity and expression of PGC-1 $\alpha$ [197], besides it exerts transcriptional repression on a range of inflammatory proteins (reviewed in [198]). It has already proved its efficacy MPTP studies [199,200] and the phase II safety and futility clinical trial is already recruiting its participants with early Parkinson's disease (NCT01280123).

SNpc neurons possess specific vulnerability against the engagement of L-type $\mathrm{Ca}(\mathrm{v}) 1.3 \mathrm{Ca}^{2+}$ channels due to subsequent mitochondrial oxidative stress [201]. Blocking these channels by isradipine showed neuroprotective efficacy in animal models of PD [202,203] without impairing the autonomous pacemaking activity of SNpc neurons [204]. Moreover, isradipine has proven to be of therapeutic use against L-DOPA-induced dyskinesias [205]. A phase II clinical trial examining the safety and the efficacy of isradipine administration in PD patients has just been finished (NCT00753636), another one is currently active (STEADY-PD).

\section{PD and the kynurenine system}

Considering that $\mathrm{SNpc}$ receives glutamatergic inputs from a number of cortical and subcortical regions including the cerebral cortex, subthalamic nucleus and amygdala 
(reviewed in [206]), and that complex I deficiency results in increased sensitivity to excitotoxic insults in SNpc of PD patients [135], furthermore, that the role of mitochondrial $\mathrm{NO}^{\circ}$ accumulation in PD has recently emerged (reviewed in [207]), it is understandable that an increasing interest is focusing on the potential roles of endogenous neurotoxins and neuroprotectants of the kynurenine system in the pathogenesis of the disease.

The systemic administration of MPTP has been demonstrated to decrease KAT I activity in murine SN [208], and ex vivo rat cerebral cortical slices show diminished activity of KAT II and subsequent decrease in KYNA following MPP+ insult [209]. Consistent human post mortem studies of PD brains have reported decreased KYNA level and L-KYN/3$\mathrm{OH}-\mathrm{L}-\mathrm{KYN}$ ratio in the putamen, SNpc and the frontal cortex, and elevated 3-OH-L-KYN level in SNpc and the putamen [210]. Plasma levels of QUIN have also been found to be elevated in PD patients [211]. The switch of TRP metabolism to the direction of 3-OH-LKYN and QUIN might be secondary to the inhibited state of complex I and subsequently increased $\mathrm{NAD}^{+}$demand, and it may contribute to further nigrostriatal degeneration by enhanced excitotoxicity and oxidative stress.

Interestingly, there seems to be a physiological inverse regulation between striatal KYNA and dopamine levels. Systemic administration of L-DOPA [212] and D-amphetamine [213] causes a decrease in KYNA levels in the rat brain. On the other hand, exhibits indirect inhibition on dopamine release KYNA in nanomolar concentrations by blocking astrocytic $\alpha 7$ nicotinic acetylcholine receptors, whereas direct inhibition in higher concentrations through blocking NMDARs and non-NMDARs [214]. In addition, the selective inhibition of KAT II leads to a two- to threefold increase in extracellular striatal dopamine level, which can be rescued by the co-infusion of KYNA [215]. Thus, dopaminergic stimulation, e.g. by Damphetamine or L-DOPA can theoretically and experimentally result in higher striatal vulnerability against excitotoxic insults further deteriorating nigrostriatal degeneration [216]. However, chronic admininistration of L-DOPA, which is the first-line symptomatic therapy in PD, has previously been demonstrated by others to have no deteriorating effect on the remaining nigrostriatal neurons [217].

The co-infusion of nicotinylalanine, L-KYN and probenecid into SNpc provides protection against neurotoxicity induced by locally administered NMDA and QUIN in rats [100]. Furthermore, the bilateral injection of KYNA to the medial segment of globus pallidus of severely parkinsonian MPTP-treated monkeys [218,219] and rats [219] alleviate motor symptoms such as akinesia, tremor and rigidity in a dose-dependent manner [219].

Taken together, the long-term pharmacological increase of brain KYNA levels might be beneficial in PD due to its neuroprotective potential; furthermore, it has been proven to be effective in treating L-DOPA-induced dyskinesias without compromising the antiparkinsonian effect of chronic L-DOPA therapy in monkeys [220].

\section{HUNTINGTON'S DISEASE}

Huntington's disease (HD) is a chronic inherited autosomal dominant neurodegenerative disorder characterized by the preferential loss of the striatal $\gamma$-aminobutyric acidergic (GABAergic) medium-sized spiny neurons (MSNs) and the appearance of intranuclear and intracytoplasmic aggregates of mutant huntingin protein widely distributed in 
neuronal and extaneuronal tissues. The clinical symptoms appear around the mid 40s manifesting in hypotonic hyperkinesias (chorea, ballism) in early stages, becoming accompanied by dystonia, pyramidal symptoms, psychosis and dementia as the disease progrediates.

\section{Mitochondrial dysfunction in HD}

The association of HD with deficient activity of mitochondrial complex II was very early revealed by a human post mortem examination [221], whereas later studies reported the involvement of complex III and IV as well [222,223]. The effect of mitochondrial dysfunction and subsequent oxidative stress to cellular compartments can be observed in the increased number of mitochondrial mutations in HD patients [224]. The inhibition of complex II either irreversibly by 3-nitropropionic acid (3NP) [225] or reversibly by malonate [226] is widely applied in modeling HD in vivo. Systemic intoxication by $3 \mathrm{NP}$ has been shown to effectively recapitulate most of the clinical and histological characteristics of $\mathrm{HD}$, including preferential neurodegeneration of GABAergic MSNs in the striatum [227]. Meanwhile the relevance of the malonate model as a preclinical screen has recently been questioned due to the poor reflectivity of its results to that of transgenic HD models [228].

Huntingtin protein is encoded by the IT15 (interesting transcript 15) gene localized in the short arm of chromosome 4, and the pathognomonic polyglutamine (polyQ) repeatcontaining mutant variant develops due to the expansion of its CAG trinucleotid repeat sequence. The number of CAG repeats strongly correlates with clinical severity [229]. Mutant huntingtin is able to directly bind to mitochondria [230] and appears to be causative in HD due to its toxic gain of function resulting in mitochondrial dysfunction through many ways including the transcriptional repression of PGC-1 $\alpha$ [231], the dysregulation of mitochondrial trafficking [232], and the impairment of mitochondrial $\mathrm{Ca}^{2+}$ handling [233] with increased susceptibility to $\mathrm{Ca}^{2+}$-induced permeability transition and cytochrome $c$-mediated apoptosis [234,235]. However, an increasing amount of evidence suggests a differential effect of mutant huntingtin inclusions to cell survival, causing neurodegeneration in the form of small aggregates or aberrantly folded monomers, whilst being protective as larger aggregates probably via the sequestration of the toxic forms [236]. Furthermore, it is suggested that the relatively late symptomatic onset of an early expressing genetic mutation is due to a sort of compensatory mechanism induced by mutant huntingtin, the effect of which can be seen in the prominent resistance of young R6/2 transgenic HD animals against QUIN [237], kainic acid [238], 3NP [239] and malonate [240] compared to wild-type littermates or more aged mutants [241]. Indeed, the enhanced sensitivity of the striatum of $R 6 / 2$ animals to glutamatergic exctitotoxicity appears to be age-dependent and correlates with decreased levels of glutamate transporters within the striatum [242].

Serious efforts have been made to find drug candidates capable of overcoming mitochondrial dysfunction in HD. Similarly to its results in $\mathrm{PD}$, coenzyme $Q 10$ provides contradictory findings in HD both in preclinical and clinical levels of investigation. While a number of authors have reported significant neuroprotection by means of decrease in 3NPinduced striatal lesions [190,243] and improvement in both survival and motor performance in 
transgenic HD mice [190,244], other groups investigating transgenic animal models either report amelioration only in motor performance, but not in survival [245], or find no significant differences in any endpoint [246,247]. A most interesting, recently published comprehensive study has proposed that the reported beneficial effects of coenzyme Q10 on survival and motor performance of transgenic mice could be due to inappropriate husbandry, when HD pathology could interfere with adequate nutrition and secondarily lead to coenzyme Q deficiency [247]. The first human multicenter clinical trial with Q10 (CARE-HD) showed a non-significant tendency to slow functional decline in HD [248]. Having proven its safety and tolerability in higher doses (Pre2CARE) [249], Q10 is currently running in a larger phase III study with $2.4 \mathrm{~g}$ /day oral administration (2CARE) along with a phase II prevention study (PREQUEL) for pre-manifest HD patients.

Likewise in PD, the antioxidant and energy buffer creatine has showed promising neuroprotective efficacy in animal models of HD [190,250] and has been reported to dosedependently inhibit polyQ aggregation in a slice culture assay [251]. Furthermore, creatinekinase has recently been proposed as a biomarker for the deterioration of HD pathology as it has been found to be reduced in 3NP-intoxicated rats [252], in transgenic HD mice and in HD patients in a disease severity-dependent manner [253]. Its oral administration has proven to be safe, tolerable, and beneficial for the antioxidant status in HD [254]. However, up to now, clinical trials with orally administered creatine have failed to reveal any improvement in the cognitive, functional and neuromuscular status of HD patients [255-257]. A phase II and a phase III clinical trial were initiated in 2007 and 2009 to evaluate tolerability and efficacy of higher doses of creatine in pre-manifest (PRECREST) and manifest (CREST-E) HD, respectively.

L-carnitine is involved in the mitochondrial exchange of fatty acids and harbors effective antioxidant properties (reviewed in [258]). It is able to suppress 3NP-induced permeability transition in isolated mitochondria [259] and has recently been found effective in a transgenic mouse model of HD [260]. A double-bind crossover study with only few participants enrolled has revealed no significant effect of acetyl-L-carnitine on clinical status of HD patients [261]. A large, randomized, double-blind, placebo-controlled clinical trial to elucidate the therapeutic potential of L-carnitine is warranted.

Cysteamine and its oxidized form cystamine are potent antioxidants and can exert neuroprotection via pleiotropic actions including the maintenance of antioxidant status [262264] and the elevation of brain-derived neurotrophic factor (BDNF) secretion [265], a growth factor known to be deficient in HD-related CNS regions [266]. Both compounds have shown neuroprotective efficacy in in vitro [267] and in vivo models of HD [252,264,268,269]. It is known that the level of tissue transglutaminase enzyme is elevated in HD models in vitro [270], in vivo [268] and also in HD patients [271,272]. The long-held presumption that the ability of cystamine to inhibit transglutaminase activity [269,273] would be responsible for its neuroprotective effect has recently been challenged [274], along with the hypothesis that this enzyme would contribute to disease progression via cross-linking huntingin and promoting its aggregation [275]. Having completed a phase I dose finding and tolerability study (CYTE-IHD) [276], a phase II clinical trial with delayed release cysteamine RP103 is ongoing.

HD patients and transgenic HD mice exhibit similar metabolic disturbances manifesting in a hypercatabolic status [277] with marked weight loss [278], which precedes 
the development of motor symptoms [277] and appears to be directly related to the number of CAG repeats [279]. The involvement of impaired PGC-1 $\alpha$ expression in the development of metabolic disturbances is assumed [280]. Dietary $n-3$ polyunsaturated fatty acids (PUFAs), such as eicosapentaenic acid (EPA), are known to improve mitochondrial metabolism in many ways, including the activation and induction of the PPAR family (PPAR $\alpha,-\beta,-\gamma 1,-\gamma 2)$ and PGC-1 $\alpha$ [281] besides other key transcription regulatory proteins (widely reviewed in [282]). Early and sustained treatment with PUFAs has been able to diminish behavioral alterations in R6/2 transgenic mice fundamentally [283], but the administration of ethyl-EPA to mature YAC128 transgenic mice could only result in modest but significant behavioral improvement [284]. Oral administration of PUFAs resulted in significant improvement in dyskinesias, which is the first report of a significant improvement achieved in a randomized clinical trial in HD [285]. Despite its peerless effect to prevent atrophy of the affected brain regions [286], ethyl-EPA treatment has shown no clinical benefit in a randomized, double-blind trial [287]. A multicenter, randomized trial was initiated in 2008 to re-evaluate the clinical efficacy of ethyl-EPA in HD (TREND-HD) and reported no benefit after the first six months [288].

Dysfunctional epigenetic regulation is considered to be another substantial component in the pathogenesis of HD. Accordingly, various histone deacetylase inhibitors have been found protective in animal models of HD [289,290]. D- $\beta$-hydroxybutyrate, a mitochondrial energizing keton body, has recently been found protective in $3 \mathrm{NP}$ and transgenic HD models, which effects were accompanied by the inhibition of histone deacetylation mediated by mutant huntingtin [291]. These findings indicate that D- $\beta$-hydroxybutyrate may confer neuroprotection via simultaneously targeting the mitochondrial and epigenetic alterations associated with HD, which makes this compound a valuable candidate of investigation in clinical trials to come.

\section{HD and the kynurenine system}

Early observations with exogenous [292,293] and endogenous [294,295] excitotoxins raised the suggestion that striatal excitotoxicity may take the lead in the development of HD. This hypothesis has gained support by the results of a subsequent human postmortem study revealing a massive loss of NMDAR binding in the striatum [296]. Indeed, the preferential abundance of NR2B subunit containing NMDARs on striatal neurons [297,298] and the innate hypersensitivity of their mitochondria to $\mathrm{Ca}^{2+}$ overload-induced permeability transition [299] along with the robust glutamatergic input of the striatum from the thalamus and the cerebral cortex [300] make this brain region a particularly vulnerable structure to glutamatergic excitotoxicity. While normal huntingtin exhibits neuroprotection against NMDA-induced neurotoxicity via binding to the scaffolding protein PSD-95, polyQexpanded mutant huntingtin exaggerates the toxicity by inhibiting this interaction [301]. Furthermore, mutant huntingtin has been reported to increase the expression [302] and enhance the tyrosine phosphorylation of NR2B subunit-containing NMDARs [303], further contributing to the enhanced sensitivity. Very recently, the increased expression and activity of these extrasynaptic NMDARs in transgenic HD mice has been reported [304], which is associated with decreased striatal cyclic AMP response element-binding protein (CREB) signaling [304] and subsequent underexpression of PGC-1 $\alpha$ [298]. Considering that the 
enhanced sensitivity of NMDARs in HD striatum appears to be accompanied by decreased glutamate uptake in both transgenic HD mice [305] and the human HD brain [229], the demand for regulating NMDAR function makes the kynurenine system a rational target for investigation.

It has become evident very early that the intrastriatal administration of QUIN provided a fairly good model for HD [294,295,306], as it evokes cognitive, motor and neurochemical alterations closely resembling that of the human disease. It is a reasonable question whether this endogenous neurotoxin may play a role in the development of HD itself. Indeed, human studies have revealed multiple alterations in TRP metabolism in HD. On the one hand, QUIN [307] and 3-OH-L-KYN levels have been were found to be elevated in the human HD brains, particularly in the striatum [307]. Noteworthly, these alterations are apparent only in early stages of HD, and the results from studies not adjusted to the stage are fairly controversial [308,309]. Nevertheless, the role of QUIN and 3-OH-L-KYN in the initial stage of neurodegeneration in HD seems reasonable, and is in line with the observation that intrastriatally injected QUIN evokes effects that mimic earlier symptoms of HD [310]. Alterations in TRP metabolism including the abnormally high activity of the biosynthetic enzymes of QUIN and 3-OH-L-KYN have also been demonstrated in transgenic HD mice [311]. On the other hand, striatal [312], cortical [313] and cerebrospinal fluid (CSF) [309,312] KYNA levels have been reported to be decreased in HD patients, paralleled by decreased activity of the relevant KATs [312,314]. The findings that 3NP reduces KAT-I and KAT II activities in experimental rat models [209,315] indicate that the alterations of TRP metabolism might be secondary to the mitochondrial energy crisis present in HD. In such hypersensitive conditions to NMDAR-mediated toxicity, these alterations could easily contribute to the further deterioration of the neurodegenerative process. Indeed, the replication of these alterations in a KAT II knock-out mice model has demonstrated increased striatal vulnerability to QUIN [110], similarly to a transgenic HD model [316]. Correspondingly, the genetic ablation of the KAT II homologue ARO9 enhances the toxic effect of mutant huntingtin in yeasts, whereas the ablation of KMO homologue BNA4 provides protection [317]. Another research group has reported that the genetic inhibition of either KMO or tryptophan 2,3-dioxygenase (TDO) is neuroprotective in transgenic HD flies [318]. There is experimental evidence that pharmacological elevation of KYNA is neuroprotective in HD. The efficacy of the BBB-penetrant KYNA derivative prodrug 4-Cl-KYN [86] and the KMO inhibitor nicotinylalanine [107] has already been proven against striatal neurodegeneration induced by malonate [86] and QUIN [86,107] in rats, and a recently published study has demonstrated extended survival and neuroprotection in transgenic HD mice by a novel KMO inhibitor prodrug JM6 [112].

Pharmacological regulation of NMDAR activity is a double-edged sword due to its ubiquitous function in the CNS; furthermore, evidence suggests that the inhibition of synaptic NMDARs is neurotoxic via blocking BDNF and CREB pathways [38]. However, the cautious dosing of NMDAR blockers can overcome this issue and protect transgenic HD mice by the preferential blockage of extrasynaptic NMDARs [298,304]. Our laboratory has recently reported the massive neuroprotective efficacy of a novel KYNA amide N-(2-N,Ndimethylaminoethyl)-4-oxo-1H-quinoline-2-carboxamide hydrochloride [93] in N171-82Q transgenic HD mice [96], which can be a perfect candidate drug since KYNA amides may 
preferentially inhibit NR2B-containing NMDARs [97], which predominate in the extrasynaptic areas. The preclinical screening of other newly synthesized KYNA amides is underway, searching for the most valuable candidates for future clinical investigations.

\section{ALZHEIMER'S DISEASE}

Alzheimer's disease (AD) is also a classic, chronic, neurodegenerative disorder characterized by hippocampal, cortical and basal forebrain cholinergic neurodegeneration and atrophy with late-onset progressive dementia, which manifests in the loss of short-term and spatial memory and eventually most of the cortical functions. The process is accompanied by the formation of predominantly extracellular plaques of $\beta$-amyloid (A $\beta)$ and predominantly intracellular deposits of neurofibrillary tangles (NFTs) constituted by hyperphosphorylated tau proteins (pTau). AD is the most common cause of dementia (50-60\%), affecting approximately $30 \%$ of the elderly in the developed world. AD is typically a sporadic disease; familial forms are very rare and are characterized by presenile onset (reviewed in [319]).

\section{Mitochondrial dysfunction in AD}

A significant decrease in the activity of mitochondrial complex IV in the affected regions of human $\mathrm{AD}$ brains has been reported by post-mortem studies [320,321], indicating the contribution of energy impairment in the underlying pathology. In addition, AD patients appear to harbor numerous mtDNA mutations, which can severely impair mitochondrial transcription [322]. The dysregulation of mitochondrial dynamics in AD neurons has also been reported [323]. Both extracellular and intracellular $A \beta$ are known to contribute to neurotoxicity, the most toxic forms are small soluble globular structures (reviewed in [324]). Among experimental conditions, A $\beta$ preferentially accumulates in the mitochondria [325], where it is able to inhibit the activity of complex IV [326] and promote mtPTP formation [327]. The preferential ability of oligomeric $A \beta$ to accumulate in the mitochondria is supposed to be partly due to its increased lipid permeability (reviewed in [328]); however, a selective transport mechanism by the translocase of the outer membrane (TOM) machinery [329] and intramitochondrial $A \beta$ production have also been reported [330]. Additionally to the indirect elevation of ROS production through disrupted respiration, $\mathrm{A} \beta$ fragments per se generate free radicals [331]. The co-localization of the dense core plaques with the fluorescent signaling of free radicals well demonstrates the direct connection between A $\beta$ and ROS [332]. The massive overproduction of ROS can increase the accumulation of A $\beta$ vice versa, completing a vicious circle [331]. The level of intramitochondrial $\mathrm{A} \beta$ correlates with the extent of mitochondrial dysfunction and severity of cognitive impairment in transgenic AD mice [333]. Synaptosomes preferentially accumulate $A \beta$, and show increased sensitivity to A $\beta$-toxicity [334]. Recently, the crucial role of the amyloid $\beta$-binding alcohol dehydrogenase (ABAD) enzyme has been revealed as a potential direct molecular link between $A \beta$ and mitochondrial pathologies [335], which includes the selective inhibition of complex IV, ROS generation, mitochondrial transition [336] and the inhibition of intramitochondrial $A \beta$ degrading presequence peptidase (PreP) [337]. A $\beta$ has also been shown to directly interact with cyclophilin D (CypD) and adenine nucleotide translocase (ANT) [338] hence promoting the assembly of mtPTP. Most recently, $A \beta$ has been reported to disintegrate the anterograde 
transport of synaptosomes, leading to the degeneration of the synapses [339]. Besides, amyloid precursor protein (APP) [340] and $A \beta_{25-35}$ [341] inhibit the entry of nuclear encoded proteins including subunits essential for the correct assembly of respiratory complexes, which triggers further deterioration in mitochondrial function and more extensive ROS production. Intracellular A $\beta$ severely affects the function of the proteasomal degradation system as well. This effect is exaggerated in the absence of parkin [342], which appears to promote the clearance of toxic $A \beta_{1-42}$ [343]. A $\beta$ can indirectly trigger the hyperphosphorylation of tau through the activation of glycogen synthase kinase-3beta (GSK-3 $\beta$ ) and mitogen activated protein kinase (MAPK) [344,345], which results in the disintegration of axonal structure. Recent studies tend to support earlier observations [346,347] that the amount of A $\beta$ and pTau burden within the brain is in direct correlation with the severity of cognitive impairment [348351], whereas plasma and CSF levels of $A \beta$ have an inverse correlation [352-354]. The direct contribution of pTau to mitochondrial dysfunction has also been reported as P301L tau transgenic mice exhibit a decreased activity of complex I and decreased expression of complex V $[355,356]$. The involvement of the deregulation of metabolic master regulator and mitochondrial biogenesis enhancer PGC- $1 \alpha$ has recently been demonstrated in AD pathology as well, as its expression is decreased in the hippocampus of AD patients [357].

Epidemiological studies indicate that the regular intake of dietary 3-n PUFAs is associated with a decreased risk for $\mathrm{AD}$ [358]. 3-n PUFAs are involved in several mitochondrial processes such as gene expression, free radical production, mitochondrial apoptosis and calcium homeostasis (reviewed in [359]). The plasma level of the 3-n PUFA docosohexaenaic acid (DHA) - an essential neuronal membrane phospholipid component has been reported to inversely correlate with the severity of cognitive decline in AD [360]. Accordingly, experimental depletion of 3-n PUFA causes behavioral alterations, evokes a marked loss in postsynaptic proteins [361] and in NMDAR subunits NR2A and NR2B, and triggers the activation of apoptotic caspases [362] in transgenic AD models. These effects can be prevented by the dietary administration of DHA. DHA has also been demonstrated to reduce amyloid burden and tau phosphorylation [363,364] and to improve cognition in transgenic AD mice [364]. These protective effects of DHA are proposed to be mediated by the elevation of ApoE receptor family member SorLa (LR11) [365], which is robustly downregulated in AD [366] and appears to be essential in the regulation of APP trafficking and intracellular $A \beta$ accumulation [367]. Initial clinical trials with 3-n PUFA/DHA supplementation could only detect significant cognitive improvement in patients with mild cognitive impairment (MCI) [368,369] or with very mild cognitive dysfunction [370], but not with definitive $\mathrm{AD}$. A subsequent clinical trial has also failed to show any cognitive benefit in AD [371]; however, subgroup analyses have revealed significantly lower declines in Alzheimer's Disease Assessment Scale cognitive subscale (ADAS-cog) and Mini-Mental State Examination (MMSE) scores during the 18 months of investigation among ApoE4 noncarrier patients, an allele which has been associated with increased risk for AD when present [372]. A phase I/II (NCT01058941) and a phase III clinical trial (MAPT) are currently ongoing to study the potential therapeutic efficacy of DHA through different lengths of observation period. 
Acetyl-L-carnitine has widely been tested in $\mathrm{AD}$ as well. In vitro and in vivo studies indicate that this compound could be of therapeutic use in AD since it potently reduces oxidative damage [373,374], restores metabolic changes [375], attenuates tau phosphorylation [376], protects against $A \beta$ toxicity [373], and halts cognitive decline [374,376] in a wide range of AD models. Human trials from the early 1990s provided promising results with significantly slower rate of cognitive deterioration in many aspects [377-379]. A subsequent larger trial have failed to demonstrate any significant improvement [380]; however, there has been an observable tendency to slow the rapid deterioration of relatively younger patients with early-onset $\mathrm{AD}$, which has proved to be statistically significant during the reanalysis of the data [381]. Unfortunately, in a subsequent prospective study acetyl-L-carnitine has failed to halt the decline in patients with young-onset AD [382]. Some recent results still seems to give hope, demonstrating that acetyl-L-carnitine improves the response rate of AD patients to acetylcholinesterase (AChE) inhibitor therapy [383], which is currently the first-line treatment in AD. Two recent clinical investigations run by the same research group have reported clinically observable improvement and maintenance in performance in many outcomes due to the administration of an antioxidant combination formula containing $500 \mathrm{mg}$ acetyl-Lcarnitine [384,385]. An independent phase II clinical trial with MCI patients has just been finished (NCT00903695), while another phase II study with MCI and definitive AD patients (NCT01320527) is currently recruiting participants to confirm or deny the promising results of this formulation.

One of the biggest disappointments was the failure of a former non-selective antihistamine 2,8-dimethyl-5-(2-(6-methylpyridin-3-yl)ethyl)-2,3,4,5-tetrahydro-1H-pyrido[4,3b]indole hydrochloride (latrepirdine, Dimebon). Latrepirdine has provided neuroprotection and enhanced cognitive performance in a wide range of experimental models [386-388]. It is presumed to have multiple mechanisms of action that might include NMDAR inhibition [389], AchE inhibition [390], enhancement of cerebral glucose utilization [391] and the improvement of mitochondrial function [388], mediated partly by the inhibition of L-type $\mathrm{Ca}^{2+}$ channels [386]. However, its efficacy to inhibit mtPTP [392] has recently been questioned [393] along with the clinical relevance of its ability to block NMDARs and AChE [387]. The initial human investigations have demonstrated unusually promising results with a phase II clinical trial (NCT00377715) reporting significant improvement in all primary and secondary outcomes [394]. In contrast, the results of a phase III efficacy and safety study (CONNECTION) have recently been announced reporting zero benefit in any endpoint [395]. Several phase III trials with latrepirdine have subsequently been terminated (CONTACT, NCT00912288, NCT00939783), one has just been completed (NCT00838110) and another one is still ongoing to elucidate its efficacy in $\mathrm{AD}$ patients on Donepezil treatment (CONCERT). It might be possible that the apparent ability of latrepirdine to increase cognitive performance is achieved through mechanisms not necessarily involved in the pathology of $\mathrm{AD}$, which is in line with the recent findings that this efficacy of latrepirdine is unrelated to cerebral A $\beta$ burden in transgenic AD mice [396], but it is also apparent in healthy animals [396,397]. The robust discrepancies between preclinical and clinical examinations, and also between two independent clinical trials raise serious concerns about the correct interpretation of preclinical findings. 


\section{AD and the kynurenine system}

The distribution of the pathological hallmarks of $\mathrm{AD}$ in the brain is consistent with the regions of memory formation, where the glutamatergic circuitry is fundamental. One of the most affected structures is the hippocampal formation. Hippocampus, and particularly cornu ammonis 1 (CA1) [398], is known to be extremely vulnerable to a wide range of insults including glutamatergic excitotoxicity (reviewed in [399]), at least in part due to the high concentration of exctitatory amino acid receptors. Experimental AD models provide evidence that the presence of $A \beta_{1-42}$ further increases neuronal vulnerability to excitotoxic stress [400,401]. Furthermore, $A \beta_{1-42}$, but not $A \beta_{1-40}$, significantly induces the expression of indoleamine 2,3-dioxygenase 1 (IDO1) and the production of QUIN [402], which are both abundantly present in AD hippocampus with the highest abundance in the perimeter $\mathrm{A} \beta$ senile plaques [403] and in specific conjunction with NFTs [404]. The increased production of QUIN in AD brain has been associated with the need for inflammatory circumstances being present $[405,406]$, which is in line with the recent findings that $A \beta_{1-42}$ pre-treatment primes only a slight induction of IDO expression in in vitro microglia models, and the robust activation can only be seen after the administration of the pro-inflammatory cytokine interferon- $\gamma$ to the $A \beta_{1-42}$ pre-treated cells [407]. QUIN has a high affinity towards inducing lipid peroxidation [408], which corresponds with the observations that lipid peroxidation is a characteristic feature of $\mathrm{AD}$ but not of normal aging (reviewed in [409]). There is considerable evidence that QUIN also contributes to the hyperphosphorylation of tau proteins via the overactivation of NMDARs [410]. These findings substantially overwrite the conclusions from earlier observations that QUIN would not play a crucial role in the development of neurodegeneration in AD.

The findings regarding KYNA are not that concording. Although decreased KYNA levels were found in the blood [411] and CSF [309] of AD patients, marked elevation in KYNA concentrations was detected in the striatum with increased KAT I and KAT II activities, and also slight elevation in the hippocampus with no KAT alterations [412]. The elevation of KYNA might be due compensatory mechanisms and can contribute to the cognitive impairment [413-415] as it is suggested also in Down syndrome and schizophrenia.

There is considerable evidence that the modulation of QUIN synthesis can offer neuroprotection in animal models of AD. Recently the novel KMO inhibitor prodrug JM6 has been reported to be effective in preventing spatial memory deficits, anxiety behavior, and synaptic loss in transgenic AD mice [112]. In experimental conditions, the systemic administration of probenecid with L-KYN as an immediate metabolic precursor of KYNA exerts neuroprotection against intrahippocampal $A \beta_{25-35}$ [102]. Similar effects have been reported about 4-Cl-KYN against QUIN induced hippocampal toxicity [87]. However, the therapeutic relevance of these approaches in $\mathrm{AD}$ might be questioned with respect to the arising evidence that elevated KYNA levels are involved in the cognitive decline in AD. It seems reasonable that the treatment of $\mathrm{AD}$ via the modulation of TRP metabolism will require the most sophisticated pharmaceutical approache that includes, on the one hand, the inhibition of QUIN synthesis to provide neuroprotection against excitotoxic insults, and on the other hand, the reduction of excessive KYNA levels to offer proper NMDAR function for adequate memory formation and recall $[414,415]$. 


\section{Figure 3. Mitochondria in neurodegenerative diseases}

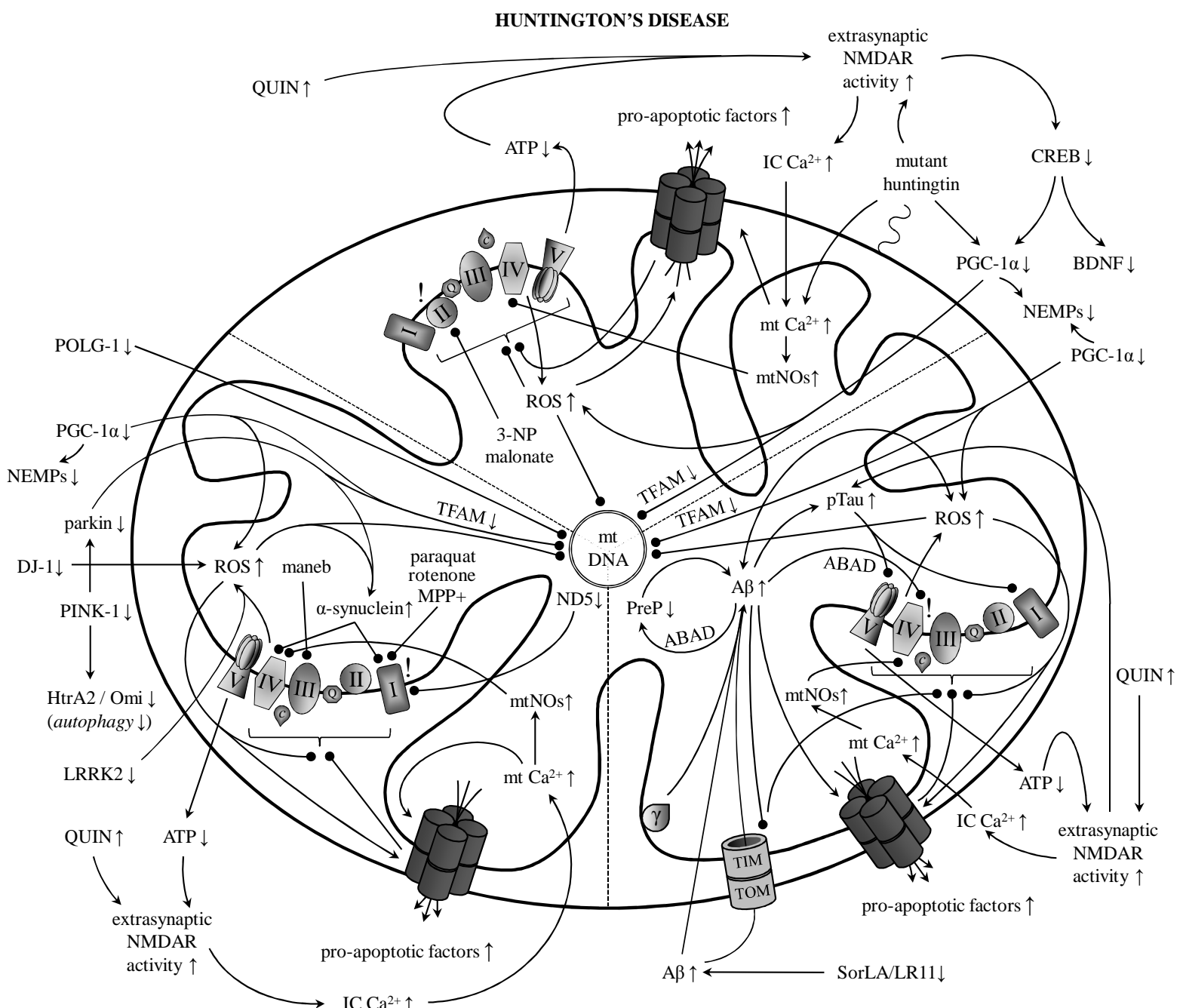

PARKINSON'S DISEASE

ALZHEIMER'S DISEASE

The figure presents the schematic overview of the processes involved in mitochondrial dysfunction related to Parkinson's, Huntington's and Alzheimer's diseases. For detailed description, we refer to the corresponding parts of the article.

$\uparrow=$ increased presence/expression/activity; $\downarrow=$ decreased presence/expression/activity; arrow $=$ promotion; bulb-headed arrow $=$ inhibition/deterioration; $\mathrm{I}-\mathrm{V}=$ mitochondrial complexes; $3 \mathrm{NP}=3$-nitropropionic acid; $\mathrm{A} \beta=\beta$-amyloid (toxic isoforms); $\mathrm{ABAD}=$ amyloid $\beta$-binding alcohol dehydrogenase; BDNF = brain-derived neurotrophic factor; $\mathrm{c}=$ cytochrome $c$; CREB $=$ cyclic AMP response element-binding protein; $\gamma=$ gamma secretase; $\mathrm{HtrA} 2 / \mathrm{Omi}=$ high temperature requirement factor A2; IC $\mathrm{Ca}^{2+}=$ intracellular calcium; LRRK2 = leucine-rich repeat kinase 2; $\mathrm{MPP}+=1$-methyl-4-phenylpyridinium; $\mathrm{mt} \mathrm{Ca}^{2+}=$ mitochondrial calcium; mtDNA $=$ mitochondrial DNA; $m$ tNOS $=$ mitochondrial nitric oxide synthase; NEMP $=$ nuclear-encoded mitochondrial protein; NMDAR $=N$-methyl-D-aspartate-sensitive glutamate 
receptor; PINK1 $=($ PTEN $)$-induced putative kinase 1 ; PGC-1 $\alpha=$ PPAR $\gamma$ coactivator $-1 \alpha$; POLG1 = mtDNA polymerase gamma $1 ;$ PreP = presequence peptidase; $\mathrm{pTau}=$ hyperphosphorylated tau protein; $\mathrm{Q}=$ coenzyme $\mathrm{Q} 10$ (ubiquinone); QUIN = quinolinic acid; ROS $=$ reactive oxygen species; TFAM = mitochondrial transcription factor $\mathrm{A} ; \mathrm{TIM}=$ translocase of the inner membrane; TOM = translocase of the outer membrane.

\section{CONCLUDING REMARKS}

The pathogenesis of common neurodegenerative disorders such as PD, HD and AD is robustly associated with mitochondrial dysfunction. The putative origins of these diseases are distinct; however, the shared contribution of mitochondrial dysfunction can lead to certain extent of symptomatic overlap in the terminal phases of the clinical pathology. The underlying causes behind the preferential involvement of particular CNS regions in these diseases require further elucidation; however, it can be concluded that the extreme energy demand of the affected structures make them highly vulnerable to any sort of mitochondrial disturbances. Mitochondria targeted therapies aiming to overcome the energy impairment and the extensive oxidative stress show great promises in a wide range of experimental conditions. Unfortunately, the results gained from human clinical trails are rather disappointing or at best very controversial. One of the reasons underlying this phenomenon can be the extreme genetic and conditional homogeneity of the experimental animals in contrast to the heterogeneity of the clinical population usually recruited in a trial. Another concern is the relatively young age of animals applied for the experimental setups versus the relatively aged subjects of the clinical trials. This can lead to false positive results in terms of neuroprotection in vivo, since younger animals can be more resistant to the experimentally induced mitochondrial toxicity, thus the protective effect of a drug candidate can be more pronounced. Thirdly, most of the preclinical investigations focus on the prevention or reduction of the neurodegenerative effect of the applied toxin or genetic alteration, which is obviously unable to model the status of trial participants, who have already suffered an extensive loss of neurons in the affected CNS regions by the time of the diagnosis. These shortcomings are to be considered in the future during the setup of both in vivo examinations and human trials.

Considering that NMDAR-mediated excitotixicity seems to be ubiquitous in neurodegenerative disorders, and that the affected structures possess anatomical and physiological susceptibility to be highly sensitive to this process, the investigation of the kynurenine system as the endogenous regulator of NMDAR functioning is of great interest. May the alterations in TRP metabolism be rather secondary to the underlying pathological processes, it can be concluded that the local decrease in KYNA and the local elevation in QUIN and 3-OH-L-KYN levels can contribute to neurodegeneration through the overactivation of NMDARs. Alzheimer's disease might be an exception where the elevation of KYNA levels in the affected structures has been reported, which probably contributes to the development of cognitive decline. Promising experimental results have come to rise in the near past in different models of neurodegenerative diseases through the exogenous regulation of TRP metabolism. The application of novel KYNA analogues and KMO inhibitors show the greatest therapeutic promise. Thorough examinations and well set-up human trials are warranted to elucidate the therapeutic potential of these candidates. 


\section{LIST OF ABBREVIATIONS}

3-HAO = 3-hydroxyanthranic acid 3,4-dioxygenase; 3NP = 3-nitropropionic acid; 3-OHANA $=3$-hydroxy-anthranilic acid; 3-OH-L-KYN $=3$-hydroxy-L-kynurenine; $; \mathrm{A} \beta=\beta$ amyloid $; \mathrm{ABAD}=$ amyloid $\beta$-binding alcohol dehydrogenase; $\mathrm{AChE}=$ acetylcholinesterase; $\mathrm{AD}=$ Alzheimer's disease; ADAS-cog $=$ Alzheimer's Disease Assessment Scale cognitive subscale; $\mathrm{AIF}=$ apoptosis-inducing factor; $\mathrm{ANA}=$ anthranilic acid, $\mathrm{ANT}=$ adenine nucleotide translocase; Apaf-1 $=$ apoptotic protease activating factor 1 ; APP $=$ amyloid precursor protein $\mathrm{BBB}=$ blood-brain barrier; $\mathrm{BDNF}=$ brain-derived neurotrophic factor; $\mathrm{CA} 1=$ cornu ammonis $1 ; \mathrm{CREB}=$ cyclic $\mathrm{AMP}$ response element-binding protein $; \mathrm{CSF}=$ cerebrospinal fluid; $\mathrm{CypD}=$ cyclophilin $\mathrm{D} ; \mathrm{DHA}=$ docosohexaenaic acid; $\mathrm{EPA}=$ eicosapentaenic acid; GABA $=\gamma$-aminobutyric acid; GSK- $3 \beta=$ glycogen synthase kinase3beta; $\mathrm{H}_{2} \mathrm{O}_{2}=$ hydrogen peroxide; $\mathrm{HD}=$ Huntington's disease; $\mathrm{HtrA} 2=$ high temperature requirement factor $\mathrm{A} 2(\mathrm{Omi})$; IDO = indoleamine 2,3-dioxygenase; IT15 = interesting transcript 15; JM6 = 2-(3,4-dimethoxybenzenesulfonylamino)-4-(3-nitrophenyl)-5-(piperidin1-yl)methylthiazole; $\mathrm{KAT}=$ kynurenine aminotransferase; $\mathrm{KMO}=$ kynurenine 3 monooxygenase (kynurenine 3-hydroxylase); $\mathrm{KYNA}=$ kynurenic acid; latrepirdine $=2,8$ dimethyl-5-(2-(6-methylpyridin-3-yl)ethyl)-2,3,4,5-tetrahydro-1H-pyrido[4,3-

b]indole hydrochloride; L-KYN = L-kynurenine; LRRK2 = leucine-rich repeat kinase 2; MAPK $=$ mitogen activated protein kinase; $\mathrm{MCI}=$ mild cognitive impairment; MMSE $=$ Mini-Mental State Examination; MnSOD = manganese superoxide dismutase; $\mathrm{MPP}+=1$ methyl-4-phenylpyridinium; MPTP = 1-methyl-4-phenyl-1,2,3,6-tetrahydropyridine; MSN = medium-sized spiny neuron; mtAAT $=$ aspartate aminotransferase; $\mathrm{mtDNA}=$ mitochondrial DNA; $\mathrm{mtNOS}=$ mitochondrial nitric oxide synthase; $\mathrm{mtPTP}=$ mitochondrial permeability transition pore; NCR-631 = 4,6-dibromo-3-OH-ANA; nDNA = nuclear DNA; NFT = neurofibrillary tangle; NMDA $=N$-methyl-D-aspartate; NMDAR $=N$-methyl-D-aspartatesensitive glutamate receptor; $\mathrm{nNOS}=$ neuronal nitric oxide synthase; $\mathrm{NO}^{\circ}=$ nitric oxide radical; $\mathrm{NOS}=$ nitric oxide synthase; $\mathrm{O}_{2}^{-}=$superoxide anion; $\mathrm{OH}^{-}=$hydroxyl radical; PARP-1 = poly(ADP-ribose) polymerase-1; PD = Parkinson's disease; PGC-1 $\alpha=$ PPAR $\gamma$ coactivator-1 $\alpha$; PINK1 = (PTEN)-induced putative kinase 1; PNU $156561=4,5$ dichlorobenzoylalanine $($ FCE 288833A); POLG1 $=$ mtDNA polymerase gamma 1; polyQ $=$ polyglutamine; $\operatorname{PPAR} \gamma=$ peroxisome proliferator-activated receptor $-\gamma$; PreP $=$ presequence peptidase; PSD-95 = postsynaptic density protein of molecular weight $95 \mathrm{kDa}$; pTau $=$ hyperphosphorylated tau protein; PUFA = polyunsaturated fatty acid; QUIN = quinolinic acid; Ro 61-8048 = 3,4-dimethoxy-[-N-4-(nitrophenyl)thiazol-2-yl]-benzenesulfonamide; ROS $=$ reactive oxygen species; SNP $=$ single nucleotide polymorphism; SNpc $=$ substantia nigra pars compacta; TFAM $=$ mitochondrial transcription factor A; TIM = translocase of the inner membrane; TOM $=$ translocase of the outer membrane; TRAP1 $=$ tumor necrosis factor receptor-associated protein 1 ; TRP = tryptophan; UPF $648=(1 \mathrm{~S}, 2 \mathrm{~S})-2-(3,4-$ dichlorobenzoyl $)$ cyclopropane-1-carboxylic acid.

\section{ACKNOWLEDGMENTS}

This work was supported by ETT 026-04, OTKA (K 75628) and TÁMOP-4.2.1/B-091/KONV-2010-0005 - Creating the Center of Excellence at the University of Szeged. 


\section{CONFLICTS OF INTEREST}

Authors report no relevant conflicts of interest.

\section{REFERENCES}

[1] Sagan, L. On the origin of mitosing cells. J. Theor. Biol., 1967, 14(3), 255-274.

[2] Sas, K.; Pardutz, A.; Toldi, J.; Vecsei, L. Dementia, stroke and migraine--some common pathological mechanisms. J. Neurol. Sci., 2010, 299(1-2), 55-65.

[3] Mitchell, P.; Moyle, J. Chemiosmotic hypothesis of oxidative phosphorylation. Nature, 1967, 213(5072), 137-139.

[4] Anderson, S.; Bankier, A.T.; Barrell, B.G.; de Bruijn, M.H.; Coulson, A.R.; Drouin, J.; Eperon, I.C.; Nierlich, D.P.; Roe, B.A.; Sanger, F.; Schreier, P.H.; Smith, A.J.; Staden, R.; Young, I.G. Sequence and organization of the human mitochondrial genome. Nature, 1981, 290(5806), 457-465.

[5] Sutovsky, P.; Moreno, R.D.; Ramalho-Santos, J.; Dominko, T.; Simerly, C.; Schatten, G. Ubiquitin tag for sperm mitochondria. Nature, 1999, 402(6760), 371-372.

[6] Wiesner, R.J.; Ruegg, J.C.; Morano, I. Counting target molecules by exponential polymerase chain reaction: copy number of mitochondrial DNA in rat tissues. Biochem Biophys. Res. Commun., 1992, 183(2), 553-559.

[7] Nicholls, D.G. Mitochondrial calcium function and dysfunction in the central nervous system. Biochim. Biophys. Acta, 2009, 1787(11), 1416-1424.

[8] Green, D.R.; Reed, J.C. Mitochondria and apoptosis. Science, 1998, 281(5381), 13091312.

[9] Brookes, P.S.; Yoon, Y.; Robotham, J.L.; Anders, M.W.; Sheu, S.S. Calcium, ATP, and ROS: a mitochondrial love-hate triangle. Am. J. Physio.l Cell Physiol., 2004, 287(4), C817-833.

[10] Yakes, F.M.; Van Houten, B. Mitochondrial DNA damage is more extensive and persists longer than nuclear DNA damage in human cells following oxidative stress. Proc. Natl. Acad. Sci. U S A, 1997, 94(2), 514-519.

[11] Wallace, D.C. Mitochondrial DNA sequence variation in human evolution and disease. Pro.c Natl. Acad. Sci. U S A, 1994, 91(19), 8739-8746.

[12] Sas, K.; Robotka, H.; Toldi, J.; Vecsei, L. Mitochondria, metabolic disturbances, oxidative stress and the kynurenine system, with focus on neurodegenerative disorders. J. Neurol. Sci., 2007, 257(1-2), 221-239.

[13] Poole, A.C.; Thomas, R.E.; Yu, S.; Vincow, E.S.; Pallanck, L. The mitochondrial fusion-promoting factor mitofusin is a substrate of the PINK1/parkin pathway. PLoS One, 2010, 5(4), e10054.

[14] Ziviani, E.; Tao, R.N.; Whitworth, A.J. Drosophila parkin requires PINK1 for mitochondrial translocation and ubiquitinates mitofusin. Proc. Natl. Acad. Sci. U S A, 2010, 107(11), 5018-5023.

[15] Virag, L. Structure and function of poly(ADP-ribose) polymerase-1: role in oxidative stress-related pathologies. Cur.r Vasc. Pharmacol., 2005, 3(3), 209-214.

[16] Mecocci, P.; MacGarvey, U.; Kaufman, A.E.; Koontz, D.; Shoffner, J.M.; Wallace, D.C.; Beal, M.F. Oxidative damage to mitochondrial DNA shows marked agedependent increases in human brain. Ann. Neurol., 1993, 34(4), 609-616.

[17] Ames, B.N.; Shigenaga, M.K.; Hagen, T.M. Mitochondrial decay in aging. Biochim. Biophys. Acta, 1995, 1271(1), 165-170.

[18] Beal, M.F. Aging, energy, and oxidative stress in neurodegenerative diseases. Ann. Neurol., 1995, 38(3), 357-366. 
[19] Mariani, E.; Polidori, M.C.; Cherubini, A.; Mecocci, P. Oxidative stress in brain aging, neurodegenerative and vascular diseases: an overview. J. Chromatogr. B. Analyt. Technol. Biomed. Life Sci., 2005, 827(1), 65-75.

[20] Papa, S. Mitochondrial oxidative phosphorylation changes in the life span. Molecular aspects and physiopathological implications. Biochim. Biophys. Acta, 1996, 1276(2), 87-105.

[21] Almeida, A.; Almeida, J.; Bolanos, J.P.; Moncada, S. Different responses of astrocytes and neurons to nitric oxide: the role of glycolytically generated ATP in astrocyte protection. Pro.c Natl. Acad. Sci.U S A, 2001, 98(26), 15294-15299.

[22] Lau, A.; Tymianski, M. Glutamate receptors, neurotoxicity and neurodegeneration. Pflugers Arch., 2010, 460(2), 525-542.

[23] Novelli, A.; Reilly, J.A.; Lysko, P.G.; Henneberry, R.C. Glutamate becomes neurotoxic via the N-methyl-D-aspartate receptor when intracellular energy levels are reduced. Brain Res., 1988, 451(1-2), 205-212.

[24] Ichas, F.; Mazat, J.P. From calcium signaling to cell death: two conformations for the mitochondrial permeability transition pore. Switching from low- to high-conductance state. Biochim. Biophys. Acta, 1998, 1366(1-2), 33-50.

[25] Crompton, M. The mitochondrial permeability transition pore and its role in cell death. Biochem. J., 1999, 341 (Pt 2), 233-249.

[26] Li, P.; Nijhawan, D.; Budihardjo, I.; Srinivasula, S.M.; Ahmad, M.; Alnemri, E.S.; Wang, X. Cytochrome c and dATP-dependent formation of Apaf-1/caspase-9 complex initiates an apoptotic protease cascade. Cell, 1997, 91(4), 479-489.

[27] Riobo, N.A.; Melani, M.; Sanjuan, N.; Fiszman, M.L.; Gravielle, M.C.; Carreras, M.C.; Cadenas, E.; Poderoso, J.J. The modulation of mitochondrial nitric-oxide synthase activity in rat brain development. J. Biol. Chem., 2002, 277(45), 4244742455.

[28] Poderoso, J.J.; Carreras, M.C.; Lisdero, C.; Riobo, N.; Schopfer, F.; Boveris, A. Nitric oxide inhibits electron transfer and increases superoxide radical production in rat heart mitochondria and submitochondrial particles. Arch. Biochem. Biophys., 1996, 328(1), 85-92.

[29] Balakirev, M.; Khramtsov, V.V.; Zimmer, G. Modulation of the mitochondrial permeability transition by nitric oxide. Eur. J. Biochem., 1997, 246(3), 710-718.

[30] Bonfoco, E.; Krainc, D.; Ankarcrona, M.; Nicotera, P.; Lipton, S.A. Apoptosis and necrosis: two distinct events induced, respectively, by mild and intense insults with $\mathrm{N}$ methyl-D-aspartate or nitric oxide/superoxide in cortical cell cultures. Proc. Natl. Acad. Sci. U S A, 1995, 92(16), 7162-7166.

[31] Ankarcrona, M.; Dypbukt, J.M.; Bonfoco, E.; Zhivotovsky, B.; Orrenius, S.; Lipton, S.A.; Nicotera, P. Glutamate-induced neuronal death: a succession of necrosis or apoptosis depending on mitochondrial function. Neuron, 1995, 15(4), 961-973.

[32] Tymianski, M.; Charlton, M.P.; Carlen, P.L.; Tator, C.H. Source specificity of early calcium neurotoxicity in cultured embryonic spinal neurons. J. Neurosci., 1993, 13(5), 2085-2104.

[33] Sattler, R.; Xiong, Z.; Lu, W.Y.; Hafner, M.; MacDonald, J.F.; Tymianski, M. Specific coupling of NMDA receptor activation to nitric oxide neurotoxicity by PSD95 protein. Science, 1999, 284(5421), 1845-1848.

[34] Dawson, V.L.; Dawson, T.M.; London, E.D.; Bredt, D.S.; Snyder, S.H. Nitric oxide mediates glutamate neurotoxicity in primary cortical cultures. Proc. Natl. Acad. Sci. U $S$ A, 1991, 88(14), 6368-6371. 
[35] Dawson, V.L.; Kizushi, V.M.; Huang, P.L.; Snyder, S.H.; Dawson, T.M. Resistance to neurotoxicity in cortical cultures from neuronal nitric oxide synthase-deficient mice. $J$. Neurosci., 1996, 16(8), 2479-2487.

[36] Liu, Y.; Wong, T.P.; Aarts, M.; Rooyakkers, A.; Liu, L.; Lai, T.W.; Wu, D.C.; Lu, J.; Tymianski, M.; Craig, A.M.; Wang, Y.T. NMDA receptor subunits have differential roles in mediating excitotoxic neuronal death both in vitro and in vivo. J. Neurosci., 2007, 27(11), 2846-2857.

[37] Tovar, K.R.; Westbrook, G.L. The incorporation of NMDA receptors with a distinct subunit composition at nascent hippocampal synapses in vitro. J. Neurosci., 1999, 19(10), 4180-4188.

[38] Hardingham, G.E.; Fukunaga, Y.; Bading, H. Extrasynaptic NMDARs oppose synaptic NMDARs by triggering CREB shut-off and cell death pathways. Nat. Neurosci., 2002, 5(5), 405-414.

[39] Leveille, F.; El Gaamouch, F.; Gouix, E.; Lecocq, M.; Lobner, D.; Nicole, O.; Buisson, A. Neuronal viability is controlled by a functional relation between synaptic and extrasynaptic NMDA receptors. FASEB J., 2008, 22(12), 4258-4271.

[40] Beadle, G.W.; Mitchell, H.K.; Nyc, J.F. Kynurenine as an Intermediate in the Formation of Nicotinic Acid from Tryptophane by Neurospora. Pro.c Natl. Acad. Sci. U S A, 1947, 33(6), 155-158.

[41] Ikeda, M.; Tsuji, H.; Nakamura, S.; Ichiyama, A.; Nishizuka, Y.; Hayaishi, O. Studies on the Biosynthesis of Nicotinamide Adenine Dinucleotide. Ii. a Role of Picolinic Carboxylase in the Biosynthesis of Nicotinamide Adenine Dinucleotide from Tryptophan in Mammals. J. Biol. Chem., 1965, 240, 1395-1401.

[42] Joseph, M.H. The determination of kynurenine by gas-liquid chromatography; evidence for its presence in rat brain [proceedings]. Br. J. Pharmacol., 1977, 59(3), $525 \mathrm{P}$.

[43] Joseph, M.H.; Kadam, B.V. Kynurenine: penetration to the brain, effect on brain tryptophan and 5-hydroxytryptamine metabolism and binding to plasma albumin [proceedings]. Br. J. Pharmacol., 1979, 66(3), 483P-484P.

[44] Gal, E.M.; Sherman, A.D. Synthesis and metabolism of L-kynurenine in rat brain. J. Neurochem., 1978, 30(3), 607-613.

[45] Fukui, S.; Schwarcz, R.; Rapoport, S.I.; Takada, Y.; Smith, Q.R. Blood-brain barrier transport of kynurenines: implications for brain synthesis and metabolism. $J$. Neurochem., 1991, 56(6), 2007-2017.

[46] Vecsei, L. Kynurenines in the brain. From experiments to clinics. Nova Science Publishers: New York, 2005.

[47] Henderson, L.M.; Hirsch, H.M. Quinolinic acid metabolism; urinary excretion by the rat following tryptophan and 3-hydroxyanthranilic acid administration. J. Biol. Chem., 1949, 181(2), 667-675.

[48] Han, Q.; Cai, T.; Tagle, D.A.; Li, J. Structure, expression, and function of kynurenine aminotransferases in human and rodent brains. Cell. Mol. Life Sci., 2010, 67(3), 353368.

[49] Okuno, E.; Nakamura, M.; Schwarcz, R. Two kynurenine aminotransferases in human brain. Brain Res., 1991, 542(2), 307-312.

[50] Csillik, A.E.; Okuno, E.; Csillik, B.; Knyihar, E.; Vecsei, L. Expression of kynurenine aminotransferase in the subplate of the rat and its possible role in the regulation of programmed cell death. Cereb. Cortex, 2002, 12(11), 1193-1201.

[51] Guidetti, P.; Amori, L.; Sapko, M.T.; Okuno, E.; Schwarcz, R. Mitochondrial aspartate aminotransferase: a third kynurenate-producing enzyme in the mammalian brain. J. Neurochem., 2007, 102(1), 103-111. 
[52] Yu, P.; Li, Z.; Zhang, L.; Tagle, D.A.; Cai, T. Characterization of kynurenine aminotransferase III, a novel member of a phylogenetically conserved KAT family. Gene, 2006, 365, 111-118.

[53] Kessler, M.; Terramani, T.; Lynch, G.; Baudry, M. A glycine site associated with Nmethyl-D-aspartic acid receptors: characterization and identification of a new class of antagonists. J. Neurochem., 1989, 52(4), 1319-1328.

[54] Perkins, M.N.; Stone, T.W. Actions of kynurenic acid and quinolinic acid in the rat hippocampus in vivo. Exp. Neurol., 1985, 88(3), 570-579.

[55] Prescott, C.; Weeks, A.M.; Staley, K.J.; Partin, K.M. Kynurenic acid has a dual action on AMPA receptor responses. Neurosci. Lett., 2006, 402(1-2), 108-112.

[56] Rozsa, E.; Robotka, H.; Vecsei, L.; Toldi, J. The Janus-face kynurenic acid. J. Neural. Transm., 2008, 115(8), 1087-1091.

[57] Hilmas, C.; Pereira, E.F.; Alkondon, M.; Rassoulpour, A.; Schwarcz, R.; Albuquerque, E.X. The brain metabolite kynurenic acid inhibits alpha7 nicotinic receptor activity and increases non-alpha7 nicotinic receptor expression: physiopathological implications. J. Neurosci., 2001, 21(19), 7463-7473.

[58] Carpenedo, R.; Pittaluga, A.; Cozzi, A.; Attucci, S.; Galli, A.; Raiteri, M.; Moroni, F. Presynaptic kynurenate-sensitive receptors inhibit glutamate release. Eur. J. Neurosci., 2001, 13(11), 2141-2147.

[59] Zadori, D.; Klivenyi, P.; Plangar, I.; Toldi, J.; Vecsei, L. Endogenous neuroprotection in chronic neurodegenerative disorders: with particular regard to the kynurenines. $J$ Cell. Mol. Med., 2011, 15(4), 701-717.

[60] Stone, T.W. Sensitivity of hippocampal neurones to kainic acid, and antagonism by kynurenate. Br. J. Pharmacol., 1990, 101(4), 847-852.

[61] Winn, P.; Stone, T.W.; Latimer, M.; Hastings, M.H.; Clark, A.J. A comparison of excitotoxic lesions of the basal forebrain by kainate, quinolinate, ibotenate, N-methylD-aspartate or quisqualate, and the effects on toxicity of 2-amino-5-phosphonovaleric acid and kynurenic acid in the rat. Br. J. Pharmacol., 1991, 102(4), 904-908.

[62] Foster, A.C.; Vezzani, A.; French, E.D.; Schwarcz, R. Kynurenic acid blocks neurotoxicity and seizures induced in rats by the related brain metabolite quinolinic acid. Neurosci. Lett., 1984, 48(3), 273-278.

[63] Uckele, J.E.; McDonald, J.W.; Johnston, M.V.; Silverstein, F.S. Effect of glycine and glycine receptor antagonists on NMDA-induced brain injury. Neurosci. Lett., 1989, 107(1-3), 279-283.

[64] Poeggeler, B.; Rassoulpour, A.; Guidetti, P.; Wu, H.Q.; Schwarcz, R. Dopaminergic control of kynurenate levels and N-methyl-D-aspartate toxicity in the developing rat striatum. Dev. Neurosci., 1998, 20(2-3), 146-153.

[65] Scharfman, H.E.; Goodman, J.H.; Schwarcz, R. Electrophysiological effects of exogenous and endogenous kynurenic acid in the rat brain: studies in vivo and in vitro. Amino Acids, 2000, 19(1), 283-297.

[66] Vecsei, L.; Beal, M.F. Intracerebroventricular injection of kynurenic acid, but not kynurenine, induces ataxia and stereotyped behavior in rats. Brain Res. Bull., 1990, 25(4), 623-627.

[67] Vecsei, L.; Beal, M.F. Comparative behavioral and pharmacological studies with centrally administered kynurenine and kynurenic acid in rats. Eur. J. Pharmacol., 1991, 196(3), 239-246.

[68] Lugo-Huitron, R.; Blanco-Ayala, T.; Ugalde-Muniz, P.; Carrillo-Mora, P.; PedrazaChaverri, J.; Silva-Adaya, D.; Maldonado, P.D.; Torres, I.; Pinzon, E.; Ortiz-Islas, E.; Lopez, T.; Garcia, E.; Pineda, B.; Torres-Ramos, M.; Santamaria, A.; La Cruz, V.P. 
On the antioxidant properties of kynurenic acid: Free radical scavenging activity and inhibition of oxidative stress. Neurotoxicol. Teratol., 2011, 33(5), 538-547.

[69] de Carvalho, L.P.; Bochet, P.; Rossier, J. The endogenous agonist quinolinic acid and the non endogenous homoquinolinic acid discriminate between NMDAR2 receptor subunits. Neurochem. Int., 1996, 28(4), 445-452.

[70] Stone, T.W.; Perkins, M.N. Quinolinic acid: a potent endogenous excitant at amino acid receptors in CNS. Eur. J. Pharmacol., 1981, 72(4), 411-412.

[71] Connick, J.H.; Stone, T.W. Quinolinic acid effects on amino acid release from the rat cerebral cortex in vitro and in vivo. Br. J. Pharmacol., 1988, 93(4), 868-876.

[72] Tavares, R.G.; Tasca, C.I.; Santos, C.E.; Alves, L.B.; Porciuncula, L.O.; Emanuelli, T.; Souza, D.O. Quinolinic acid stimulates synaptosomal glutamate release and inhibits glutamate uptake into astrocytes. Neurochem. Int., 2002, 40(7), 621-627.

[73] Rodriguez-Martinez, E.; Camacho, A.; Maldonado, P.D.; Pedraza-Chaverri, J.; Santamaria, D.; Galvan-Arzate, S.; Santamaria, A. Effect of quinolinic acid on endogenous antioxidants in rat corpus striatum. Brain Res., 2000, 858(2), 436-439.

[74] Behan, W.M.; McDonald, M.; Darlington, L.G.; Stone, T.W. Oxidative stress as a mechanism for quinolinic acid-induced hippocampal damage: protection by melatonin and deprenyl. Br. J. Pharmacol., 1999, 128(8), 1754-1760.

[75] Rios, C.; Santamaria, A. Quinolinic acid is a potent lipid peroxidant in rat brain homogenates. Neurochem. Res., 1991, 16(10), 1139-1143.

[76] Santamaria, D.; Espinoza-Gonzalez, V.; Rios, C.; Santamaria, A. Nomega-nitro-Larginine, a nitric oxide synthase inhibitor, antagonizes quinolinic acid-induced neurotoxicity and oxidative stress in rat striatal slices. Neurochem. Res., 1999, 24(7), 843-848.

[77] Santamaria, A.; Rios, C. MK-801, an N-methyl-D-aspartate receptor antagonist, blocks quinolinic acid-induced lipid peroxidation in rat corpus striatum. Neurosci. Lett., 1993, 159(1-2), 51-54.

[78] Okuda, S.; Nishiyama, N.; Saito, H.; Katsuki, H. 3-Hydroxykynurenine, an endogenous oxidative stress generator, causes neuronal cell death with apoptotic features and region selectivity. J. Neurochem., 1998, 70(1), 299-307.

[79] Dykens, J.A.; Sullivan, S.G.; Stern, A. Oxidative reactivity of the tryptophan metabolites 3-hydroxyanthranilate, cinnabarinate, quinolinate and picolinate. Biochem. Pharmacol., 1987, 36(2), 211-217.

[80] Guidetti, P.; Schwarcz, R. 3-Hydroxykynurenine potentiates quinolinate but not NMDA toxicity in the rat striatum. Eur. J. Neurosci., 1999, 11(11), 3857-3863.

[81] Guillemin, G.J.; Kerr, S.J.; Smythe, G.A.; Smith, D.G.; Kapoor, V.; Armati, P.J.; Croitoru, J.; Brew, B.J. Kynurenine pathway metabolism in human astrocytes: a paradox for neuronal protection. J. Neurochem., 2001, 78(4), 842-853.

[82] Mellor, A.L.; Munn, D.H. IDO expression by dendritic cells: tolerance and tryptophan catabolism. Nat. Rev. Immunol., 2004, 4(10), 762-774.

[83] Foster, A.C.; Kemp, J.A.; Leeson, P.D.; Grimwood, S.; Donald, A.E.; Marshall, G.R.; Priestley, T.; Smith, J.D.; Carling, R.W. Kynurenic acid analogues with improved affinity and selectivity for the glycine site on the N-methyl-D-aspartate receptor from rat brain. Mol. Pharmacol., 1992, 41(5), 914-922.

[84] Fulop, F.; Szatmari, I.; Vamos, E.; Zadori, D.; Toldi, J.; Vecsei, L. Syntheses, transformations and pharmaceutical applications of kynurenic acid derivatives. Curr. Med. Chem., 2009, 16(36), 4828-4842.

[85] Kemp, J.A.; Foster, A.C.; Leeson, P.D.; Priestley, T.; Tridgett, R.; Iversen, L.L.; Woodruff, G.N. 7-Chlorokynurenic acid is a selective antagonist at the glycine 
modulatory site of the N-methyl-D-aspartate receptor complex. Proc. Natl. Acad. Sci. $U S A, 1988,85(17), 6547-6550$.

[86] Guidetti, P.; Wu, H.Q.; Schwarcz, R. In situ produced 7-chlorokynurenate provides protection against quinolinate- and malonate-induced neurotoxicity in the rat striatum. Exp. Neurol., 2000, 163(1), 123-130.

[87] Wu, H.Q.; Lee, S.C.; Schwarcz, R. Systemic administration of 4-chlorokynurenine prevents quinolinate neurotoxicity in the rat hippocampus. Eur. J. Pharmacol., 2000, 390(3), 267-274.

[88] Moroni, F.; Alesiani, M.; Galli, A.; Mori, F.; Pecorari, R.; Carla, V.; Cherici, G.; Pellicciari, R. Thiokynurenates: a new group of antagonists of the glycine modulatory site of the NMDA receptor. Eur. J. Pharmacol., 1991, 199(2), 227-232.

[89] Bonina, F.P.; Arenare, L.; Ippolito, R.; Boatto, G.; Battaglia, G.; Bruno, V.; de Caprariis, P. Synthesis, pharmacokinetics and anticonvulsant activity of 7chlorokynurenic acid prodrugs. Int. J. Pharm., 2000, 202(1-2), 79-88.

[90] Fuvesi, J.; Somlai, C.; Nemeth, H.; Varga, H.; Kis, Z.; Farkas, T.; Karoly, N.; Dobszay, M.; Penke, Z.; Penke, B.; Vecsei, L.; Toldi, J. Comparative study on the effects of kynurenic acid and glucosamine-kynurenic acid. Pharmacol. Biochem. Behav., 2004, 77(1), 95-102.

[91] Robotka, H.; Nemeth, H.; Somlai, C.; Vecsei, L.; Toldi, J. Systemically administered glucosamine-kynurenic acid, but not pure kynurenic acid, is effective in decreasing the evoked activity in area CA1 of the rat hippocampus. Eur. J. Pharmacol., 2005, 513(12), 75-80.

[92] Knyihar-Csillik, E.; Mihaly, A.; Krisztin-Peva, B.; Robotka, H.; Szatmari, I.; Fulop, F.; Toldi, J.; Csillik, B.; Vecsei, L. The kynurenate analog SZR-72 prevents the nitroglycerol-induced increase of c-fos immunoreactivity in the rat caudal trigeminal nucleus: comparative studies of the effects of SZR-72 and kynurenic acid. Neurosci. Res., 2008, 61(4), 429-432.

[93] Marosi, M.; Nagy, D.; Farkas, T.; Kis, Z.; Rozsa, E.; Robotka, H.; Fulop, F.; Vecsei, L.; Toldi, J. A novel kynurenic acid analogue: a comparison with kynurenic acid. An in vitro electrophysiological study. J. Neural. Transm., 2010, 117(2), 183-188.

[94] Vamos, E.; Fejes, A.; Koch, J.; Tajti, J.; Fulop, F.; Toldi, J.; Pardutz, A.; Vecsei, L. Kynurenate derivative attenuates the nitroglycerin-induced CamKIIalpha and CGRP expression changes. Headache, 2010, 50(5), 834-843.

[95] Zadori, D.; Ilisz, I.; Klivenyi, P.; Szatmari, I.; Fulop, F.; Toldi, J.; Vecsei, L.; Peter, A. Time-course of kynurenic acid concentration in mouse serum following the administration of a novel kynurenic acid analog. J. Pharm. Biomed. Anal., 2011, 55(3), 540-543.

[96] Zadori, D.; Nyiri, G.; Szonyi, A.; Szatmari, I.; Fulop, F.; Toldi, J.; Freund, T.F.; Vecsei, L.; Klivenyi, P. Neuroprotective effects of a novel kynurenic acid analogue in a transgenic mouse model of Huntington's disease. J. Neural. Transm., 2011, 118(6), 865-875.

[97] Borza, I.; Kolok, S.; Galgoczy, K.; Gere, A.; Horvath, C.; Farkas, S.; Greiner, I.; Domany, G. Kynurenic acid amides as novel NR2B selective NMDA receptor antagonists. Bioorg. Med. Chem. Lett., 2007, 17(2), 406-409.

[98] Leeson, P.D.; Baker, R.; Carling, R.W.; Curtis, N.R.; Moore, K.W.; Williams, B.J.; Foster, A.C.; Donald, A.E.; Kemp, J.A.; Marshall, G.R. Kynurenic acid derivatives. Structure-activity relationships for excitatory amino acid antagonism and identification of potent and selective antagonists at the glycine site on the N-methylD-aspartate receptor. J. Med. Chem., 1991, 34(4), 1243-1252. 
[99] Nozaki, K.; Beal, M.F. Neuroprotective effects of L-kynurenine on hypoxia-ischemia and NMDA lesions in neonatal rats. J. Cereb. Blood Flow Metab., 1992, 12(3), 400407.

[100] Miranda, A.F.; Boegman, R.J.; Beninger, R.J.; Jhamandas, K. Protection against quinolinic acid-mediated excitotoxicity in nigrostriatal dopaminergic neurons by endogenous kynurenic acid. Neuroscience, 1997, 78(4), 967-975.

[101] Gigler, G.; Szenasi, G.; Simo, A.; Levay, G.; Harsing, L.G., Jr.; Sas, K.; Vecsei, L.; Toldi, J. Neuroprotective effect of L-kynurenine sulfate administered before focal cerebral ischemia in mice and global cerebral ischemia in gerbils. Eur. J. Pharmacol., 2007, 564(1-3), 116-122.

[102] Carrillo-Mora, P.; Mendez-Cuesta, L.A.; Perez-De La Cruz, V.; Fortoul-van Der Goes, T.I.; Santamaria, A. Protective effect of systemic L-kynurenine and probenecid administration on behavioural and morphological alterations induced by toxic soluble amyloid beta (25-35) in rat hippocampus. Behav. Brain Res., 2010, 210(2), 240-250.

[103] Vecsei, L.; Miller, J.; MacGarvey, U.; Beal, M.F. Kynurenine and probenecid inhibit pentylenetetrazol- and NMDLA-induced seizures and increase kynurenic acid concentrations in the brain. Brain Res. Bull., 1992, 28(2), 233-238.

[104] Nemeth, H.; Robotka, H.; Kis, Z.; Rozsa, E.; Janaky, T.; Somlai, C.; Marosi, M.; Farkas, T.; Toldi, J.; Vecsei, L. Kynurenine administered together with probenecid markedly inhibits pentylenetetrazol-induced seizures. An electrophysiological and behavioural study. Neuropharmacology, 2004, 47(6), 916-925.

[105] Bahn, A.; Ljubojevic, M.; Lorenz, H.; Schultz, C.; Ghebremedhin, E.; Ugele, B.; Sabolic, I.; Burckhardt, G.; Hagos, Y. Murine renal organic anion transporters mOAT1 and mOAT3 facilitate the transport of neuroactive tryptophan metabolites. Am. J. Physiol. Cell Physiol., 2005, 289(5), C1075-1084.

[106] Russi, P.; Alesiani, M.; Lombardi, G.; Davolio, P.; Pellicciari, R.; Moroni, F. Nicotinylalanine increases the formation of kynurenic acid in the brain and antagonizes convulsions. J. Neurochem., 1992, 59(6), 2076-2080.

[107] Harris, C.A.; Miranda, A.F.; Tanguay, J.J.; Boegman, R.J.; Beninger, R.J.; Jhamandas, $\mathrm{K}$. Modulation of striatal quinolinate neurotoxicity by elevation of endogenous brain kynurenic acid. Br. J. Pharmacol., 1998, 124(2), 391-399.

[108] Pellicciari, R.; Natalini, B.; Costantino, G.; Mahmoud, M.R.; Mattoli, L.; Sadeghpour, B.M.; Moroni, F.; Chiarugi, A.; Carpenedo, R. Modulation of the kynurenine pathway in search for new neuroprotective agents. Synthesis and preliminary evaluation of (mnitrobenzoyl)alanine, a potent inhibitor of kynurenine-3-hydroxylase. J. Med. Chem., 1994, 37(5), 647-655.

[109] Speciale, C.; Wu, H.Q.; Cini, M.; Marconi, M.; Varasi, M.; Schwarcz, R. (R,S)-3,4dichlorobenzoylalanine (FCE 28833A) causes a large and persistent increase in brain kynurenic acid levels in rats. Eur. J. Pharmacol., 1996, 315(3), 263-267.

[110] Sapko, M.T.; Guidetti, P.; Yu, P.; Tagle, D.A.; Pellicciari, R.; Schwarcz, R. Endogenous kynurenate controls the vulnerability of striatal neurons to quinolinate: Implications for Huntington's disease. Exp. Neurol., 2006, 197(1), 31-40.

[111] Rover, S.; Cesura, A.M.; Huguenin, P.; Kettler, R.; Szente, A. Synthesis and biochemical evaluation of N-(4-phenylthiazol-2-yl)benzenesulfonamides as highaffinity inhibitors of kynurenine 3-hydroxylase. J. Med. Chem., 1997, 40(26), 43784385 .

[112] Zwilling, D.; Huang, S.Y.; Sathyasaikumar, K.V.; Notarangelo, F.M.; Guidetti, P.; Wu, H.Q.; Lee, J.; Truong, J.; Andrews-Zwilling, Y.; Hsieh, E.W.; Louie, J.Y.; Wu, T.; Scearce-Levie, K.; Patrick, C.; Adame, A.; Giorgini, F.; Moussaoui, S.; Laue, G.; Rassoulpour, A.; Flik, G.; Huang, Y.; Muchowski, J.M.; Masliah, E.; Schwarcz, R.; 
Muchowski, P.J. Kynurenine 3-monooxygenase inhibition in blood ameliorates neurodegeneration. Cell, 2011, 145(6), 863-874.

[113] Heiss, C.; Anderson, J.; Phillips, R.S. Differential effects of bromination on substrates and inhibitors of kynureninase from Pseudomonas fluorescens. Org. Biomol. Chem., 2003, 1(2), 288-295.

[114] Drysdale, M.J.; Reinhard, J.F. S-aryl cysteine S,S-dioxides as inhibitors of mammalian kynureninase. Bioorg. Med. Chem. Lett., 1998, 8(2), 133-138.

[115] Fitzgerald, D.H.; Muirhead, K.M.; Botting, N.P. A comparative study on the inhibition of human and bacterial kynureninase by novel bicyclic kynurenine analogues. Bioorg. Med. Chem., 2001, 9(4), 983-989.

[116] Ross, F.C.; Botting, N.P.; Leeson, P.D. Synthesis of phosphinic acid transition state analogues for the reaction catalysed by kynureninase. Bioorg. Med. Chem. Lett. , 1996, 6(22), 2643-2646.

[117] Chiarugi, A.; Carpenedo, R.; Moroni, F. Kynurenine disposition in blood and brain of mice: effects of selective inhibitors of kynurenine hydroxylase and of kynureninase. $J$. Neurochem., 1996, 67(2), 692-698.

[118] Walsh, H.A.; Leslie, P.L.; O'Shea, K.C.; Botting, N.P. 2-Amino-4-[3'hydroxyphenyl]-4-hydroxybutanoic acid; a potent inhibitor of rat and recombinant human kynureninase. Bioorg. Med. Chem. Lett., 2002, 12(3), 361-363.

[119] Carpenedo, R.; Chiarugi, A.; Russi, P.; Lombardi, G.; Carla, V.; Pellicciari, R.; Mattoli, L.; Moroni, F. Inhibitors of kynurenine hydroxylase and kynureninase increase cerebral formation of kynurenate and have sedative and anticonvulsant activities. Neuroscience, 1994, 61(2), 237-243.

[120] Heyes, M.P.; Hutto, B.; Markey, S.P. 4-chloro-3-hydroxyanthranilate inhibits brain 3hydroxyanthranate oxidase. Neurochem. Int., 1988, 13(3), 405-408.

[121] Luthman, J.; Radesater, A.C.; Oberg, C. Effects of the 3-hydroxyanthranilic acid analogue NCR-631 on anoxia-, IL-1 beta- and LPS-induced hippocampal pyramidal cell loss in vitro. Amino Acids, 1998, 14(1-3), 263-269.

[122] Luthman, J. Anticonvulsant effects of the 3-hydroxyanthranilic acid dioxygenase inhibitor NCR-631. Amino Acids, 2000, 19(1), 325-334.

[123] Fornstedt-Wallin, B.; Lundstrom, J.; Fredriksson, G.; Schwarcz, R.; Luthman, J. 3Hydroxyanthranilic acid accumulation following administration of the 3hydroxyanthranilic acid 3,4-dioxygenase inhibitor NCR-631. Eur. J. Pharmacol., 1999, 386(1), 15-24.

[124] Chiarugi, A.; Moroni, F. Regulation of quinolinic acid synthesis by mitochondria and o-methoxybenzoylalanine. Adv. Exp. Med. Biol., 1999, 467, 233-239.

[125] Parli, C.J.; Krieter, P.; Schmidt, B. Metabolism of 6-chlorotryptophan to 4-chloro-3hydroxyanthranilic acid: a potent inhibitor of 3-hydroxyanthranilic acid oxidase. Arch Biochem. Biophys., 1980, 203(1), 161-166.

[126] Behan, W.M.; Stone, T.W. Role of kynurenines in the neurotoxic actions of kainic acid. Br. J. Pharmacol., 2000, 129(8), 1764-1770.

[127] Forno, L.S. Neuropathology of Parkinson's disease. J. Neuropathol. Exp. Neurol., 1996, 55(3), 259-272.

[128] Lang, A.E.; Lozano, A.M. Parkinson's disease. First of two parts. N. Engl. J. Med., 1998, 339(15), 1044-1053.

[129] Lang, A.E.; Lozano, A.M. Parkinson's disease. Second of two parts. N. Engl. J. Med., 1998, 339(16), 1130-1143.

[130] Shulman, J.M.; De Jager, P.L.; Feany, M.B. Parkinson's disease: genetics and pathogenesis. Annu. Rev. Pathol., 2011, 6, 193-222. 
[131] Forno, L.S.; DeLanney, L.E.; Irwin, I.; Langston, J.W. Similarities and differences between MPTP-induced parkinsonsim and Parkinson's disease. Neuropathologic considerations. Adv. Neurol., 1993, 60, 600-608.

[132] Ramsay, R.R.; Salach, J.I.; Dadgar, J.; Singer, T.P. Inhibition of mitochondrial NADH dehydrogenase by pyridine derivatives and its possible relation to experimental and idiopathic parkinsonism. Biochem. Biophys. Res. Commun., 1986, 135(1), 269-275.

[133] Javitch, J.A.; D'Amato, R.J.; Strittmatter, S.M.; Snyder, S.H. Parkinsonism-inducing neurotoxin, N-methyl-4-phenyl-1,2,3,6 -tetrahydropyridine: uptake of the metabolite $\mathrm{N}$-methyl-4-phenylpyridine by dopamine neurons explains selective toxicity. Proc. Natl. Acad. Sci. U S A, 1985, 82(7), 2173-2177.

[134] Banerjee, R.; Starkov, A.A.; Beal, M.F.; Thomas, B. Mitochondrial dysfunction in the limelight of Parkinson's disease pathogenesis. Biochim. Biophys. Acta, 2009, 1792(7), 651-663.

[135] Schapira, A.H.; Cooper, J.M.; Dexter, D.; Jenner, P.; Clark, J.B.; Marsden, C.D. Mitochondrial complex I deficiency in Parkinson's disease. Lancet, 1989, 1(8649), 1269.

[136] Choi, W.S.; Kruse, S.E.; Palmiter, R.D.; Xia, Z. Mitochondrial complex I inhibition is not required for dopaminergic neuron death induced by rotenone, MPP+, or paraquat. Proc. Natl. Acad. Sci. U S A, 2008, 105(39), 15136-15141.

[137] Elbaz, A.; Tranchant, C. Epidemiologic studies of environmental exposures in Parkinson's disease. J. Neurol. Sci., 2007, 262(1-2), 37-44.

[138] Fung, H.C.; Scholz, S.; Matarin, M.; Simon-Sanchez, J.; Hernandez, D.; Britton, A.; Gibbs, J.R.; Langefeld, C.; Stiegert, M.L.; Schymick, J.; Okun, M.S.; Mandel, R.J.; Fernandez, H.H.; Foote, K.D.; Rodriguez, R.L.; Peckham, E.; De Vrieze, F.W.; Gwinn-Hardy, K.; Hardy, J.A.; Singleton, A. Genome-wide genotyping in Parkinson's disease and neurologically normal controls: first stage analysis and public release of data. Lancet Neurol., 2006, 5(11), 911-916.

[139] Davidzon, G.; Greene, P.; Mancuso, M.; Klos, K.J.; Ahlskog, J.E.; Hirano, M.; DiMauro, S. Early-onset familial parkinsonism due to POLG mutations. Ann. Neurol., 2006, 59(5), 859-862.

[140] Luoma, P.T.; Eerola, J.; Ahola, S.; Hakonen, A.H.; Hellstrom, O.; Kivisto, K.T.; Tienari, P.J.; Suomalainen, A. Mitochondrial DNA polymerase gamma variants in idiopathic sporadic Parkinson disease. Neurology, 2007, 69(11), 1152-1159.

[141] Parker, W.D., Jr.; Parks, J.K. Mitochondrial ND5 mutations in idiopathic Parkinson's disease. Biochem. Biophys. Res. Commun., 2005, 326(3), 667-669.

[142] van der Walt, J.M.; Nicodemus, K.K.; Martin, E.R.; Scott, W.K.; Nance, M.A.; Watts, R.L.; Hubble, J.P.; Haines, J.L.; Koller, W.C.; Lyons, K.; Pahwa, R.; Stern, M.B.; Colcher, A.; Hiner, B.C.; Jankovic, J.; Ondo, W.G.; Allen, F.H., Jr.; Goetz, C.G.; Small, G.W.; Mastaglia, F.; Stajich, J.M.; McLaurin, A.C.; Middleton, L.T.; Scott, B.L.; Schmechel, D.E.; Pericak-Vance, M.A.; Vance, J.M. Mitochondrial polymorphisms significantly reduce the risk of Parkinson disease. Am. J. Hum. Genet., 2003, 72(4), 804-811.

[143] Pyle, A.; Foltynie, T.; Tiangyou, W.; Lambert, C.; Keers, S.M.; Allcock, L.M.; Davison, J.; Lewis, S.J.; Perry, R.H.; Barker, R.; Burn, D.J.; Chinnery, P.F. Mitochondrial DNA haplogroup cluster UKJT reduces the risk of PD. Ann. Neurol., 2005, 57(4), 564-567.

[144] Devi, L.; Raghavendran, V.; Prabhu, B.M.; Avadhani, N.G.; Anandatheerthavarada, H.K. Mitochondrial import and accumulation of alpha-synuclein impair complex I in human dopaminergic neuronal cultures and Parkinson disease brain. J. Biol. Chem., 2008, 283(4), 9089-9100. 
[145] Chinta, S.J.; Mallajosyula, J.K.; Rane, A.; Andersen, J.K. Mitochondrial alphasynuclein accumulation impairs complex I function in dopaminergic neurons and results in increased mitophagy in vivo. Neurosci. Lett., 2010, 486(3), 235-239.

[146] Elkon, H.; Don, J.; Melamed, E.; Ziv, I.; Shirvan, A.; Offen, D. Mutant and wild-type alpha-synuclein interact with mitochondrial cytochrome C oxidase. J. Mol. Neurosci., 2002, 18(3), 229-238.

[147] Norris, E.H.; Uryu, K.; Leight, S.; Giasson, B.I.; Trojanowski, J.Q.; Lee, V.M. Pesticide exposure exacerbates alpha-synucleinopathy in an A53T transgenic mouse model. Am. J. Pathol., 2007, 170(2), 658-666.

[148] Klivenyi, P.; Siwek, D.; Gardian, G.; Yang, L.; Starkov, A.; Cleren, C.; Ferrante, R.J.; Kowall, N.W.; Abeliovich, A.; Beal, M.F. Mice lacking alpha-synuclein are resistant to mitochondrial toxins. Neurobiol. Dis., 2006, 21(3), 541-548.

[149] Betarbet, R.; Sherer, T.B.; MacKenzie, G.; Garcia-Osuna, M.; Panov, A.V.; Greenamyre, J.T. Chronic systemic pesticide exposure reproduces features of Parkinson's disease. Nat. Neurosci., 2000, 3(12), 1301-1306.

[150] Shimura, H.; Hattori, N.; Kubo, S.; Mizuno, Y.; Asakawa, S.; Minoshima, S.; Shimizu, N.; Iwai, K.; Chiba, T.; Tanaka, K.; Suzuki, T. Familial Parkinson disease gene product, parkin, is a ubiquitin-protein ligase. Nat. Genet., 2000, 25(3), 302-305.

[151] Whitworth, A.J.; Theodore, D.A.; Greene, J.C.; Benes, H.; Wes, P.D.; Pallanck, L.J. Increased glutathione $\mathrm{S}$-transferase activity rescues dopaminergic neuron loss in a Drosophila model of Parkinson's disease. Proc. Natl. Acad. Sci. U S A, 2005, 102(22), 8024-8029.

[152] Yang, H.; Zhou, H.Y.; Li, B.; Niu, G.Z.; Chen, S.D. Downregulation of parkin damages antioxidant defenses and enhances proteasome inhibition-induced toxicity in PC12 cells. J. Neuroimmune. Pharmacol., 2007, 2(3), 276-283.

[153] Kuroda, Y.; Mitsui, T.; Kunishige, M.; Shono, M.; Akaike, M.; Azuma, H.; Matsumoto, T. Parkin enhances mitochondrial biogenesis in proliferating cells. Hum. Mol. Genet., 2006, 15(6), 883-895.

[154] Darios, F.; Corti, O.; Lucking, C.B.; Hampe, C.; Muriel, M.P.; Abbas, N.; Gu, W.J.; Hirsch, E.C.; Rooney, T.; Ruberg, M.; Brice, A. Parkin prevents mitochondrial swelling and cytochrome c release in mitochondria-dependent cell death. Hum. Mol. Genet., 2003, 12(5), 517-526.

[155] Exner, N.; Treske, B.; Paquet, D.; Holmstrom, K.; Schiesling, C.; Gispert, S.; Carballo-Carbajal, I.; Berg, D.; Hoepken, H.H.; Gasser, T.; Kruger, R.; Winklhofer, K.F.; Vogel, F.; Reichert, A.S.; Auburger, G.; Kahle, P.J.; Schmid, B.; Haass, C. Lossof-function of human PINK1 results in mitochondrial pathology and can be rescued by parkin. J. Neurosci., 2007, 27(45), 12413-12418.

[156] Palacino, J.J.; Sagi, D.; Goldberg, M.S.; Krauss, S.; Motz, C.; Wacker, M.; Klose, J.; Shen, J. Mitochondrial dysfunction and oxidative damage in parkin-deficient mice. $J$. Biol. Chem., 2004, 279(18), 18614-18622.

[157] Pesah, Y.; Pham, T.; Burgess, H.; Middlebrooks, B.; Verstreken, P.; Zhou, Y.; Harding, M.; Bellen, H.; Mardon, G. Drosophila parkin mutants have decreased mass and cell size and increased sensitivity to oxygen radical stress. Development, 2004, 131(9), 2183-2194.

[158] Thomas, B.; von Coelln, R.; Mandir, A.S.; Trinkaus, D.B.; Farah, M.H.; Leong Lim, K.; Calingasan, N.Y.; Flint Beal, M.; Dawson, V.L.; Dawson, T.M. MPTP and DSP-4 susceptibility of substantia nigra and locus coeruleus catecholaminergic neurons in mice is independent of parkin activity. Neurobiol. Dis., 2007, 26(2), 312-322.

[159] Yang, Y.; Gehrke, S.; Imai, Y.; Huang, Z.; Ouyang, Y.; Wang, J.W.; Yang, L.; Beal, M.F.; Vogel, H.; Lu, B. Mitochondrial pathology and muscle and dopaminergic 
neuron degeneration caused by inactivation of Drosophila Pink1 is rescued by Parkin. Proc. Natl. Acad. Sci. U S A, 2006, 103(28), 10793-10798.

[160] Gautier, C.A.; Kitada, T.; Shen, J. Loss of PINK1 causes mitochondrial functional defects and increased sensitivity to oxidative stress. Proc. Natl. Acad. Sci. U S A, 2008, 105(32), 11364-11369.

[161] Clark, I.E.; Dodson, M.W.; Jiang, C.; Cao, J.H.; Huh, J.R.; Seol, J.H.; Yoo, S.J.; Hay, B.A.; Guo, M. Drosophila pink1 is required for mitochondrial function and interacts genetically with parkin. Nature, 2006, 441(7097), 1162-1166.

[162] Haque, M.E.; Thomas, K.J.; D'Souza, C.; Callaghan, S.; Kitada, T.; Slack, R.S.; Fraser, P.; Cookson, M.R.; Tandon, A.; Park, D.S. Cytoplasmic Pink1 activity protects neurons from dopaminergic neurotoxin MPTP. Proc. Natl. Acad. Sci. U S A, 2008, 105(5), 1716-1721.

[163] Pridgeon, J.W.; Olzmann, J.A.; Chin, L.S.; Li, L. PINK1 protects against oxidative stress by phosphorylating mitochondrial chaperone TRAP1. PLoS Biol., 2007, 5(7), e172.

[164] Gandhi, S.; Wood-Kaczmar, A.; Yao, Z.; Plun-Favreau, H.; Deas, E.; Klupsch, K.; Downward, J.; Latchman, D.S.; Tabrizi, S.J.; Wood, N.W.; Duchen, M.R.; Abramov, A.Y. PINK1-associated Parkinson's disease is caused by neuronal vulnerability to calcium-induced cell death. Mol. Cell, 2009, 33(5), 627-638.

[165] Martins, L.M.; Morrison, A.; Klupsch, K.; Fedele, V.; Moisoi, N.; Teismann, P.; Abuin, A.; Grau, E.; Geppert, M.; Livi, G.P.; Creasy, C.L.; Martin, A.; Hargreaves, I.; Heales, S.J.; Okada, H.; Brandner, S.; Schulz, J.B.; Mak, T.; Downward, J. Neuroprotective role of the Reaper-related serine protease HtrA2/Omi revealed by targeted deletion in mice. Mol. Cell Biol., 2004, 24(22), 9848-9862.

[166] Li, B.; Hu, Q.; Wang, H.; Man, N.; Ren, H.; Wen, L.; Nukina, N.; Fei, E.; Wang, G. $\mathrm{Omi} / \mathrm{HtrA} 2$ is a positive regulator of autophagy that facilitates the degradation of mutant proteins involved in neurodegenerative diseases. Cell Death Differ., 2010, 17(11), 1773-1784.

[167] McCoy, M.K.; Cookson, M.R. DJ-1 regulation of mitochondrial function and autophagy through oxidative stress. Autophagy, 2011, 7(5), 531-532.

[168] Andres-Mateos, E.; Perier, C.; Zhang, L.; Blanchard-Fillion, B.; Greco, T.M.; Thomas, B.; Ko, H.S.; Sasaki, M.; Ischiropoulos, H.; Przedborski, S.; Dawson, T.M.; Dawson, V.L. DJ-1 gene deletion reveals that DJ-1 is an atypical peroxiredoxin-like peroxidase. Proc. Natl. Acad. Sci. U S A, 2007, 104(37), 14807-14812.

[169] Kim, R.H.; Smith, P.D.; Aleyasin, H.; Hayley, S.; Mount, M.P.; Pownall, S.; Wakeham, A.; You-Ten, A.J.; Kalia, S.K.; Horne, P.; Westaway, D.; Lozano, A.M.; Anisman, H.; Park, D.S.; Mak, T.W. Hypersensitivity of DJ-1-deficient mice to 1methyl-4-phenyl-1,2,3,6-tetrahydropyrindine (MPTP) and oxidative stress. Proc. Natl. Acad. Sci. U S A, 2005, 102(14), 5215-5220.

[170] Meulener, M.; Whitworth, A.J.; Armstrong-Gold, C.E.; Rizzu, P.; Heutink, P.; Wes, P.D.; Pallanck, L.J.; Bonini, N.M. Drosophila DJ-1 mutants are selectively sensitive to environmental toxins associated with Parkinson's disease. Curr. Biol., 2005, 15(17), 1572-1577.

[171] Waak, J.; Weber, S.S.; Waldenmaier, A.; Gorner, K.; Alunni-Fabbroni, M.; Schell, H.; Vogt-Weisenhorn, D.; Pham, T.T.; Reumers, V.; Baekelandt, V.; Wurst, W.; Kahle, P.J. Regulation of astrocyte inflammatory responses by the Parkinson's diseaseassociated gene DJ-1. FASEB J, 2009, 23(8), 2478-2489.

[172] Thomas, K.J.; McCoy, M.K.; Blackinton, J.; Beilina, A.; van der Brug, M.; Sandebring, A.; Miller, D.; Maric, D.; Cedazo-Minguez, A.; Cookson, M.R. DJ-1 acts 
in parallel to the PINK1/parkin pathway to control mitochondrial function and autophagy. Hum. Mol. Genet., 2011, 20(1), 40-50.

[173] Xiong, H.; Wang, D.; Chen, L.; Choo, Y.S.; Ma, H.; Tang, C.; Xia, K.; Jiang, W.; Ronai, Z.; Zhuang, X.; Zhang, Z. Parkin, PINK1, and DJ-1 form a ubiquitin E3 ligase complex promoting unfolded protein degradation. J. Clin. Invest., 2009, 119(3), 650660.

[174] Biskup, S.; Moore, D.J.; Celsi, F.; Higashi, S.; West, A.B.; Andrabi, S.A.; Kurkinen, K.; Yu, S.W.; Savitt, J.M.; Waldvogel, H.J.; Faull, R.L.; Emson, P.C.; Torp, R.; Ottersen, O.P.; Dawson, T.M.; Dawson, V.L. Localization of LRRK2 to membranous and vesicular structures in mammalian brain. Ann. Neurol., 2006, 60(5), 557-569.

[175] Mortiboys, H.; Johansen, K.K.; Aasly, J.O.; Bandmann, O. Mitochondrial impairment in patients with Parkinson disease with the G2019S mutation in LRRK2. Neurology, 2010, 75(22), 2017-2020.

[176] Saha, S.; Guillily, M.D.; Ferree, A.; Lanceta, J.; Chan, D.; Ghosh, J.; Hsu, C.H.; Segal, L.; Raghavan, K.; Matsumoto, K.; Hisamoto, N.; Kuwahara, T.; Iwatsubo, T.; Moore, L.; Goldstein, L.; Cookson, M.; Wolozin, B. LRRK2 modulates vulnerability to mitochondrial dysfunction in Caenorhabditis elegans. J. Neurosci., 2009, 29(29), 9210-9218.

[177] Klivenyi, P.; Vecsei, L. Novel therapeutic strategies in Parkinson's disease. Eur. J. Clin. Pharmacol., 2010, 66(2), 119-125.

[178] Ascherio, A.; LeWitt, P.A.; Watts, A.; Kieburtz, K.; Rudolph, A.; Schwid, S.R.; Matson, W.R.; Beal, M.F.; Lang, A.E.; Oakes, D.; Fahn, S.; I., S.; Schwarzschild, M.A. In Movement Disorders Society International Congress on Parkinson's Disease and Movement Disorders: Kyoto, Japan, October 29-November 2, 2006.

[179] Schwarzschild, M.A.; Schwid, S.R.; Marek, K.; Watts, A.; Lang, A.E.; Oakes, D.; Shoulson, I.; Ascherio, A.; Hyson, C.; Gorbold, E.; Rudolph, A.; Kieburtz, K.; Fahn, S.; Gauger, L.; Goetz, C.; Seibyl, J.; Forrest, M.; Ondrasik, J. Serum urate as a predictor of clinical and radiographic progression in Parkinson disease. Arch. Neurol., 2008, 65(6), 716-723.

[180] Menke, T.; Gille, G.; Reber, F.; Janetzky, B.; Andler, W.; Funk, R.H.; Reichmann, H. Coenzyme Q10 reduces the toxicity of rotenone in neuronal cultures by preserving the mitochondrial membrane potential. Biofactors, 2003, 18(1-4), 65-72.

[181] Cleren, C.; Yang, L.; Lorenzo, B.; Calingasan, N.Y.; Schomer, A.; Sireci, A.; Wille, E.J.; Beal, M.F. Therapeutic effects of coenzyme Q10 (CoQ10) and reduced CoQ10 in the MPTP model of Parkinsonism. J. Neurochem., 2008, 104(6), 1613-1621.

[182] Schulz, J.B.; Henshaw, D.R.; Matthews, R.T.; Beal, M.F. Coenzyme Q10 and nicotinamide and a free radical spin trap protect against MPTP neurotoxicity. Exp. Neurol., 1995, 132(2), 279-283.

[183] Shults, C.W.; Oakes, D.; Kieburtz, K.; Beal, M.F.; Haas, R.; Plumb, S.; Juncos, J.L.; Nutt, J.; Shoulson, I.; Carter, J.; Kompoliti, K.; Perlmutter, J.S.; Reich, S.; Stern, M.; Watts, R.L.; Kurlan, R.; Molho, E.; Harrison, M.; Lew, M. Effects of coenzyme Q10 in early Parkinson disease: evidence of slowing of the functional decline. Arch. Neurol., 2002, 59, 1541-1550.

[184] Storch, A.; Jost, W.H.; Vieregge, P.; Spiegel, J.; Greulich, W.; Durner, J.; Muller, T.; Kupsch, A.; Henningsen, H.; Oertel, W.H.; Fuchs, G.; Kuhn, W.; Niklowitz, P.; Koch, R.; Herting, B.; Reichmann, H. Randomized, double-blind, placebo-controlled trial on symptomatic effects of coenzyme Q(10) in Parkinson disease. Arch. Neurol., 2007, 64(7), 938-944.

[185] Snow, B.J.; Rolfe, F.L.; Lockhart, M.M.; Frampton, C.M.; O'Sullivan, J.D.; Fung, V.; Smith, R.A.; Murphy, M.P.; Taylor, K.M. A double-blind, placebo-controlled study to 
assess the mitochondria-targeted antioxidant MitoQ as a disease-modifying therapy in Parkinson's disease. Mov. Disord., 2010, 25(11), 1670-1674.

[186] Beal, M.F. Neuroprotective effects of creatine. Amino Acids, 2011, 40(5), 1305-1313.

[187] Matthews, R.T.; Ferrante, R.J.; Klivenyi, P.; Yang, L.; Klein, A.M.; Mueller, G.; Kaddurah-Daouk, R.; Beal, M.F. Creatine and cyclocreatine attenuate MPTP neurotoxicity. Exp. Neurol., 1999, 157(1), 142-149.

[188] Klivenyi, P.; Calingasan, N.Y.; Starkov, A.; Stavrovskaya, I.G.; Kristal, B.S.; Yang, L.; Wieringa, B.; Beal, M.F. Neuroprotective mechanisms of creatine occur in the absence of mitochondrial creatine kinase. Neurobiol. Dis., 2004, 15(3), 610-617.

[189] Hosamani, R.; Ramesh, S.R.; Muralidhara Attenuation of rotenone-induced mitochondrial oxidative damage and neurotoxicty in Drosophila melanogaster supplemented with creatine. Neurochem. Res., 2010, 35(9), 1402-1412.

[190] Yang, L.; Calingasan, N.Y.; Wille, E.J.; Cormier, K.; Smith, K.; Ferrante, R.J.; Beal, M.F. Combination therapy with coenzyme Q10 and creatine produces additive neuroprotective effects in models of Parkinson's and Huntington's diseases. $J$. Neurochem., 2009, 109(5), 1427-1439.

[191] NINDS NET-PD Investigators. A randomized, double-blind, futility clinical trial of creatine and minocycline in early Parkinson disease. Neurology, 2006, 66(5), 664-671.

[192] NINDS NET-PD Investigators. A pilot clinical trial of creatine and minocycline in early Parkinson disease: 18-month results. Clin. Neuropharmacol., 2008, 31(3), 141150.

[193] Kelly, D.P.; Scarpulla, R.C. Transcriptional regulatory circuits controlling mitochondrial biogenesis and function. Genes Dev., 2004, 18(4), 357-368.

[194] St-Pierre, J.; Drori, S.; Uldry, M.; Silvaggi, J.M.; Rhee, J.; Jager, S.; Handschin, C.; Zheng, K.; Lin, J.; Yang, W.; Simon, D.K.; Bachoo, R.; Spiegelman, B.M. Suppression of reactive oxygen species and neurodegeneration by the PGC-1 transcriptional coactivators. Cell, 2006, 127(2), 397-408.

[195] Zheng, B.; Liao, Z.; Locascio, J.J.; Lesniak, K.A.; Roderick, S.S.; Watt, M.L.; Eklund, A.C.; Zhang-James, Y.; Kim, P.D.; Hauser, M.A.; Grunblatt, E.; Moran, L.B.; Mandel, S.A.; Riederer, P.; Miller, R.M.; Federoff, H.J.; Wullner, U.; Papapetropoulos, S.; Youdim, M.B.; Cantuti-Castelvetri, I.; Young, A.B.; Vance, J.M.; Davis, R.L.; Hedreen, J.C.; Adler, C.H.; Beach, T.G.; Graeber, M.B.; Middleton, F.A.; Rochet, J.C.; Scherzer, C.R. PGC-1alpha, a potential therapeutic target for early intervention in Parkinson's disease. Sci. Transl. Med., 2010, 2(52), 52 ra73.

[196] Clark, J.; Reddy, S.; Zheng, K.; Betensky, R.A.; Simon, D.K. Association of PGC1alpha polymorphisms with age of onset and risk of Parkinson's disease. BMC Med. Genet., 2011, 12, 69.

[197] Hondares, E.; Mora, O.; Yubero, P.; Rodriguez de la Concepcion, M.; Iglesias, R.; Giralt, M.; Villarroya, F. Thiazolidinediones and rexinoids induce peroxisome proliferator-activated receptor-coactivator (PGC)-1alpha gene transcription: an autoregulatory loop controls PGC-1alpha expression in adipocytes via peroxisome proliferator-activated receptor-gamma coactivation. Endocrinology, 2006, 147(6), 2829-2838.

[198] Kiaei, M. Peroxisome Proliferator-Activated Receptor-gamma in Amyotrophic Lateral Sclerosis and Huntington's Disease. PPAR Res., 2008, 2008, 418765.

[199] Breidert, T.; Callebert, J.; Heneka, M.T.; Landreth, G.; Launay, J.M.; Hirsch, E.C. Protective action of the peroxisome proliferator-activated receptor-gamma agonist pioglitazone in a mouse model of Parkinson's disease. J. Neurochem., 2002, 82(3), 615-624. 
[200] Dehmer, T.; Heneka, M.T.; Sastre, M.; Dichgans, J.; Schulz, J.B. Protection by pioglitazone in the MPTP model of Parkinson's disease correlates with I kappa B alpha induction and block of NF kappa B and iNOS activation. J. Neurochem., 2004, 88(2), 494-501.

[201] Guzman, J.N.; Sanchez-Padilla, J.; Wokosin, D.; Kondapalli, J.; Ilijic, E.; Schumacker, P.T.; Surmeier, D.J. Oxidant stress evoked by pacemaking in dopaminergic neurons is attenuated by DJ-1. Nature, 2010, 468(7324), 696-700.

[202] Chan, C.S.; Guzman, J.N.; Ilijic, E.; Mercer, J.N.; Rick, C.; Tkatch, T.; Meredith, G.E.; Surmeier, D.J. 'Rejuvenation' protects neurons in mouse models of Parkinson's disease. Nature, 2007, 447(7148), 1081-1086.

[203] Meredith, G.E.; Totterdell, S.; Potashkin, J.A.; Surmeier, D.J. Modeling PD pathogenesis in mice: advantages of a chronic MPTP protocol. Parkinsonism. Relat. Disord., 2008, 14 Suppl 2, S112-115.

[204] Guzman, J.N.; Sanchez-Padilla, J.; Chan, C.S.; Surmeier, D.J. Robust pacemaking in substantia nigra dopaminergic neurons. J. Neurosci., 2009, 29(35), 11011-11019.

[205] Schuster, S.; Doudnikoff, E.; Rylander, D.; Berthet, A.; Aubert, I.; Ittrich, C.; Bloch, B.; Cenci, M.A.; Surmeier, D.J.; Hengerer, B.; Bezard, E. Antagonizing L-type Ca2+ channel reduces development of abnormal involuntary movement in the rat model of L-3,4-dihydroxyphenylalanine-induced dyskinesia. Biol. Psychiatry, 2009, 65(6), 518526.

[206] Misgeld, U. Innervation of the substantia nigra. Cell Tissue Res., 2004, 318(1), 107114.

[207] Carreras, M.C.; Franco, M.C.; Peralta, J.G.; Poderoso, J.J. Nitric oxide, complex I, and the modulation of mitochondrial reactive species in biology and disease. Mol. Aspects Med., 2004, 25(1-2), 125-139.

[208] Knyihar-Csillik, E.; Csillik, B.; Pakaski, M.; Krisztin-Peva, B.; Dobo, E.; Okuno, E.; Vecsei, L. Decreased expression of kynurenine aminotransferase-I (KAT-I) in the substantia nigra of mice after 1-methyl-4-phenyl-1,2,3,6-tetrahydropyridine (MPTP) treatment. Neuroscience, 2004, 126(4), 899-914.

[209] Luchowski, P.; Luchowska, E.; Turski, W.A.; Urbanska, E.M. 1-Methyl-4phenylpyridinium and 3-nitropropionic acid diminish cortical synthesis of kynurenic acid via interference with kynurenine aminotransferases in rats. Neurosci. Lett., 2002, $330(1), 49-52$.

[210] Ogawa, T.; Matson, W.R.; Beal, M.F.; Myers, R.H.; Bird, E.D.; Milbury, P.; Saso, S. Kynurenine pathway abnormalities in Parkinson's disease. Neurology, 1992, 42(9), 1702-1706.

[211] Ravikumar, A.; Deepadevi, K.V.; Arun, P.; Manojkumar, V.; Kurup, P.A. Tryptophan and tyrosine catabolic pattern in neuropsychiatric disorders. Neurol. India, 2000, 48(3), 231-238.

[212] Wu, H.Q.; Rassoulpour, A.; Schwarcz, R. Effect of systemic L-DOPA administration on extracellular kynurenate levels in the rat striatum. J. Neural. Transm., 2002, 109(3), 239-249.

[213] Rassoulpour, A.; Wu, H.Q.; Poeggeler, B.; Schwarcz, R. Systemic d-amphetamine administration causes a reduction of kynurenic acid levels in rat brain. Brain Res., 1998, 802(1-2), 111-118.

[214] Rassoulpour, A.; Wu, H.Q.; Ferre, S.; Schwarcz, R. Nanomolar concentrations of kynurenic acid reduce extracellular dopamine levels in the striatum. J. Neurochem., 2005, 93(3), 762-765. 
[215] Wu, H.Q.; Rassoulpour, A.; Schwarcz, R. Kynurenic acid leads, dopamine follows: a new case of volume transmission in the brain? J. Neural. Transm., 2007, 114(1), 3341.

[216] Poeggeler, B.; Rassoulpour, A.; Wu, H.Q.; Guidetti, P.; Roberts, R.C.; Schwarcz, R. Dopamine receptor activation reveals a novel, kynurenate-sensitive component of striatal N-methyl-D-aspartate neurotoxicity. Neuroscience, 2007, 148(1), 188-197.

[217] Datla, K.P.; Blunt, S.B.; Dexter, D.T. Chronic L-DOPA administration is not toxic to the remaining dopaminergic nigrostriatal neurons, but instead may promote their functional recovery, in rats with partial 6-OHDA or $\mathrm{FeCl}(3)$ nigrostriatal lesions. Mov. Disord., 2001, 16(3), 424-434.

[218] Graham, W.C.; Robertson, R.G.; Sambrook, M.A.; Crossman, A.R. Injection of excitatory amino acid antagonists into the medial pallidal segment of a 1-methyl-4phenyl-1,2,3,6-tetrahydropyridine (MPTP) treated primate reverses motor symptoms of parkinsonism. Life Sci., 1990, 47(18), PL91-97.

[219] Brotchie, J.M.; Mitchell, I.J.; Sambrook, M.A.; Crossman, A.R. Alleviation of parkinsonism by antagonism of excitatory amino acid transmission in the medial segment of the globus pallidus in rat and primate. Mov. Disord., 1991, 6(2), 133-138.

[220] Samadi, P.; Gregoire, L.; Rassoulpour, A.; Guidetti, P.; Izzo, E.; Schwarcz, R.; Bedard, P.J. Effect of kynurenine 3-hydroxylase inhibition on the dyskinetic and antiparkinsonian responses to levodopa in Parkinsonian monkeys. Mov. Disord., 2005, 20(7), 792-802.

[221] Stahl, W.L.; Swanson, P.D. Biochemical abnormalities in Huntington's chorea brains. Neurology, 1974, 24(9), 813-819.

[222] Gu, M.; Gash, M.T.; Mann, V.M.; Javoy-Agid, F.; Cooper, J.M.; Schapira, A.H. Mitochondrial defect in Huntington's disease caudate nucleus. Ann. Neurol., 1996, 39(3), 385-389.

[223] Browne, S.E.; Bowling, A.C.; MacGarvey, U.; Baik, M.J.; Berger, S.C.; Muqit, M.M.; Bird, E.D.; Beal, M.F. Oxidative damage and metabolic dysfunction in Huntington's disease: selective vulnerability of the basal ganglia. Ann. Neurol., 1997, 41(5), 646653.

[224] Horton, T.M.; Graham, B.H.; Corral-Debrinski, M.; Shoffner, J.M.; Kaufman, A.E.; Beal, M.F.; Wallace, D.C. Marked increase in mitochondrial DNA deletion levels in the cerebral cortex of Huntington's disease patients. Neurology, 1995, 45(10), 18791883.

[225] Gould, D.H.; Gustine, D.L. Basal ganglia degeneration, myelin alterations, and enzyme inhibition induced in mice by the plant toxin 3-nitropropanoic acid. Neuropathol. Appl. Neurobiol., 1982, 8(5), 377-393.

[226] Beal, M.F.; Brouillet, E.; Jenkins, B.; Henshaw, R.; Rosen, B.; Hyman, B.T. Agedependent striatal excitotoxic lesions produced by the endogenous mitochondrial inhibitor malonate. J. Neurochem., 1993, 61(3), 1147-1150.

[227] Brouillet, E.; Conde, F.; Beal, M.F.; Hantraye, P. Replicating Huntington's disease phenotype in experimental animals. Prog. Neurobiol., 1999, 59(5), 427-468.

[228] Sivananthan, S.N.; Leavitt, B.R. Cystamine and ethyl-eicosapentaenoic acid treatment fail to prevent malonate-induced striatal toxicity in mice. Neurobiol. Aging., 2011, 32(12), 2326.e1-4.

[229] Hassel, B.; Tessler, S.; Faull, R.L.; Emson, P.C. Glutamate uptake is reduced in prefrontal cortex in Huntington's disease. Neurochem. Res., 2008, 33(2), 232-237.

[230] Orr, A.L.; Li, S.; Wang, C.E.; Li, H.; Wang, J.; Rong, J.; Xu, X.; Mastroberardino, P.G.; Greenamyre, J.T.; Li, X.J. N-terminal mutant huntingtin associates with 
mitochondria and impairs mitochondrial trafficking. J. Neurosci., 2008, 28(11), 27832792.

[231] Cui, L.; Jeong, H.; Borovecki, F.; Parkhurst, C.N.; Tanese, N.; Krainc, D. Transcriptional repression of PGC-1alpha by mutant huntingtin leads to mitochondrial dysfunction and neurodegeneration. Cell, 2006, 127(1), 59-69.

[232] Chang, D.T.; Rintoul, G.L.; Pandipati, S.; Reynolds, I.J. Mutant huntingtin aggregates impair mitochondrial movement and trafficking in cortical neurons. Neurobiol. Dis., 2006, 22(2), 388-400.

[233] Panov, A.V.; Gutekunst, C.A.; Leavitt, B.R.; Hayden, M.R.; Burke, J.R.; Strittmatter, W.J.; Greenamyre, J.T. Early mitochondrial calcium defects in Huntington's disease are a direct effect of polyglutamines. Nat. Neurosci., 2002, 5(8), 731-736.

[234] Sawa, A.; Wiegand, G.W.; Cooper, J.; Margolis, R.L.; Sharp, A.H.; Lawler, J.F., Jr.; Greenamyre, J.T.; Snyder, S.H.; Ross, C.A. Increased apoptosis of Huntington disease lymphoblasts associated with repeat length-dependent mitochondrial depolarization. Nat. Med., 1999, 5(10), 1194-1198.

[235] Choo, Y.S.; Johnson, G.V.; MacDonald, M.; Detloff, P.J.; Lesort, M. Mutant huntingtin directly increases susceptibility of mitochondria to the calcium-induced permeability transition and cytochrome c release. Hum. Mol. Genet., 2004, 13(14), 1407-1420.

[236] Arrasate, M.; Mitra, S.; Schweitzer, E.S.; Segal, M.R.; Finkbeiner, S. Inclusion body formation reduces levels of mutant huntingtin and the risk of neuronal death. Nature, 2004, 431(7010), 805-810.

[237] Hansson, O.; Petersen, A.; Leist, M.; Nicotera, P.; Castilho, R.F.; Brundin, P. Transgenic mice expressing a Huntington's disease mutation are resistant to quinolinic acid-induced striatal excitotoxicity. Proc. Natl. Acad. Sci. U S A, 1999, 96(15), 87278732.

[238] Morton, A.J.; Leavens, W. Mice transgenic for the human Huntington's disease mutation have reduced sensitivity to kainic acid toxicity. Brain Res. Bull., 2000, 52(1), 51-59.

[239] Hickey, M.A.; Morton, A.J. Mice transgenic for the Huntington's disease mutation are resistant to chronic 3-nitropropionic acid-induced striatal toxicity. J. Neurochem., 2000, 75(5), 2163-2171.

[240] Hansson, O.; Castilho, R.F.; Korhonen, L.; Lindholm, D.; Bates, G.P.; Brundin, P. Partial resistance to malonate-induced striatal cell death in transgenic mouse models of Huntington's disease is dependent on age and CAG repeat length. J. Neurochem., 2001, 78(4), 694-703.

[241] Bogdanov, M.B.; Ferrante, R.J.; Kuemmerle, S.; Klivenyi, P.; Beal, M.F. Increased vulnerability to 3-nitropropionic acid in an animal model of Huntington's disease. $J$. Neurochem., 1998, 71(6), 2642-2644.

[242] Estrada-Sanchez, A.M.; Montiel, T.; Segovia, J.; Massieu, L. Glutamate toxicity in the striatum of the R6/2 Huntington's disease transgenic mice is age-dependent and correlates with decreased levels of glutamate transporters. Neurobiol. Dis., 2009, 34(1), 78-86.

[243] Matthews, R.T.; Yang, L.; Browne, S.; Baik, M.; Beal, M.F. Coenzyme Q10 administration increases brain mitochondrial concentrations and exerts neuroprotective effects. Proc. Natl. Acad. Sci. U S A, 1998, 95(15), 8892-8897.

[244] Ferrante, R.J.; Andreassen, O.A.; Dedeoglu, A.; Ferrante, K.L.; Jenkins, B.G.; Hersch, S.M.; Beal, M.F. Therapeutic effects of coenzyme Q10 and remacemide in transgenic mouse models of Huntington's disease. J. Neurosci., 2002, 22(5), 1592-1599. 
[245] Schilling, G.; Coonfield, M.L.; Ross, C.A.; Borchelt, D.R. Coenzyme Q10 and remacemide hydrochloride ameliorate motor deficits in a Huntington's disease transgenic mouse model. Neurosci. Lett., 2001, 315(3), 149-153.

[246] Bahadorani, S.; Hilliker, A.J. Antioxidants cannot suppress the lethal phenotype of a Drosophila melanogaster model of Huntington's disease. Genome, 2008, 51(5), 392395.

[247] Menalled, L.B.; Patry, M.; Ragland, N.; Lowden, P.A.; Goodman, J.; Minnich, J.; Zahasky, B.; Park, L.; Leeds, J.; Howland, D.; Signer, E.; Tobin, A.J.; Brunner, D. Comprehensive behavioral testing in the R6/2 mouse model of Huntington's disease shows no benefit from CoQ10 or minocycline. PLoS One, 2010, 5(3), e9793.

[248] Huntington Study Group. A randomized, placebo-controlled trial of coenzyme Q10 and remacemide in Huntington's disease. Neurology, 2001, 57(3), 397-404.

[249] Huntington Study Group Pre2CARE Investigators; Hyson, H.C.; Kieburtz, K.; Shoulson, I.; McDermott, M.; Ravina, B.; de Blieck, E.A.; Cudkowicz, M.E.; Ferrante, R.J.; Como, P.; Frank, S.; Zimmerman, C.; Cudkowicz, M.E.; Ferrante, K.; Newhall, K.; Jennings, D.; Kelsey, T.; Walker, F.; Hunt, V.; Daigneault, S.; Goldstein, M.; Weber, J.; Watts, A.; Beal, M.F.; Browne, S.E.; Metakis, L.J. Safety and tolerability of high-dosage coenzyme Q10 in Huntington's disease and healthy subjects. Mov. Disord., 2010, 25(12), 1924-1928.

[250] Matthews, R.T.; Yang, L.; Jenkins, B.G.; Ferrante, R.J.; Rosen, B.R.; KaddurahDaouk, R.; Beal, M.F. Neuroprotective effects of creatine and cyclocreatine in animal models of Huntington's disease. J. Neurosci., 1998, 18(1), 156-163.

[251] Smith, D.L.; Portier, R.; Woodman, B.; Hockly, E.; Mahal, A.; Klunk, W.E.; Li, X.J.; Wanker, E.; Murray, K.D.; Bates, G.P. Inhibition of polyglutamine aggregation in R6/2 HD brain slices-complex dose-response profiles. Neurobiol. Dis., 2001, 8(6), 1017-1026.

[252] Abd El-Gawad, H.M.; El-Abhar, H.S.; Arafa, N.M. Cysteamine in 3- nitropropionic acid model of Huntington's disease in rats: Modulation of mitochondrial function and amino acid pattern. Int. J. Med. Med. Sci., 2009, 1(6), 254-262.

[253] Kim, J.; Amante, D.J.; Moody, J.P.; Edgerly, C.K.; Bordiuk, O.L.; Smith, K.; Matson, S.A.; Matson, W.R.; Scherzer, C.R.; Rosas, H.D.; Hersch, S.M.; Ferrante, R.J. Reduced creatine kinase as a central and peripheral biomarker in Huntington's disease. Biochim. Biophys. Acta, 2010, 1802(7-8), 673-681.

[254] Hersch, S.M.; Gevorkian, S.; Marder, K.; Moskowitz, C.; Feigin, A.; Cox, M.; Como, P.; Zimmerman, C.; Lin, M.; Zhang, L.; Ulug, A.M.; Beal, M.F.; Matson, W.; Bogdanov, M.; Ebbel, E.; Zaleta, A.; Kaneko, Y.; Jenkins, B.; Hevelone, N.; Zhang, H.; Yu, H.; Schoenfeld, D.; Ferrante, R.; Rosas, H.D. Creatine in Huntington disease is safe, tolerable, bioavailable in brain and reduces serum $8 \mathrm{OH} 2$ 'dG. Neurology, 2006, 66(2), 250-252.

[255] Verbessem, P.; Lemiere, J.; Eijnde, B.O.; Swinnen, S.; Vanhees, L.; Van Leemputte, M.; Hespel, P.; Dom, R. Creatine supplementation in Huntington's disease: a placebocontrolled pilot trial. Neurology, 2003, 61(7), 925-930.

[256] Tabrizi, S.J.; Blamire, A.M.; Manners, D.N.; Rajagopalan, B.; Styles, P.; Schapira, A.H.; Warner, T.T. Creatine therapy for Huntington's disease: clinical and MRS findings in a 1-year pilot study. Neurology, 2003, 61(1), 141-142.

[257] Tabrizi, S.J.; Blamire, A.M.; Manners, D.N.; Rajagopalan, B.; Styles, P.; Schapira, A.H.; Warner, T.T. High-dose creatine therapy for Huntington disease: a 2-year clinical and MRS study. Neurology, 2005, 64(9), 1655-1656. 
[258] Liu, J.; Atamna, H.; Kuratsune, H.; Ames, B.N. Delaying brain mitochondrial decay and aging with mitochondrial antioxidants and metabolites. Ann. N. Y. Acad. Sci., 2002, 959, 133-166.

[259] Nishimura, M.; Okimura, Y.; Fujita, H.; Yano, H.; Lee, J.; Suzaki, E.; Inoue, M.; Utsumi, K.; Sasaki, J. Mechanism of 3-nitropropionic acid-induced membrane permeability transition of isolated mitochondria and its suppression by L-carnitine. Cell Biochem. Funct., 2008, 26(8), 881-891.

[260] Vamos, E.; Voros, K.; Vecsei, L.; Klivenyi, P. Neuroprotective effects of L-carnitine in a transgenic animal model of Huntington's disease. Biomed. Pharmacother., 2010, 64(4), 282-286.

[261] Goety, C.G.; Tanner, C.M.; Cohen, J.A.; Thelen, J.A.; Carroll, V.S.; Klawans, H.L.; Fariello, R.G. L-acetyl-carnitine in Huntington's disease: double-blind placebo controlled crossover study of drug effects on movement disorder and dementia. Mov. Disord., 1990, 5(3), 263-265.

[262] Rech, V.C.; Feksa, L.R.; Fleck, R.M.; Athaydes, G.A.; Dornelles, P.K.; RodriguesJunior, V.; Wannmacher, C.M. Cysteamine prevents inhibition of thiol-containing enzymes caused by cystine or cystine dimethylester loading in rat brain cortex. Metab. Brain Dis., 2008, 23(2), 133-145.

[263] Kessler, A.; Biasibetti, M.; da Silva Melo, D.A.; Wajner, M.; Dutra-Filho, C.S.; de Souza Wyse, A.T.; Wannmacher, C.M. Antioxidant effect of cysteamine in brain cortex of young rats. Neurochem. Res., 2008, 33(5), 737-744.

[264] Fox, J.H.; Barber, D.S.; Singh, B.; Zucker, B.; Swindell, M.K.; Norflus, F.; Buzescu, R.; Chopra, R.; Ferrante, R.J.; Kazantsev, A.; Hersch, S.M. Cystamine increases Lcysteine levels in Huntington's disease transgenic mouse brain and in a PC12 model of polyglutamine aggregation. J. Neurochem., 2004, 91(2), 413-422.

[265] Borrell-Pages, M.; Canals, J.M.; Cordelieres, F.P.; Parker, J.A.; Pineda, J.R.; Grange, G.; Bryson, E.A.; Guillermier, M.; Hirsch, E.; Hantraye, P.; Cheetham, M.E.; Neri, C.; Alberch, J.; Brouillet, E.; Saudou, F.; Humbert, S. Cystamine and cysteamine increase brain levels of BDNF in Huntington disease via HSJ1b and transglutaminase. J. Clin. Invest., 2006, 116(5), 1410-1424.

[266] Ferrer, I.; Goutan, E.; Marin, C.; Rey, M.J.; Ribalta, T. Brain-derived neurotrophic factor in Huntington disease. Brain Res., 2000, 866(1-2), 257-261.

[267] Mao, Z.; Choo, Y.S.; Lesort, M. Cystamine and cysteamine prevent 3-NP-induced mitochondrial depolarization of Huntington's disease knock-in striatal cells. Eur. J. Neurosci., 2006, 23(7), 1701-1710.

[268] Van Raamsdonk, J.M.; Pearson, J.; Bailey, C.D.; Rogers, D.A.; Johnson, G.V.; Hayden, M.R.; Leavitt, B.R. Cystamine treatment is neuroprotective in the YAC128 mouse model of Huntington disease. J. Neurochem., 2005, 95(1), 210-220.

[269] Dedeoglu, A.; Kubilus, J.K.; Jeitner, T.M.; Matson, S.A.; Bogdanov, M.; Kowall, N.W.; Matson, W.R.; Cooper, A.J.; Ratan, R.R.; Beal, M.F.; Hersch, S.M.; Ferrante, R.J. Therapeutic effects of cystamine in a murine model of Huntington's disease. $J$. Neurosci., 2002, 22(20), 8942-8950.

[270] Lesort, M.; Tucholski, J.; Zhang, J.; Johnson, G.V. Impaired mitochondrial function results in increased tissue transglutaminase activity in situ. J. Neurochem., 2000, 75(5), 1951-1961.

[271] Lesort, M.; Chun, W.; Johnson, G.V.; Ferrante, R.J. Tissue transglutaminase is increased in Huntington's disease brain. J. Neurochem., 1999, 73(5), 2018-2027.

[272] Karpuj, M.V.; Becher, M.W.; Steinman, L. Evidence for a role for transglutaminase in Huntington's disease and the potential therapeutic implications. Neurochem. Int., 2002, 40(1), 31-36. 
[273] Karpuj, M.V.; Becher, M.W.; Springer, J.E.; Chabas, D.; Youssef, S.; Pedotti, R.; Mitchell, D.; Steinman, L. Prolonged survival and decreased abnormal movements in transgenic model of Huntington disease, with administration of the transglutaminase inhibitor cystamine. Nat. Med., 2002, 8(2), 143-149.

[274] Bailey, C.D.; Johnson, G.V. The protective effects of cystamine in the R6/2 Huntington's disease mouse involve mechanisms other than the inhibition of tissue transglutaminase. Neurobiol. Aging, 2006, 27(6), 871-879.

[275] Bailey, C.D.; Johnson, G.V. Tissue transglutaminase contributes to disease progression in the R6/2 Huntington's disease mouse model via aggregate-independent mechanisms. J. Neurochem., 2005, 92(1), 83-92.

[276] Dubinsky, R.; Gray, C. CYTE-I-HD: phase I dose finding and tolerability study of cysteamine (Cystagon) in Huntington's disease. Mov. Disord., 2006, 21(4), 530-533.

[277] Underwood, B.R.; Broadhurst, D.; Dunn, W.B.; Ellis, D.I.; Michell, A.W.; Vacher, C.; Mosedale, D.E.; Kell, D.B.; Barker, R.A.; Grainger, D.J.; Rubinsztein, D.C. Huntington disease patients and transgenic mice have similar pro-catabolic serum metabolite profiles. Brain, 2006, 129(Pt 4), 877-886.

[278] Djousse, L.; Knowlton, B.; Cupples, L.A.; Marder, K.; Shoulson, I.; Myers, R.H. Weight loss in early stage of Huntington's disease. Neurology, 2002, 59(9), 13251330 .

[279] Aziz, N.A.; van der Burg, J.M.; Landwehrmeyer, G.B.; Brundin, P.; Stijnen, T.; Roos, R.A. Weight loss in Huntington disease increases with higher CAG repeat number. Neurology, 2008, 71(19), 1506-1513.

[280] Phan, J.; Hickey, M.A.; Zhang, P.; Chesselet, M.F.; Reue, K. Adipose tissue dysfunction tracks disease progression in two Huntington's disease mouse models. Hum. Mol. Genet., 2009, 18(6), 1006-1016.

[281] Garcia-Rojas, P.; Antaramian, A.; Gonzalez-Davalos, L.; Villarroya, F.; Shimada, A.; Varela-Echavarria, A.; Mora, O. Induction of peroxisomal proliferator-activated receptor gamma and peroxisomal proliferator-activated receptor gamma coactivator 1 by unsaturated fatty acids, retinoic acid, and carotenoids in preadipocytes obtained from bovine white adipose tissue1,2. J Anim. Sci., 2010, 88(5), 1801-1808.

[282] Jump, D.B. The biochemistry of n-3 polyunsaturated fatty acids. J. Biol. Chem., 2002, 277(11), 8755-8758.

[283] Clifford, J.J.; Drago, J.; Natoli, A.L.; Wong, J.Y.; Kinsella, A.; Waddington, J.L.; Vaddadi, K.S. Essential fatty acids given from conception prevent topographies of motor deficit in a transgenic model of Huntington's disease. Neuroscience, 2002, 109(1), 81-88.

[284] Van Raamsdonk, J.M.; Pearson, J.; Rogers, D.A.; Lu, G.; Barakauskas, V.E.; Barr, A.M.; Honer, W.G.; Hayden, M.R.; Leavitt, B.R. Ethyl-EPA treatment improves motor dysfunction, but not neurodegeneration in the YAC128 mouse model of Huntington disease. Exp. Neurol., 2005, 196(2), 266-272.

[285] Vaddadi, K.S.; Soosai, E.; Chiu, E.; Dingjan, P. A randomised, placebo-controlled, double blind study of treatment of Huntington's disease with unsaturated fatty acids. Neuroreport, 2002, 13(1), 29-33.

[286] Puri, B.K.; Bydder, G.M.; Counsell, S.J.; Corridan, B.J.; Richardson, A.J.; Hajnal, J.V.; Appel, C.; McKee, H.M.; Vaddadi, K.S.; Horrobin, D.F. MRI and neuropsychological improvement in Huntington disease following ethyl-EPA treatment. Neuroreport, 2002, 13(1), 123-126.

[287] Puri, B.K.; Leavitt, B.R.; Hayden, M.R.; Ross, C.A.; Rosenblatt, A.; Greenamyre, J.T.; Hersch, S.; Vaddadi, K.S.; Sword, A.; Horrobin, D.F.; Manku, M.; Murck, H. 
Ethyl-EPA in Huntington disease: a double-blind, randomized, placebo-controlled trial. Neurology, 2005, 65(2), 286-292.

[288] Investigators, H.S.G.T.-H. Randomized controlled trial of ethyl-eicosapentaenoic acid in Huntington disease: the TREND-HD study. Arch. Neurol., 2008, 65(12), 15821589.

[289] Zadori, D.; Geisz, A.; Vamos, E.; Vecsei, L.; Klivenyi, P. Valproate ameliorates the survival and the motor performance in a transgenic mouse model of Huntington's disease. Pharmacol. Biochem. Behav., 2009, 94(1), 148-153.

[290] Gardian, G.; Browne, S.E.; Choi, D.K.; Klivenyi, P.; Gregorio, J.; Kubilus, J.K.; Ryu, H.; Langley, B.; Ratan, R.R.; Ferrante, R.J.; Beal, M.F. Neuroprotective effects of phenylbutyrate in the N171-82Q transgenic mouse model of Huntington's disease. $J$. Biol. Chem., 2005, 280(1), 556-563.

[291] Lim, S.; Chesser, A.S.; Grima, J.C.; Rappold, P.M.; Blum, D.; Przedborski, S.; Tieu, $\mathrm{K}$. D-beta-hydroxybutyrate is protective in mouse models of Huntington's disease. PLoS One, 2011, 6(9), e24620.

[292] McGeer, E.G.; McGeer, P.L. Duplication of biochemical changes of Huntington's chorea by intrastriatal injections of glutamic and kainic acids. Nature, 1976, 263(5577), 517-519.

[293] Schwarcz, R.; Hokfelt, T.; Fuxe, K.; Jonsson, G.; Goldstein, M.; Terenius, L. Ibotenic acid-induced neuronal degeneration: a morphological and neurochemical study. Exp Brain. Res., 1979, 37(2), 199-216.

[294] Beal, M.F.; Kowall, N.W.; Ellison, D.W.; Mazurek, M.F.; Swartz, K.J.; Martin, J.B. Replication of the neurochemical characteristics of Huntington's disease by quinolinic acid. Nature, 1986, 321(6066), 168-171.

[295] Schwarcz, R.; Kohler, C. Differential vulnerability of central neurons of the rat to quinolinic acid. Neurosci. Lett., 1983, 38(1), 85-90.

[296] Young, A.B.; Greenamyre, J.T.; Hollingsworth, Z.; Albin, R.; D'Amato, C.; Shoulson, I.; Penney, J.B. NMDA receptor losses in putamen from patients with Huntington's disease. Science, 1988, 241(4868), 981-983.

[297] Kuppenbender, K.D.; Standaert, D.G.; Feuerstein, T.J.; Penney, J.B., Jr.; Young, A.B.; Landwehrmeyer, G.B. Expression of NMDA receptor subunit mRNAs in neurochemically identified projection and interneurons in the human striatum. $J$. Comp. Neurol., 2000, 419(4), 407-421.

[298] Okamoto, S.; Pouladi, M.A.; Talantova, M.; Yao, D.; Xia, P.; Ehrnhoefer, D.E.; Zaidi, R.; Clemente, A.; Kaul, M.; Graham, R.K.; Zhang, D.; Vincent Chen, H.S.; Tong, G.; Hayden, M.R.; Lipton, S.A. Balance between synaptic versus extrasynaptic NMDA receptor activity influences inclusions and neurotoxicity of mutant huntingtin. Nat. Med., 2009, 15(12), 1407-1413.

[299] Brustovetsky, N.; Brustovetsky, T.; Purl, K.J.; Capano, M.; Crompton, M.; Dubinsky, J.M. Increased susceptibility of striatal mitochondria to calcium-induced permeability transition. J. Neurosci., 2003, 23(12), 4858-4867.

[300] Dube, L.; Smith, A.D.; Bolam, J.P. Identification of synaptic terminals of thalamic or cortical origin in contact with distinct medium-size spiny neurons in the rat neostriatum. J. Comp. Neurol., 1988, 267(4), 455-471.

[301] Sun, Y.; Savanenin, A.; Reddy, P.H.; Liu, Y.F. Polyglutamine-expanded huntingtin promotes sensitization of N-methyl-D-aspartate receptors via post-synaptic density 95. J. Biol. Chem., 2001, 276(27), 24713-24718.

[302] Chen, N.; Luo, T.; Wellington, C.; Metzler, M.; McCutcheon, K.; Hayden, M.R.; Raymond, L.A. Subtype-specific enhancement of NMDA receptor currents by mutant huntingtin. J. Neurochem., 1999, 72(5), 1890-1898. 
[303] Song, C.; Zhang, Y.; Parsons, C.G.; Liu, Y.F. Expression of polyglutamine-expanded huntingtin induces tyrosine phosphorylation of N-methyl-D-aspartate receptors. $J$. Biol. Chem., 2003, 278(35), 33364-33369.

[304] Milnerwood, A.J.; Gladding, C.M.; Pouladi, M.A.; Kaufman, A.M.; Hines, R.M.; Boyd, J.D.; Ko, R.W.; Vasuta, O.C.; Graham, R.K.; Hayden, M.R.; Murphy, T.H.; Raymond, L.A. Early increase in extrasynaptic NMDA receptor signaling and expression contributes to phenotype onset in Huntington's disease mice. Neuron, 2010, 65(2), 178-190.

[305] Lievens, J.C.; Woodman, B.; Mahal, A.; Spasic-Boscovic, O.; Samuel, D.; KerkerianLe Goff, L.; Bates, G.P. Impaired glutamate uptake in the R6 Huntington's disease transgenic mice. Neurobiol. Dis., 2001, 8(5), 807-821.

[306] Vecsei, L.; Beal, M.F. Comparative behavioral and neurochemical studies with striatal kainic acid- or quinolinic acid-lesioned rats. Pharmacol. Biochem. Behav., 1991, 39(2), 473-478.

[307] Guidetti, P.; Luthi-Carter, R.E.; Augood, S.J.; Schwarcz, R. Neostriatal and cortical quinolinate levels are increased in early grade Huntington's disease. Neurobiol. Dis., 2004, 17(3), 455-461.

[308] Reynolds, G.P.; Pearson, S.J.; Halket, J.; Sandler, M. Brain quinolinic acid in Huntington's disease. J. Neurochem., 1988, 50(6), 1959-1960.

[309] Heyes, M.P.; Saito, K.; Crowley, J.S.; Davis, L.E.; Demitrack, M.A.; Der, M.; Dilling, L.A.; Elia, J.; Kruesi, M.J.; Lackner, A.; et al. Quinolinic acid and kynurenine pathway metabolism in inflammatory and non-inflammatory neurological disease. Brain, 1992, 115 ( Pt 5), 1249-1273.

[310] Shear, D.A.; Dong, J.; Gundy, C.D.; Haik-Creguer, K.L.; Dunbar, G.L. Comparison of intrastriatal injections of quinolinic acid and 3-nitropropionic acid for use in animal models of Huntington's disease. Prog. Neuropsychopharmacol. Biol. Psychiatry, 1998, 22(7), 1217-1240.

[311] Sathyasaikumar, K.V.; Stachowski, E.K.; Amori, L.; Guidetti, P.; Muchowski, P.J.; Schwarcz, R. Dysfunctional kynurenine pathway metabolism in the R6/2 mouse model of Huntington's disease. J. Neurochem., 2010, 113(6), 1416-1425.

[312] Beal, M.F.; Matson, W.R.; Swartz, K.J.; Gamache, P.H.; Bird, E.D. Kynurenine pathway measurements in Huntington's disease striatum: evidence for reduced formation of kynurenic acid. J. Neurochem., 1990, 55(4), 1327-1339.

[313] Beal, M.F.; Matson, W.R.; Storey, E.; Milbury, P.; Ryan, E.A.; Ogawa, T.; Bird, E.D. Kynurenic acid concentrations are reduced in Huntington's disease cerebral cortex. $J$. Neurol. Sci., 1992, 108(1), 80-87.

[314] Jauch, D.; Urbanska, E.M.; Guidetti, P.; Bird, E.D.; Vonsattel, J.P.; Whetsell, W.O., Jr.; Schwarcz, R. Dysfunction of brain kynurenic acid metabolism in Huntington's disease: focus on kynurenine aminotransferases. J. Neurol. Sci., 1995, 130(1), 39-47.

[315] Csillik, A.; Knyihar, E.; Okuno, E.; Krisztin-Peva, B.; Csillik, B.; Vecsei, L. Effect of 3-nitropropionic acid on kynurenine aminotransferase in the rat brain. Exp. Neurol., 2002, 177(1), 233-241.

[316] Zeron, M.M.; Hansson, O.; Chen, N.; Wellington, C.L.; Leavitt, B.R.; Brundin, P.; Hayden, M.R.; Raymond, L.A. Increased sensitivity to N-methyl-D-aspartate receptormediated excitotoxicity in a mouse model of Huntington's disease. Neuron, 2002, 33(6), 849-860.

[317] Giorgini, F.; Guidetti, P.; Nguyen, Q.; Bennett, S.C.; Muchowski, P.J. A genomic screen in yeast implicates kynurenine 3-monooxygenase as a therapeutic target for Huntington disease. Nat. Genet., 2005, 37(5), 526-531. 
[318] Campesan, S.; Green, E.W.; Breda, C.; Sathyasaikumar, K.V.; Muchowski, P.J.; Schwarcz, R.; Kyriacou, C.P.; Giorgini, F. The kynurenine pathway modulates neurodegeneration in a Drosophila model of Huntington's disease. Curr. Biol., 2011, 21(11), 961-966.

[319] Blennow, K.; de Leon, M.J.; Zetterberg, H. Alzheimer's disease. Lancet, 2006, 368(9533), 387-403.

[320] Kish, S.J.; Bergeron, C.; Rajput, A.; Dozic, S.; Mastrogiacomo, F.; Chang, L.J.; Wilson, J.M.; DiStefano, L.M.; Nobrega, J.N. Brain cytochrome oxidase in Alzheimer's disease. J. Neurochem., 1992, 59(2), 776-779.

[321] Mutisya, E.M.; Bowling, A.C.; Beal, M.F. Cortical cytochrome oxidase activity is reduced in Alzheimer's disease. J. Neurochem., 1994, 63(6), 2179-2184.

[322] Coskun, P.E.; Beal, M.F.; Wallace, D.C. Alzheimer's brains harbor somatic mtDNA control-region mutations that suppress mitochondrial transcription and replication. Proc. Natl. Acad. Sci. U S A, 2004, 101(29), 10726-10731.

[323] Hirai, K.; Aliev, G.; Nunomura, A.; Fujioka, H.; Russell, R.L.; Atwood, C.S.; Johnson, A.B.; Kress, Y.; Vinters, H.V.; Tabaton, M.; Shimohama, S.; Cash, A.D.; Siedlak, S.L.; Harris, P.L.; Jones, P.K.; Petersen, R.B.; Perry, G.; Smith, M.A. Mitochondrial abnormalities in Alzheimer's disease. J. Neurosci., 2001, 21(9), 30173023.

[324] Li, M.; Chen, L.; Lee, D.H.; Yu, L.C.; Zhang, Y. The role of intracellular amyloid beta in Alzheimer's disease. Prog. Neurobiol., 2007, 83(3), 131-139.

[325] Manczak, M.; Anekonda, T.S.; Henson, E.; Park, B.S.; Quinn, J.; Reddy, P.H. Mitochondria are a direct site of A beta accumulation in Alzheimer's disease neurons: implications for free radical generation and oxidative damage in disease progression. Hum. Mol. Genet., 2006, 15(9), 1437-1449.

[326] Canevari, L.; Clark, J.B.; Bates, T.E. beta-Amyloid fragment 25-35 selectively decreases complex IV activity in isolated mitochondria. FEBS Lett., 1999, 457(1), 131-134.

[327] Moreira, P.I.; Santos, M.S.; Moreno, A.; Oliveira, C. Amyloid beta-peptide promotes permeability transition pore in brain mitochondria. Biosci. Rep., 2001, 21(6), 789-800.

[328] Glabe, C.G.; Kayed, R. Common structure and toxic function of amyloid oligomers implies a common mechanism of pathogenesis. Neurology, 2006, 66(2 Suppl 1), S7478.

[329] Hansson Petersen, C.A.; Alikhani, N.; Behbahani, H.; Wiehager, B.; Pavlov, P.F.; Alafuzoff, I.; Leinonen, V.; Ito, A.; Winblad, B.; Glaser, E.; Ankarcrona, M. The amyloid beta-peptide is imported into mitochondria via the TOM import machinery and localized to mitochondrial cristae. Proc. Natl. Acad. Sci. U S A, 2008, 105(35), 13145-13150.

[330] Pavlov, P.F.; Wiehager, B.; Sakai, J.; Frykman, S.; Behbahani, H.; Winblad, B.; Ankarcrona, M. Mitochondrial gamma-secretase participates in the metabolism of mitochondria-associated amyloid precursor protein. FASEB J., 2011, 25(1), 78-88.

[331] Hensley, K.; Carney, J.M.; Mattson, M.P.; Aksenova, M.; Harris, M.; Wu, J.F.; Floyd, R.A.; Butterfield, D.A. A model for beta-amyloid aggregation and neurotoxicity based on free radical generation by the peptide: relevance to Alzheimer disease. Proc. Natl. Acad. Sci. U S A, 1994, 91(8), 3270-3274.

[332] McLellan, M.E.; Kajdasz, S.T.; Hyman, B.T.; Bacskai, B.J. In vivo imaging of reactive oxygen species specifically associated with thioflavine S-positive amyloid plaques by multiphoton microscopy. J. Neurosci., 2003, 23(6), 2212-2217.

[333] Dragicevic, N.; Mamcarz, M.; Zhu, Y.; Buzzeo, R.; Tan, J.; Arendash, G.W.; Bradshaw, P.C. Mitochondrial amyloid-beta levels are associated with the extent of 
mitochondrial dysfunction in different brain regions and the degree of cognitive impairment in Alzheimer's transgenic mice. J. Alzheimers Dis., 2010, 20 Suppl 2, S535-550.

[334] Du, H.; Guo, L.; Yan, S.; Sosunov, A.A.; McKhann, G.M.; Yan, S.S. Early deficits in synaptic mitochondria in an Alzheimer's disease mouse model. Proc. Natl. Acad. Sci. U S A, 2010, 107(43), 18670-18675.

[335] Lustbader, J.W.; Cirilli, M.; Lin, C.; Xu, H.W.; Takuma, K.; Wang, N.; Caspersen, C.; Chen, X.; Pollak, S.; Chaney, M.; Trinchese, F.; Liu, S.; Gunn-Moore, F.; Lue, L.F.; Walker, D.G.; Kuppusamy, P.; Zewier, Z.L.; Arancio, O.; Stern, D.; Yan, S.S.; Wu, H. ABAD directly links Abeta to mitochondrial toxicity in Alzheimer's disease. Science, 2004, 304(5669), 448-452.

[336] Takuma, K.; Yao, J.; Huang, J.; Xu, H.; Chen, X.; Luddy, J.; Trillat, A.C.; Stern, D.M.; Arancio, O.; Yan, S.S. ABAD enhances Abeta-induced cell stress via mitochondrial dysfunction. FASEB J., 2005, 19(6), 597-598.

[337] Yao, J.; Du, H.; Yan, S.; Fang, F.; Wang, C.; Lue, L.F.; Guo, L.; Chen, D.; Stern, D.M.; Gunn Moore, F.J.; Xi Chen, J.; Arancio, O.; Yan, S.S. Inhibition of amyloidbeta (Abeta) peptide-binding alcohol dehydrogenase-Abeta interaction reduces Abeta accumulation and improves mitochondrial function in a mouse model of Alzheimer's disease. J. Neurosci., 2011, 31(6), 2313-2320.

[338] Singh, P.; Suman, S.; Chandna, S.; Das, T.K. Possible role of amyloid-beta, adenine nucleotide translocase and cyclophilin-D interaction in mitochondrial dysfunction of Alzheimer's disease. Bioinformation, 2009, 3(10), 440-445.

[339] Calkins, M.J.; Reddy, P.H. Amyloid beta impairs mitochondrial anterograde transport and degenerates synapses in Alzheimer's disease neurons. Biochim. Biophys. Acta, 2011, 1812(4), 507-513.

[340] Devi, L.; Prabhu, B.M.; Galati, D.F.; Avadhani, N.G.; Anandatheerthavarada, H.K. Accumulation of amyloid precursor protein in the mitochondrial import channels of human Alzheimer's disease brain is associated with mitochondrial dysfunction. $J$. Neurosci., 2006, 26(35), 9057-9068.

[341] Sirk, D.; Zhu, Z.; Wadia, J.S.; Shulyakova, N.; Phan, N.; Fong, J.; Mills, L.R. Chronic exposure to sub-lethal beta-amyloid (Abeta) inhibits the import of nuclear-encoded proteins to mitochondria in differentiated PC12 cells. J. Neurochem., 2007, 103(5), 1989-2003.

[342] Rosen, K.M.; Moussa, C.E.; Lee, H.K.; Kumar, P.; Kitada, T.; Qin, G.; Fu, Q.; Querfurth, H.W. Parkin reverses intracellular beta-amyloid accumulation and its negative effects on proteasome function. J. Neurosci. Res., 2010, 88(1), 167-178.

[343] Burns, M.P.; Zhang, L.; Rebeck, G.W.; Querfurth, H.W.; Moussa, C.E. Parkin promotes intracellular Abeta1-42 clearance. Hum. Mol. Genet., 2009, 18(17), 32063216.

[344] Takashima, A.; Honda, T.; Yasutake, K.; Michel, G.; Murayama, O.; Murayama, M.; Ishiguro, K.; Yamaguchi, H. Activation of tau protein kinase I/glycogen synthase kinase-3beta by amyloid beta peptide (25-35) enhances phosphorylation of tau in hippocampal neurons. Neurosci. Res., 1998, 31(4), 317-323.

[345] Zheng, W.H.; Bastianetto, S.; Mennicken, F.; Ma, W.; Kar, S. Amyloid beta peptide induces tau phosphorylation and loss of cholinergic neurons in rat primary septal cultures. Neuroscience, 2002, 115(1), 201-211.

[346] Naslund, J.; Haroutunian, V.; Mohs, R.; Davis, K.L.; Davies, P.; Greengard, P.; Buxbaum, J.D. Correlation between elevated levels of amyloid beta-peptide in the brain and cognitive decline. JAMA, 2000, 283(12), 1571-1577. 
[347] Parvathy, S.; Davies, P.; Haroutunian, V.; Purohit, D.P.; Davis, K.L.; Mohs, R.C.; Park, H.; Moran, T.M.; Chan, J.Y.; Buxbaum, J.D. Correlation between Abetax-40-, Abetax-42-, and Abetax-43-containing amyloid plaques and cognitive decline. Arch. Neurol., 2001, 58(12), 2025-2032.

[348] Reitz, C.; Honig, L.; Vonsattel, J.P.; Tang, M.X.; Mayeux, R. Memory performance is related to amyloid and tau pathology in the hippocampus. J. Neurol. Neurosurg. Psychiatry, 2009, 80(7), 715-721.

[349] Rentz, D.M.; Locascio, J.J.; Becker, J.A.; Moran, E.K.; Eng, E.; Buckner, R.L.; Sperling, R.A.; Johnson, K.A. Cognition, reserve, and amyloid deposition in normal aging. Ann. Neurol., 2010, 67(3), 353-364.

[350] Sabbagh, M.N.; Cooper, K.; DeLange, J.; Stoehr, J.D.; Thind, K.; Lahti, T.; Reisberg, B.; Sue, L.; Vedders, L.; Fleming, S.R.; Beach, T.G. Functional, global and cognitive decline correlates to accumulation of Alzheimer's pathology in MCI and AD. Curr. Alzheimer Res., 2010, 7(4), 280-286.

[351] Villemagne, V.L.; Pike, K.E.; Chetelat, G.; Ellis, K.A.; Mulligan, R.S.; Bourgeat, P.; Ackermann, U.; Jones, G.; Szoeke, C.; Salvado, O.; Martins, R.; O'Keefe, G.; Mathis, C.A.; Klunk, W.E.; Ames, D.; Masters, C.L.; Rowe, C.C. Longitudinal assessment of Abeta and cognition in aging and Alzheimer disease. Ann. Neurol., 2011, 69(1), 181192.

[352] Seppala, T.T.; Herukka, S.K.; Hanninen, T.; Tervo, S.; Hallikainen, M.; Soininen, H.; Pirttila, T. Plasma Abeta42 and Abeta40 as markers of cognitive change in follow-up: a prospective, longitudinal, population-based cohort study. J. Neurol. Neurosurg. Psychiatry, 2010, 81(10), 1123-1127.

[353] Yaffe, K.; Weston, A.; Graff-Radford, N.R.; Satterfield, S.; Simonsick, E.M.; Younkin, S.G.; Younkin, L.H.; Kuller, L.; Ayonayon, H.N.; Ding, J.; Harris, T.B. Association of plasma beta-amyloid level and cognitive reserve with subsequent cognitive decline. JAMA, 2011, 305(3), 261-266.

[354] Snider, B.J.; Fagan, A.M.; Roe, C.; Shah, A.R.; Grant, E.A.; Xiong, C.; Morris, J.C.; Holtzman, D.M. Cerebrospinal fluid biomarkers and rate of cognitive decline in very mild dementia of the Alzheimer type. Arch. Neurol., 2009, 66(5), 638-645.

[355] David, D.C.; Hauptmann, S.; Scherping, I.; Schuessel, K.; Keil, U.; Rizzu, P.; Ravid, R.; Drose, S.; Brandt, U.; Muller, W.E.; Eckert, A.; Gotz, J. Proteomic and functional analyses reveal a mitochondrial dysfunction in P301L tau transgenic mice. J. Biol. Chem., 2005, 280(25), 23802-23814.

[356] Rhein, V.; Song, X.; Wiesner, A.; Ittner, L.M.; Baysang, G.; Meier, F.; Ozmen, L.; Bluethmann, H.; Drose, S.; Brandt, U.; Savaskan, E.; Czech, C.; Gotz, J.; Eckert, A. Amyloid-beta and tau synergistically impair the oxidative phosphorylation system in triple transgenic Alzheimer's disease mice. Proc. Natl. Acad. Sci. U S A, 2009, 106(47), 20057-20062.

[357] Qin, W.; Haroutunian, V.; Katsel, P.; Cardozo, C.P.; Ho, L.; Buxbaum, J.D.; Pasinetti, G.M. PGC-1alpha expression decreases in the Alzheimer disease brain as a function of dementia. Arch. Neurol., 2009, 66(3), 352-361.

[358] Morris, M.C.; Evans, D.A.; Bienias, J.L.; Tangney, C.C.; Bennett, D.A.; Wilson, R.S.; Aggarwal, N.; Schneider, J. Consumption of fish and n-3 fatty acids and risk of incident Alzheimer disease. Arch. Neurol., 2003, 60(7), 940-946.

[359] Rohrbach, S. Effects of dietary polyunsaturated fatty acids on mitochondria. Curr. Pharm. Des., 2009, 15(36), 4103-4116.

[360] Tully, A.M.; Roche, H.M.; Doyle, R.; Fallon, C.; Bruce, I.; Lawlor, B.; Coakley, D.; Gibney, M.J. Low serum cholesteryl ester-docosahexaenoic acid levels in Alzheimer's disease: a case-control study. Br. J. Nutr., 2003, 89(4), 483-489. 
[361] Calon, F.; Lim, G.P.; Yang, F.; Morihara, T.; Teter, B.; Ubeda, O.; Rostaing, P.; Triller, A.; Salem, N., Jr.; Ashe, K.H.; Frautschy, S.A.; Cole, G.M. Docosahexaenoic acid protects from dendritic pathology in an Alzheimer's disease mouse model. Neuron, 2004, 43(5), 633-645.

[362] Calon, F.; Lim, G.P.; Morihara, T.; Yang, F.; Ubeda, O.; Salem, N., Jr.; Frautschy, S.A.; Cole, G.M. Dietary n-3 polyunsaturated fatty acid depletion activates caspases and decreases NMDA receptors in the brain of a transgenic mouse model of Alzheimer's disease. Eur. J. Neurosci., 2005, 22(3), 617-626.

[363] Green, K.N.; Martinez-Coria, H.; Khashwji, H.; Hall, E.B.; Yurko-Mauro, K.A.; Ellis, L.; LaFerla, F.M. Dietary docosahexaenoic acid and docosapentaenoic acid ameliorate amyloid-beta and tau pathology via a mechanism involving presenilin 1 levels. $J$. Neurosci., 2007, 27(16), 4385-4395.

[364] Ma, Q.L.; Yang, F.; Rosario, E.R.; Ubeda, O.J.; Beech, W.; Gant, D.J.; Chen, P.P.; Hudspeth, B.; Chen, C.; Zhao, Y.; Vinters, H.V.; Frautschy, S.A.; Cole, G.M. Betaamyloid oligomers induce phosphorylation of tau and inactivation of insulin receptor substrate via c-Jun $\mathrm{N}$-terminal kinase signaling: suppression by omega-3 fatty acids and curcumin. J. Neurosci., 2009, 29(28), 9078-9089.

[365] Ma, Q.L.; Teter, B.; Ubeda, O.J.; Morihara, T.; Dhoot, D.; Nyby, M.D.; Tuck, M.L.; Frautschy, S.A.; Cole, G.M. Omega-3 fatty acid docosahexaenoic acid increases SorLA/LR11, a sorting protein with reduced expression in sporadic Alzheimer's disease (AD): relevance to AD prevention. J. Neurosci., 2007, 27(52), 14299-14307.

[366] Scherzer, C.R.; Offe, K.; Gearing, M.; Rees, H.D.; Fang, G.; Heilman, C.J.; Schaller, C.; Bujo, H.; Levey, A.I.; Lah, J.J. Loss of apolipoprotein E receptor LR11 in Alzheimer disease. Arch. Neurol., 2004, 61(8), 1200-1205.

[367] Offe, K.; Dodson, S.E.; Shoemaker, J.T.; Fritz, J.J.; Gearing, M.; Levey, A.I.; Lah, J.J. The lipoprotein receptor LR11 regulates amyloid beta production and amyloid precursor protein traffic in endosomal compartments. J. Neurosci., 2006, 26(5), 15961603.

[368] Kotani, S.; Sakaguchi, E.; Warashina, S.; Matsukawa, N.; Ishikura, Y.; Kiso, Y.; Sakakibara, M.; Yoshimoto, T.; Guo, J.; Yamashima, T. Dietary supplementation of arachidonic and docosahexaenoic acids improves cognitive dysfunction. Neurosci. Res., 2006, 56(2), 159-164.

[369] Chiu, C.C.; Su, K.P.; Cheng, T.C.; Liu, H.C.; Chang, C.J.; Dewey, M.E.; Stewart, R.; Huang, S.Y. The effects of omega-3 fatty acids monotherapy in Alzheimer's disease and mild cognitive impairment: a preliminary randomized double-blind placebocontrolled study. Prog. Neuropsychopharmacol. Biol. Psychiatry, 2008, 32(6), 15381544.

[370] Freund-Levi, Y.; Eriksdotter-Jonhagen, M.; Cederholm, T.; Basun, H.; Faxen-Irving, G.; Garlind, A.; Vedin, I.; Vessby, B.; Wahlund, L.O.; Palmblad, J. Omega-3 fatty acid treatment in 174 patients with mild to moderate Alzheimer disease: OmegAD study: a randomized double-blind trial. Arch. Neurol., 2006, 63(10), 1402-1408.

[371] Quinn, J.F.; Raman, R.; Thomas, R.G.; Yurko-Mauro, K.; Nelson, E.B.; Van Dyck, C.; Galvin, J.E.; Emond, J.; Jack, C.R., Jr.; Weiner, M.; Shinto, L.; Aisen, P.S. Docosahexaenoic acid supplementation and cognitive decline in Alzheimer disease: a randomized trial. JAMA, 2010, 304(17), 1903-1911.

[372] Genin, E.; Hannequin, D.; Wallon, D.; Sleegers, K.; Hiltunen, M.; Combarros, O.; Bullido, M.J.; Engelborghs, S.; De Deyn, P.; Berr, C.; Pasquier, F.; Dubois, B.; Tognoni, G.; Fievet, N.; Brouwers, N.; Bettens, K.; Arosio, B.; Coto, E.; Del Zompo, M.; Mateo, I.; Epelbaum, J.; Frank-Garcia, A.; Helisalmi, S.; Porcellini, E.; Pilotto, A.; Forti, P.; Ferri, R.; Scarpini, E.; Siciliano, G.; Solfrizzi, V.; Sorbi, S.; Spalletta, G.; 
Valdivieso, F.; Vepsalainen, S.; Alvarez, V.; Bosco, P.; Mancuso, M.; Panza, F.; Nacmias, B.; Bossu, P.; Hanon, O.; Piccardi, P.; Annoni, G.; Seripa, D.; Galimberti, D.; Licastro, F.; Soininen, H.; Dartigues, J.F.; Kamboh, M.I.; Van Broeckhoven, C.; Lambert, J.C.; Amouyel, P.; Campion, D. APOE and Alzheimer disease: a major gene with semi-dominant inheritance. Mol. Psychiatry, 2011, 16(9), 903-907.

[373] Abdul, H.M.; Calabrese, V.; Calvani, M.; Butterfield, D.A. Acetyl-L-carnitineinduced up-regulation of heat shock proteins protects cortical neurons against amyloid-beta peptide 1-42-mediated oxidative stress and neurotoxicity: implications for Alzheimer's disease. J. Neurosci. Res., 2006, 84(2), 398-408.

[374] Suchy, J.; Chan, A.; Shea, T.B. Dietary supplementation with a combination of alphalipoic acid, acetyl-L-carnitine, glycerophosphocoline, docosahexaenoic acid, and phosphatidylserine reduces oxidative damage to murine brain and improves cognitive performance. Nutr. Res., 2009, 29(1), 70-74.

[375] Malow, B.A.; Baker, A.C.; Blass, J.P. Cultured cells as a screen for novel treatments of Alzheimer's disease. Arch. Neurol., 1989, 46(11), 1201-1203.

[376] Yin, Y.Y.; Liu, H.; Cong, X.B.; Liu, Z.; Wang, Q.; Wang, J.Z.; Zhu, L.Q. Acetyl-Lcarnitine attenuates okadaic acid induced tau hyperphosphorylation and spatial memory impairment in rats. J. Alzheimers Dis., 2010, 19(2), 735-746.

[377] Spagnoli, A.; Lucca, U.; Menasce, G.; Bandera, L.; Cizza, G.; Forloni, G.; Tettamanti, M.; Frattura, L.; Tiraboschi, P.; Comelli, M.; et al. Long-term acetyl-L-carnitine treatment in Alzheimer's disease. Neurology, 1991, 41(11), 1726-1732.

[378] Sano, M.; Bell, K.; Cote, L.; Dooneief, G.; Lawton, A.; Legler, L.; Marder, K.; Naini, A.; Stern, Y.; Mayeux, R. Double-blind parallel design pilot study of acetyl levocarnitine in patients with Alzheimer's disease. Arch. Neurol., 1992, 49(11), $1137-$ 1141.

[379] Pettegrew, J.W.; Klunk, W.E.; Panchalingam, K.; Kanfer, J.N.; McClure, R.J. Clinical and neurochemical effects of acetyl-L-carnitine in Alzheimer's disease. Neurobiol. Aging, 1995, 16(1), 1-4.

[380] Thal, L.J.; Carta, A.; Clarke, W.R.; Ferris, S.H.; Friedland, R.P.; Petersen, R.C.; Pettegrew, J.W.; Pfeiffer, E.; Raskind, M.A.; Sano, M.; Tuszynski, M.H.; Woolson, R.F. A 1-year multicenter placebo-controlled study of acetyl-L-carnitine in patients with Alzheimer's disease. Neurology, 1996, 47(3), 705-711.

[381] Brooks, J.O., 3rd; Yesavage, J.A.; Carta, A.; Bravi, D. Acetyl L-carnitine slows decline in younger patients with Alzheimer's disease: a reanalysis of a double-blind, placebo-controlled study using the trilinear approach. Int. Psychogeriatr., 1998, 10(2), 193-203.

[382] Thal, L.J.; Calvani, M.; Amato, A.; Carta, A. A 1-year controlled trial of acetyl-1carnitine in early-onset AD. Neurology, 2000, 55(6), 805-810.

[383] Bianchetti, A.; Rozzini, R.; Trabucchi, M. Effects of acetyl-L-carnitine in Alzheimer's disease patients unresponsive to acetylcholinesterase inhibitors. Curr. Med. Res. Opin., 2003, 19(4), 350-353.

[384] Chan, A.; Paskavitz, J.; Remington, R.; Rasmussen, S.; Shea, T.B. Efficacy of a vitamin/nutriceutical formulation for early-stage Alzheimer's disease: a 1-year, openlabel pilot study with an 16-month caregiver extension. Am. J. Alzheimers Dis. Other Demen., 2008, 23(6), 571-585.

[385] Remington, R.; Chan, A.; Paskavitz, J.; Shea, T.B. Efficacy of a vitamin/nutriceutical formulation for moderate-stage to later-stage Alzheimer's disease: a placebocontrolled pilot study. Am. J. Alzheimers Dis. Other Demen., 2009, 24(1), 27-33.

[386] Lermontova, N.N.; Redkozubov, A.E.; Shevtsova, E.F.; Serkova, T.P.; Kireeva, E.G.; Bachurin, S.O. Dimebon and tacrine inhibit neurotoxic action of beta-amyloid in 
culture and block L-type $\mathrm{Ca}(2+)$ channels. Bull. Exp. Biol. Med., 2001, 132(5), 10791083.

[387] Giorgetti, M.; Gibbons, J.A.; Bernales, S.; Alfaro, I.E.; Drieu La Rochelle, C.; Cremers, T.; Altar, C.A.; Wronski, R.; Hutter-Paier, B.; Protter, A.A. Cognitionenhancing properties of Dimebon in a rat novel object recognition task are unlikely to be associated with acetylcholinesterase inhibition or N-methyl-D-aspartate receptor antagonism. J. Pharmacol. Exp. Ther., 2010, 333(3), 748-757.

[388] Zhang, S.; Hedskog, L.; Petersen, C.A.; Winblad, B.; Ankarcrona, M. Dimebon (latrepirdine) enhances mitochondrial function and protects neuronal cells from death. J. Alzheimers. Dis., 2010, 21(2), 389-402.

[389] Grigorev, V.V.; Dranyi, O.A.; Bachurin, S.O. Comparative study of action mechanisms of dimebon and memantine on AMPA- and NMDA-subtypes glutamate receptors in rat cerebral neurons. Bull. Exp. Biol. Med., 2003, 136(5), 474-477.

[390] Bachurin, S.; Bukatina, E.; Lermontova, N.; Tkachenko, S.; Afanasiev, A.; Grigoriev, V.; Grigorieva, I.; Ivanov, Y.; Sablin, S.; Zefirov, N. Antihistamine agent Dimebon as a novel neuroprotector and a cognition enhancer. Ann. N. Y. Acad. Sci., 2001, 939, 425-435.

[391] Day, M.; Chandran, P.; Luo, F.; Rustay, N.R.; Markosyan, S.; Leblond, D.; Fox, G.B. Latrepirdine increases cerebral glucose utilization in aged mice as measured by [(18)F]-fluorodeoxyglucose positron emission tomography. Neuroscience, 2011, 189, 299-304.

[392] Bachurin, S.O.; Shevtsova, E.P.; Kireeva, E.G.; Oxenkrug, G.F.; Sablin, S.O. Mitochondria as a target for neurotoxins and neuroprotective agents. Ann. N. Y. Acad. Sci., 2003, 993, 334-344; discussion 345-339.

[393] Naga, K.K.; Geddes, J.W. Dimebon inhibits calcium-induced swelling of rat brain mitochondria but does not alter calcium retention or cytochrome $\mathrm{C}$ release. Neuromolecular Med., 2011, 13(1), 31-36.

[394] Doody, R.S.; Gavrilova, S.I.; Sano, M.; Thomas, R.G.; Aisen, P.S.; Bachurin, S.O.; Seely, L.; Hung, D. Effect of dimebon on cognition, activities of daily living, behaviour, and global function in patients with mild-to-moderate Alzheimer's disease: a randomised, double-blind, placebo-controlled study. Lancet, 2008, 372(9634), 207215.

[395] Pfizer Inc. Pfizer And Medivation Announce Results From Two Phase 3 Studies In Dimebon (latrepirdine*) Alzheimer's Disease Clinical Development Program. http://investors.medivation.com/releasedetail.Cfm?ReleaseID $=448818 \quad$ (Accessed March 30, 2010).

[396] Wang, J.; Ferruzzi, M.G.; Varghese, M.; Qian, X.; Cheng, A.; Xie, M.; Zhao, W.; Ho, L.; Pasinetti, G.M. Preclinical study of dimebon on beta-amyloid-mediated neuropathology in Alzheimer's disease. Mol. Neurodegener., 2011, 6(1), 7.

[397] Webster, S.J.; Wilson, C.A.; Lee, C.H.; Mohler, E.G.; Terry, A.V., Jr.; Buccafusco, J.J. The acute effects of dimebolin, a potential Alzheimer's disease treatment, on working memory in rhesus monkeys. Br. J. Pharmacol., 2011, 164(3), 970-978.

[398] Butler, T.R.; Self, R.L.; Smith, K.J.; Sharrett-Field, L.J.; Berry, J.N.; Littleton, J.M.; Pauly, J.R.; Mulholland, P.J.; Prendergast, M.A. Selective vulnerability of hippocampal cornu ammonis 1 pyramidal cells to excitotoxic insult is associated with the expression of polyamine-sensitive N-methyl-D-asparate-type glutamate receptors. Neuroscience, 2010, 165(2), 525-534.

[399] Stoltenburg-Didinger, G. Neuropathology of the hippocampus and its susceptibility to neurotoxic insult. Neurotoxicology, 1994, 15(3), 445-450. 
[400] Siman, R.; Reaume, A.G.; Savage, M.J.; Trusko, S.; Lin, Y.G.; Scott, R.W.; Flood, D.G. Presenilin-1 P264L knock-in mutation: differential effects on abeta production, amyloid deposition, and neuronal vulnerability. J. Neurosci., 2000, 20(23), 8717-8726.

[401] Uchida, Y.; Nakano, S.; Gomi, F.; Takahashi, H. Up-regulation of calsyntenin-3 by beta-amyloid increases vulnerability of cortical neurons. FEBS Lett., 2011, 585(4), 651-656.

[402] Guillemin, G.J.; Smythe, G.A.; Veas, L.A.; Takikawa, O.; Brew, B.J. A beta 1-42 induces production of quinolinic acid by human macrophages and microglia. Neuroreport, 2003, 14(18), 2311-2315.

[403] Guillemin, G.J.; Brew, B.J.; Noonan, C.E.; Takikawa, O.; Cullen, K.M. Indoleamine 2,3 dioxygenase and quinolinic acid immunoreactivity in Alzheimer's disease hippocampus. Neuropathol. Appl. Neurobiol., 2005, 31(4), 395-404.

[404] Bonda, D.J.; Mailankot, M.; Stone, J.G.; Garrett, M.R.; Staniszewska, M.; Castellani, R.J.; Siedlak, S.L.; Zhu, X.; Lee, H.G.; Perry, G.; Nagaraj, R.H.; Smith, M.A. Indoleamine 2,3-dioxygenase and 3-hydroxykynurenine modifications are found in the neuropathology of Alzheimer's disease. Redox Rep., 2010, 15(4), 161-168.

[405] Widner, B.; Leblhuber, F.; Walli, J.; Tilz, G.P.; Demel, U.; Fuchs, D. Degradation of tryptophan in neurodegenerative disorders. Adv. Exp. Med. Biol., 1999, 467, 133-138.

[406] Walker, D.G.; Link, J.; Lue, L.F.; Dalsing-Hernandez, J.E.; Boyes, B.E. Gene expression changes by amyloid beta peptide-stimulated human postmortem brain microglia identify activation of multiple inflammatory processes. J. Leukoc. Biol., 2006, 79(3), 596-610.

[407] Yamada, A.; Akimoto, H.; Kagawa, S.; Guillemin, G.J.; Takikawa, O. Proinflammatory cytokine interferon-gamma increases induction of indoleamine 2,3dioxygenase in monocytic cells primed with amyloid beta peptide 1-42: implications for the pathogenesis of Alzheimer's disease. J. Neurochem., 2009, 110(3), 791-800.

[408] St'astny, F.; Lisy, V.; Mares, V.; Lisa, V.; Balcar, V.J.; Santamaria, A. Quinolinic acid induces NMDA receptor-mediated lipid peroxidation in rat brain microvessels. Redox Rep., 2004, 9(4), 229-233.

[409] Montine, T.J.; Neely, M.D.; Quinn, J.F.; Beal, M.F.; Markesbery, W.R.; Roberts, L.J.; Morrow, J.D. Lipid peroxidation in aging brain and Alzheimer's disease. Free Radic. Biol. Med., 2002, 33(5), 620-626.

[410] Rahman, A.; Ting, K.; Cullen, K.M.; Braidy, N.; Brew, B.J.; Guillemin, G.J. The excitotoxin quinolinic acid induces tau phosphorylation in human neurons. PLoS One, 2009, 4(7), e6344.

[411] Hartai, Z.; Juhasz, A.; Rimanoczy, A.; Janaky, T.; Donko, T.; Dux, L.; Penke, B.; Toth, G.K.; Janka, Z.; Kalman, J. Decreased serum and red blood cell kynurenic acid levels in Alzheimer's disease. Neurochem. Int., 2007, 50(2), 308-313.

[412] Baran, H.; Jellinger, K.; Deecke, L. Kynurenine metabolism in Alzheimer's disease. $J$. Neural. Transm., 1999, 106(2), 165-181.

[413] Chess, A.C.; Simoni, M.K.; Alling, T.E.; Bucci, D.J. Elevations of endogenous kynurenic acid produce spatial working memory deficits. Schizophr. Bull., 2007, 33(3), 797-804.

[414] Potter, M.C.; Elmer, G.I.; Bergeron, R.; Albuquerque, E.X.; Guidetti, P.; Wu, H.Q.; Schwarcz, R. Reduction of endogenous kynurenic acid formation enhances extracellular glutamate, hippocampal plasticity, and cognitive behavior. Neuropsychopharmacology, 2010, 35(8), 1734-1742.

[415] Pocivavsek, A.; Wu, H.Q.; Potter, M.C.; Elmer, G.I.; Pellicciari, R.; Schwarcz, R. Fluctuations in Endogenous Kynurenic Acid Control Hippocampal Glutamate and Memory. Neuropsychopharmacology, 2011, 36(11), 2357-2367. 
